\title{
Venice Chart International Consensus Document on Atrial Fibrillation Ablation: 2011 Update
}

\author{
ANTONIO RAVIELE, M.D., * ANDREA NATALE, M.D., $\dagger$ HUGH CALKINS, M.D. $\ddagger$ \\ JOHN A. CAMM, M.D., $§$ RICCARDO CAPPATO, M.D., $₫$ SHIH ANN CHEN, M.D., ${ }^{* *}$ \\ STUART J. CONNOLLY, M.D.,$\dagger$ RALPH DAMIANO JR, M.D. $\dagger \dagger$ ROBERTO DE PONTI, M.D. $\oint \S$ \\ JAMES R. EDGERTON, M.D., \ MICHEL HAÏSSAGUERRE, M.D., ${ }^{* * *}$ \\ GERHARD HINDRICKS, M.D., †† SIEW Y. HO, M.D., $\dagger \dagger \dagger$ JOSÉ JALIFE, M.D., $\S \S \S$ \\ PAULUS KIRCHHOF, M.D., $₫ ₫$ HANS KOTTKAMP, M.D., ${ }^{* * * *}$ KARL H. KUCK, M.D., $\dagger \dagger \dagger \dagger$ \\ FRANCIS E. MARCHLINSKI, M.D., $\dagger+\ddagger$ DOUGLAS L. PACKER, M.D. $\S \S \S \S$

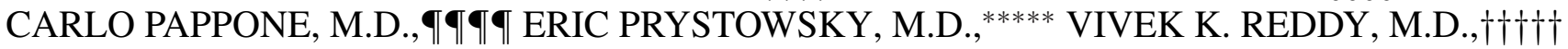 \\ SAKIS THEMISTOCLAKIS, M.D., ${ }^{*}$ ATUL VERMA, M.D. $\dagger+\dagger \dagger \ddagger$ DAVID J. WILBER, M.D., $\S \S \S \S \S$

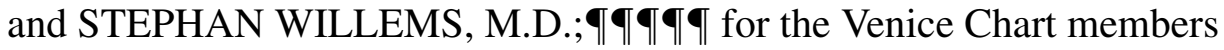

From the *Cardiovascular Department, Arrhythmia Center and Center for Atrial Fibrillation, Dell'Angelo Hospital, Venice-Mestre, Italy; $\dagger$ Texas Cardiac Arrhythmia Institute, St. David’s Medical Center, Austin, Texas, USA; †Cardiology and Electrophysiology Department, The Johns Hopkins Hospital, Baltimore, Maryland, USA; §Cardiac and Vascular Sciences, St. George's Hospital Medical School, London, UK; 9 Arrhythmia and Electrophysiology Center, IRCCS Policlinico San Donato, Milan, Italy; **Cardiology Department, Veterans

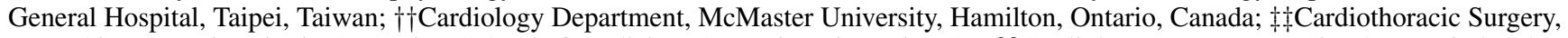
Washington University in St. Louis - School of Medicine, St. Louis, Missouri, USA; $§ \S$ Cardiology Department, Circolo Hospital and

Macchi Foundation, Varese, Italy; $\uparrow \uparrow$ Cardiothoracic Surgery Department, The Heart Hospital, Dallas, Texas, USA; ***Cardiology Department, Hôpital Haut-Lévêque, CHU de Bordeaux, Bordeaux, France; †††Herzzentrum, Leitender Arzt Universität Leipzig, Leipzig, Germany; $\dagger+\ddagger$ Cardiac Morphology Department, Royal Brompton Hospital Imperial College, London, UK; $\S \S \S$ University of Michigan,

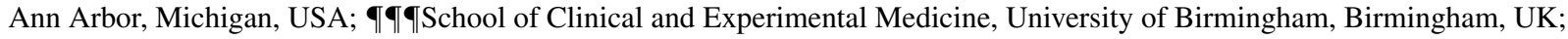

****Herz-Zentrum, Hirslanden Clinic, Zürich, Switzerland; ††††Cardiology Department, Asklepios Klinik St. Georg, Hamburg, Germany; $\ddagger+\dagger$ Cardiovascular Division, Hospital of the University of Pennsylvania, Philadelphia, Pennsylvania, USA; $\S \S \S$ Heart Rhythm Services, Mayo Clinic Health Systems/St. Mary’s Hospital, Rochester, New York, USA; ฯ \ฯArrhythmology Department,Villa Maria Cecilia Hospital, Cotignola, Italy; ${ }^{* * * * *}$ Clinical Electrophysiology Laboratory, St. Vincent Indianapolis Hospital, Indianapolis, Indiana, USA;

$\nmid \dagger \dagger \dagger \dagger$ Cardiac Arrhythmia Department, The Zena and Michael A. Wiener Cardiovascular Institute, New York, New York, USA;

$\ddagger \ddagger \dagger \ddagger$ Cardiology Department, Southlake Regional Health Center, Toronto, Ontario, Canada; $\S \S \S \S \S$ Cardiology Department, Loyola University Medical Center, Chicago, Illinois, USA; and $₫ \uparrow \uparrow \uparrow \uparrow C a r d i o l o g y$ and Electrophysiology Department, Herzzentrum Hamburg GmbH University, Hamburg, Germany

atrial fibrillation, atrial flutter, catheter ablation, guidelines, surgery

J Cardiovasc Electrophysiol, Vol. 23, pp. 890-923, August 2012

doi:10.1111/j.1540-8167.2012.02381.x

For the Venice Chart composition (Committees, members, affiliation) see Appendix.

This document was made possible by an educational grant from Biosense Webster, a Johnson \& Johnson Company.

Dr. Raviele received speaker's bureau compensation from Biosense Webster and St. Jude Medical and is a consultant to Sanofi and Boehringer Ingelheim. Dr. Natale received speaker's bureau compensation from Boston Scientific, Biosense Webster, Biotronik, Medtronic, and St. Jude Medical, and is a consultant to Biosense Webster, Endosense, Life Watch, and St. Jude Medical. At the time of this document preparation, Dr. Calkins received honoraria from Biosense Webster, and Sanofi-aventis; was on the scientific advisory boards of Atricure, Medtronic, and Biosense Webster; owned stock in VytronUS and iRhythm. Dr. Camm participated on research grants from Daiichi-Sankyo, Pfizer, and Sanofi-aventis; received speaker's bureau compensation from Sanofi-aventis, Boehringer Ingelheim, Merck, and Bayer; received honoraria from Medtronic, and Boston Scientific; is a consultant to Boehringer Ingelheim. Dr. Connolly participated on research grants from Boehringer Ingelheim, BMS, Bayer, and Portola; received honoraria from Boehringer Ingelheim, BMS, Bayer, and Pfizer; is a consultant to Boehringer Ingelheim, BMS, and Pfizer. Dr. Damiano participated on a research grant from Atricure; received honoraria from Medtronic and support for travel or lectures from Estech; is a consultant to Atricure, and Medtronic. Dr. De Ponti received speaker's bureau compensation from Biosense Webster. Dr. Edgerton received speaker's bureau compensation from Atricure, and Medtronic. Dr. Haissaguerre received research support from Biosense Webster, Phillips, Stereotaxis, CardioInsight, Bard, and Medtronic, and is a consultant to Biosense Webster, and CardioInsight. Dr. Jalife reports participation on a Gilead Research Grant, and stock options in Topera, Inc. Dr. Kirchhof reports participation on research grants from Medtronic, 3M Medica, Cardiovascular Therapeutics, Medtronic, Omron, Sanofi, St. Jude Medical, and consulting fees and honoraria from 3M Medica, Bayer, Boehringer Ingelheim, Daiichi-Sankyo, Medtronic, Merck, MSD, Otsuka Pharma, Pfizer/BMS, Sanofi, Servier, Siemens, and Takeda. Dr. Kottkamp is a consultant to Biosense Webster, and St. Jude Medical. Dr. Marchlinski received honoraria from Sanofi-aventis, and Biosense Webster, and is a consultant to Medtronic, and Biosense Webster. Dr. Packer receives research funding from Biosense Webster, Boston Scientific/EPT, Endosense, EpiEP, EP Advocate, Medtronic CryoCath LP, St. Jude Medical, Siemens, AcuNav, and Thermedical (EP Limited); in the last 12 months he has provided consulting services for Biosense Webster, CardioFocus, Cardiomedics, Cyberheart, Endosense, Johnson \& Johnson Healthcare Systems, Medtronic CryoCath, OrthoMcNeill, Sanofi-aventis, Siemens, St. Jude Medical, Siemens AG, and Valencia Technologies, but he received no personal compensation for these consulting activities. Dr. Packer received royalties from St. Jude Medical. Dr. Prystowsky is the Editor-in-Chief of $J C E$; participated on the CABANA trial; is on the board of directors and holds stock options in Stereotaxis, and Cardionet, as well as stock options in Topera, Inc; serves as a consultant to Bard and Medtronic for educational programs. Dr. Reddy participated on research grants supported by St. Jude Medical, Biosense Webster, and Endosense, Medtronic, Medtronic CryoCath, CardioFocus, Atritech, Phillips, Voyage, and Sentre Heart; he has received honoraria and is a consultant to 


\section{Introduction}

This Venice Chart International Consensus Document on atrial fibrillation (AF) ablation represents an update of the initial document published in the Journal of Cardiovascular Electrophysiology in 2007. ${ }^{1}$ Since then, many technological developments and progress have been made and AF ablation has become a well-established, widespread treatment for patients with AF.

\section{Anatomy of Structures Relevant to Atrial Fibrillation Ablation}

Over the last decade, ablation of AF has focused on the left atrium (LA) and this has stimulated further investigation on gross and microscopic anatomy of the LA and of the neighboring structures. Knowledge of their architecture and mutual relationships is necessary to access, map, and ablate the LA in a safe and successful way.

The anatomy and position of the fossa ovalis are major determinants for the electrophysiologists' ability to safely access the LA through transseptal catheterization. The dimensions of the fossa ovalis (average vertical diameter of $19 \mathrm{~mm}$, average horizontal diameter of $10 \mathrm{~mm}$, thickness of 1-3 $\mathrm{mm})^{2}$ allow a safe double transseptal puncture. Table 1 reports the congenital or acquired disorders of the chest and cardiovascular structures possibly affecting the location of the fossa ovalis and, therefore, resulting in a more difficult transseptal access. Similarly, multiple previous transseptal catheterizations causing fibrosis of the fossa ovalis are the major variables associated with difficult puncture and penetration of the transseptal needle. ${ }^{3}$ Transseptal catheterization in the presence of a device occluding the fossa ovalis is possible, because its position is more cranial as compared to the fossa ovalis position. ${ }^{4}$ However, a careful approach and additional imaging are mandatory.

Three-dimensional (3D) imaging of the LA and pulmonary veins (PVs) shows a wide range of variants of their anatomy. ${ }^{5}$ Specifically, the typical PV branching pattern with 4 distinct PV ostia (Fig. 1C) is present in approximately 20$60 \%$, while a very frequent anatomical variant is the presence of a short or long common left trunk, observed in up to 75$80 \%$ of cases. The presence of supernumerary PVs, mainly right middle $\mathrm{PV}$ or right upper $\mathrm{PV}$, is reported in 14-25\% of cases. The criss-cross of myocardial fibers and the increased thickness of the muscular sleeves at the interpulmu-

unspecified companies. Dr. Themistoclakis participated on research grants from St. Jude Medical, and Biosense Webster, and received speaker's bureau compensation from Biosense Webster, St. Jude Medical, and Sanofi-aventis. Dr. Wilber participated on a research grant from Biosense Webster; received honoraria from Biosense Webster, Medtronic, and St. Jude Medical; is a consultant to Medtronic, Biosense Webster, and St. Jude Medical. Dr. Willems participated on a research grant from St. Jude Medical; received speaker's bureau compensation from St. Jude Medical, and Boston Scientific; is a consultant to St. Jude Medical, and Boehringer Ingelheim. Other authors: No disclosures.

Address for correspondence: Antonio Raviele, M.D., Cardiovascular Department, Arrhythmia Center and Center for Atrial Fibrillation, Dell'Angelo Hospital, Venice-Mestre, Italy. Fax: +39041 965 7235; E-mail: araviele@tin.it

Manuscript received 6 February 2012; Revised manuscript received 6 February 2012; Accepted for publication 10 April 2012.

\section{TABLE 1}

Congenital or Acquired Disorders of the Chest and Cardiovascular Structures Potentially Affecting the Location of the Fossa Ovalis

\footnotetext{
-Kyphoscoliosis

-Straight back syndrome

-Pectus excavatum

-Obesity

-Persistence of left superior vena cava

-Pericardial agenesia

-Dextrocardia

-Aortic or mitral valve disease

-Marked dilatation of the ascending aorta

-Marked left ventricular hypertrophy

-Previous cardiac surgery
}
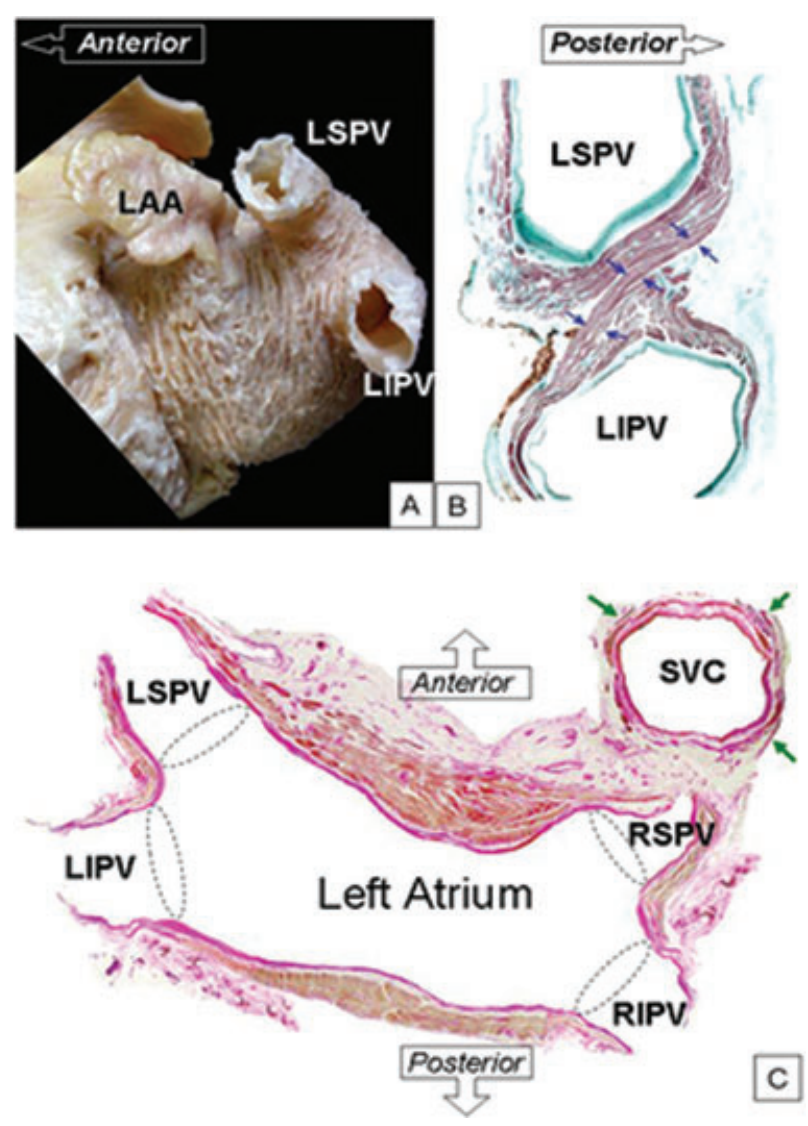

Figure 1. (A) The left atrium viewed from the left side and dissected to show the myocardial strands extending over the left superior and inferior pulmonary veins ( $L S P V, L I P V)$. The left atrial appendage (LAA) is fingerlike in shape. (B) This histologic section taken through the left pulmonary veins shows myocardial strands crossing between the veins (blue arrows). Masson's trichrome stain. (C) This histologic section shows the 4 pulmonary veins with myocardial extensions (stained brown) over the outer surface of the veins. The ovals indicate the veno-atrial junctions. Note the non-uniform thickness of the left atrial walls. The superior caval vein (SVC) is seen in cross section with its myocardial sleeve (green arrows). Elastic van Geison stain. RIPV, RSPV = right inferior, right superior pulmonary veins.

nary isthmus between the orifices of the ipsilateral PVs with the possibility of epicardially located intervenous muscular connections (Fig. 1B) may represent the anatomical basis for the complexity to achieve a permanent PV isolation by ablation techniques. ${ }^{6}$ Another critical structure for ablation procedure is the ridge or carine between LA appendage and left PVs (Fig. 1A). The ridge may be flat, round, or pointed 
TABLE 2

Key Points Regarding the Anatomy of Structures Relevant to AF Ablation

-Some congenital and acquired disorders of the chest and cardiovascular structures, multiple transseptal catheterizations, and the presence of a device occluding the fossa ovalis are all potential causes of more difficult transseptal access.

-Owing to the wide range of anatomical variants, 3D reconstruction of LA and PVs by means of imaging techniques is considered essential to perform AF ablation in a safe and successful way.

-Understanding the anatomical relationship between the LA and both the esophagus and the phrenic nerves is crucial to avoid collateral damage of these structures during AF ablation.

in profile and is $<5 \mathrm{~mm}$ wide in $75 \%$ of hearts suggesting that achieving catheter stability for adequate contact can be challenging most cases.

Understanding the anatomic relationship between the LA/PV orifices and the left atrial ganglionated plexi (GP) explains how ablation in the LA not only results in PV electrical disconnection but it may cause also modification of the autonomic tone influence with an impact on the electrical activity. ${ }^{7}$ Transmural lesions ${ }^{8}$ in the medial region of the LA, septum and/or proximal coronary sinus (CS) may disrupt interatrial conduction pathways alternative to conduction over the Bachmann's bundle and, consequently, alter the postablation atrial propagation pattern.

The very strict anatomical relationship between the LA and both the esophagus and the phrenic nerves ${ }^{9,10}$ is the major cause of concern of collateral damage to these 2 structures during AF ablation, resulting rarely in severe patient injury. Assessment of the individual anatomy, reduced power and continuous monitoring of the effect of ablation on these structures are all possible means to avoid their permanent or severe damage.

The key points regarding the anatomy of structures relevant to AF ablation are reported in Table 2.

\section{Pathophysiology of Atrial Fibrillation}

The pathogenesis of AF is often multifaceted and the arrhythmia may develop in different disease conditions as well as in the normal heart. It is well recognized that increased atrial mass, decreased conduction velocity, and decreased atrial refractoriness with increased dispersion are all pro-fibrillatory factors. Irrespective of the underlying mechanism, the onset and maintenance of AF requires an event (trigger) that initiates the arrhythmia and the presence of a predisposing substrate that perpetuates it. Additional factors (e.g., inflammation or autonomic tone) may also cooperate as "modulators" in facilitating initiation or continuation of AF.

\section{Diseases Associated with AF and the Role of Fibrosis}

Although approximately $10 \%$ of AF patients have no evident cardiac disorder (so-called "lone" AF), the arrhythmia usually occurs in patients with structural heart disease. Hypertension, coronary heart disease, valvular heart disease, dilated cardiomyopathy, and heart failure are the most frequent pathological conditions associated with AF. Atrial enlargement is often present, although it is difficult to establish if it represents the cause or the consequence of AF. Atrial fibrosis and loss of myocardial tissue may be either a substrate for
AF (due to coexisting heart disease) or a result of fibrillating atria and part of the so-called structural remodeling. ${ }^{11}$

\section{Genetic Factors and Ion Channel Diseases}

A number of studies provide irrefutable evidence for a genetic component in the case of lone AF ${ }^{12}$ Genetic linkage analyses have revealed AF chromosome loci for genetic defects in various potassium channels and the gap junctional protein Connexin 40. ${ }^{13}$ Relatively rare forms of familial AF have also been associated with inherited channelopathies such as Brugada, long QT and short QT syndromes, as well as with cardiomyopathies. ${ }^{13,14}$

\section{Electrophysiological Mechanisms}

Increased automaticity and single and multiple circuit reentry can cause AF. These mechanisms are not mutually exclusive; it is likely that areas of focal firing and areas of reentry are present simultaneously in varying degrees in the majority of patients.

\section{AF Triggers and Sources}

The PVs are an important source of ectopic beats; they are capable of initiating frequent paroxysms of AF, which can be eliminated by treatment with radiofrequency ablation. ${ }^{15}$ Other anatomical structures that may also provide ectopic beats triggering AF are the superior vena cava, the vein of Marshall, the musculature of CS, the posterior wall of the LA, and LA appendage. ${ }^{16}$

\section{The Third Dimension}

The 3D anatomical structure of the atrial muscle is likely to be a crucial factor in determining the ultimate fibrillatory behavior. Indeed, high frequency stimulation of the PVs originates wavebreaks in areas of abrupt fiber orientation and wall thickness changes in the posterior wall of the LA. ${ }^{17}$

\section{Role of the Autonomic Tone}

The autonomic tone is thought to play an important role in the pathogenesis of AF. Vagal stimulation shortens refractory period, and sympathetic stimulation increases calcium loading and automaticity. Combined, these actions result in early afterdepolarizations and triggered firing that may initiate AF. ${ }^{18-21}$ Interruption of nerves from the GP to the PVs may explain the frequent elimination of focal firing produced by PV isolation procedures during ablation therapy. These findings support the role of GP activity in the onset and perpetuation of AF, and may explain the success of early ablation studies targeting only the GP. ${ }^{22}$

\section{Structural and Electrical Remodeling}

Once established, AF begets AF through a selfperpetuation process called structural and electrical remodeling. ${ }^{23,24}$ At the structural level, AF causes atrial fibrosis, dilatation, increased compliance, and reduced contractility. Ultrastructural changes of myocytes lead to the so-called dedifferentiation, because myocytes return to the fetal phenotype. ${ }^{11}$ At the electrical level, progressive shortening and dispersion of refractory periods are the main changes occurring during AF.

The key points regarding the pathophysiology AF ablation are reported in Table 3 . 
TABLE 3

Key Points Regarding the Pathophysiology of AF

-The pathogenesis of AF is often multifaceted. Increased atrial mass, decreased conduction velocity, and decreased atrial refractoriness with increased dispersion are all profibrillatory factors.

-The onset and maintenance of AF requires an event or trigger (usually ectopic beats originating in the PVs or other anatomical structures) that initiates the arrhythmia and the presence of a predisposing substrate (atrial enlargement, atrial fibrosis, loss of myocardial tissue, etc.) that perpetuates it.

-Additional factors (e.g., inflammation or autonomic tone) may also cooperate as modulators in facilitating initiation and continuation of AF.

-Once established, AF begets AF through a self-perpetuation process called structural (atrial fibrosis, dilatation, etc.) and electrical (shortening and dispersion of refractory periods) remodeling.

\section{Techniques and Technologies for AF Catheter Ablation}

At present, multiple approaches for catheter ablation of AF have been developed. The current techniques focus on the elimination of mechanisms involved in the initiation and maintenance of AF, which are essentially represented by triggers (PVs and non-PV foci) and substrate (autonomic and electrophysiologic). The different techniques proposed for catheter ablation of AF include PV isolation, electrogrambased ablation or complex fractionated atrial electrograms (CFAEs) ablation, linear lesions, autonomic GP ablation, AF nests ablation, and sequential ablation strategy.

\section{PV Isolation}

"PV isolation" is considered the cornerstone of current AF catheter ablation techniques and is aimed at the electrical disconnection of the PV from the adjacent LA. The PV isolation comprises segmental/ostial PV ablation, circumferential PV ablation, and circumferential/antral PV isolation (Fig. 2).

\section{Segmental/ostial PV isolation}

A truly segmental PV isolation requires ablation inside the vein or very close to the output into the atrium ${ }^{15,25}$ (Fig. 2A). It is now appreciated that ablation in the PVs themselves needs to be avoided as much as possible, primarily due to concern for development of PV stenosis. Therefore, the segmental/ostial PV isolation technique in the strictest sense has generally fallen out of favor. For segmental/ostial PV isolation, a circular mapping catheter (CMC) of variable diameter $(15-25 \mathrm{~mm})$ is inserted into the LA through a long introducer via the transseptal route, and is positioned sequentially at the ostia of the $4 \mathrm{PVs}^{25}$ (Fig. 2A). Alternatively, a multielectrode array system can be used. The ablation catheter is positioned at the ostium of the vein on the atrial side; a series of segmental lesions are then created until isolation of the vein can be demonstrated by disappearance of the venous potentials on the CMC (i.e., entrance block). Electrical disconnection of the PVs can be also demonstrated by pacing from inside the PVs (i.e., exit block). Ablation can be performed in sinus rhythm or during AF. The literature data display complete agreement as to the need to achieve isolation of all 4 PVs.

\section{Circumferential PV ablation}

Circumferential PV ablation using 3D electroanatomical mapping was initially described by Pappone et al. ${ }^{26,27}$ Ini- tially, the lesion set was limited to wide $(>0.5 \mathrm{~cm}$ outside PV ostia) circumferential lesions around and outside the PV ostia but over time it was modified with wider (1-2 cm outside PV ostia) circumferential lesions (Fig. 2C). Radiofrequency (RF) energy is applied continuously on the planned circumferential lines, as the catheter is gradually dragged along the line, often in a to-and-fro fashion over a point. Successful lesion creation at each point is considered to have taken place when the local bipolar voltage has decreased by $90 \%$ or to $<0.05 \mathrm{mV}$. This technique, as initially designed, did not involve verification of PV isolation (Fig. 2C). Many other centers have adopted this technique, some of which have added circular mapping to verify PV electrical isolation.

\section{Circumferential/antral PV isolation}

The key to this technique for PV isolation is delivery of the ablation lesions to the vestibule or "antrum" of the PV, which is the funnel-shaped portion of the LA (or perhaps more accurately the PV) that is proximal to the PV-LA junction or so called "ostium." The antrum includes the entire posterior wall and extends anteriorly to the right PVs on the septum (Fig. 2B). Various tools, according to operator preference, can monitor the identification of this region during the ablation procedure. Selective pulmonary venography is used by many centers to establish the relevant anatomy. Intracardiac echocardiography (ICE) offers a better definition of the LA and proximal PV anatomy and allows localizing catheter position. ${ }^{28}$ Computerized $3 D$ mapping and navigation techniques (Carto, NavX, etc.) are useful means to clarify the anatomy of the region and provide a method of nonfluoroscopic catheter guidance. These techniques might be made more anatomically accurate by registration with other imaging techniques such as magnetic resonance (MR) or computed tomography (CT). Technologies to perform "near real time" imaging in the EP laboratory, such as with rotational angiography, are available and might help to address some of the shortcomings of preprocedural imaging, but to date are still not sufficiently effective to result in widespread adoption.

The use of a CMC for PV isolation procedures has become incredibly widespread. For the CMC guided ablation technique, 1 or 2 (double Lasso technique; Fig. 2D) ${ }^{29}$ CMCs are placed within the ipsilateral superior and inferior PVs or within the superior and inferior branches of a common PV during RF delivery. RF ablation is applied until absence or dissociation of all PV potentials are documented by CMCs within the ipsilateral superior and inferior PVs.

RF ablation catheter technologies might include standard tip (e.g., $4 \mathrm{~mm}$ ), large tip (e.g., $8 \mathrm{~mm}$ ), and closed or open irrigation. With the use of nonirrigated or closed-irrigation ablation catheter technologies, many centers employed ICE during lesion delivery to assess for the formation of microbubbles $^{30}$ and to monitor in this way tissue overheating. ${ }^{31}$ With the use of open-irrigation ablation catheters this is no longer relevant.

\section{New tools and techniques to perform PV isolation}

There has been development of new technologies to assist the operator with PV isolation for AF catheter ablation.

Various balloon-based technologies have been under investigation, generally designed specifically to deliver arcs or circumferential lesions at the PVs. ${ }^{32}$ Such technologies 
A
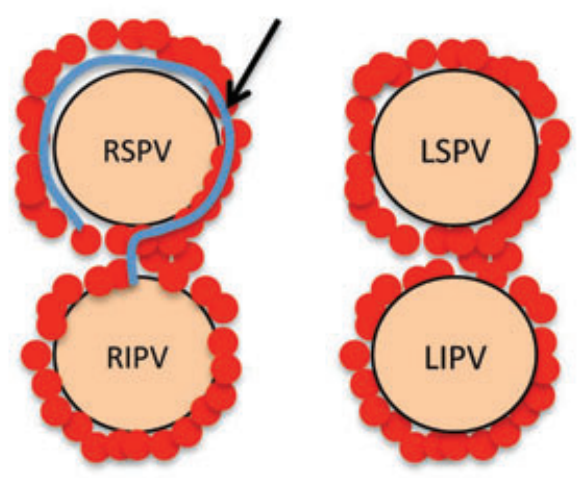

B

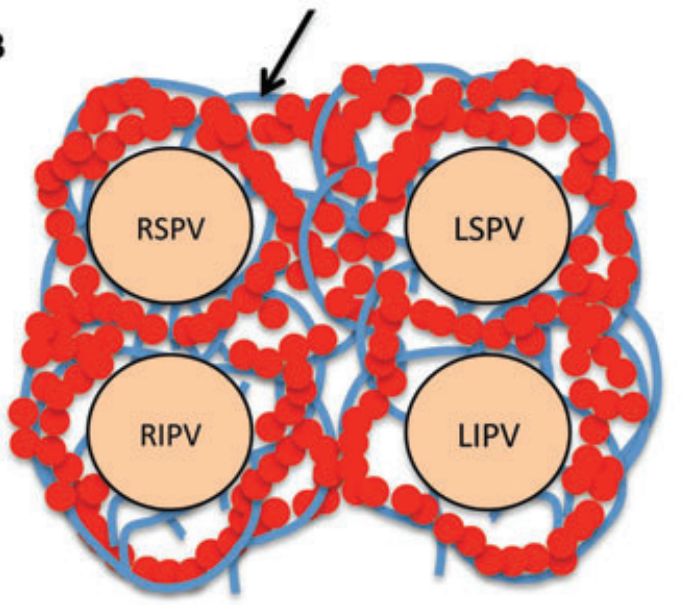

D
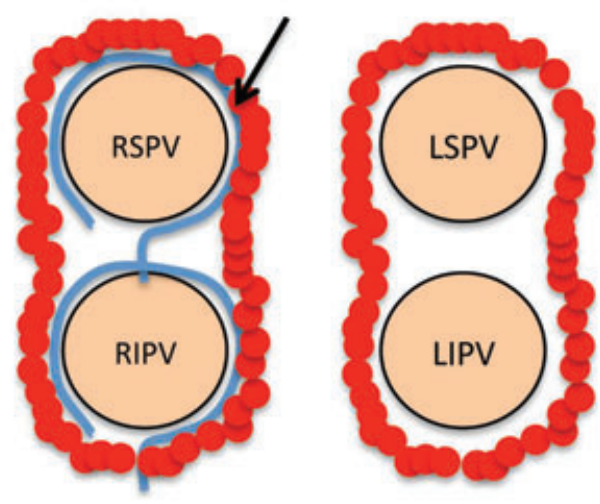

C

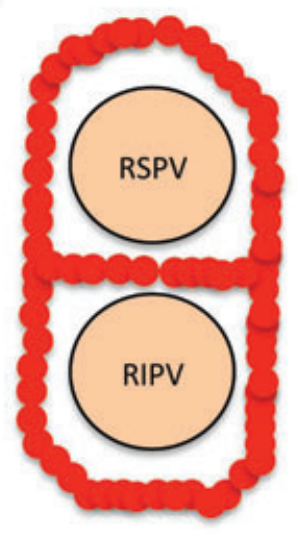

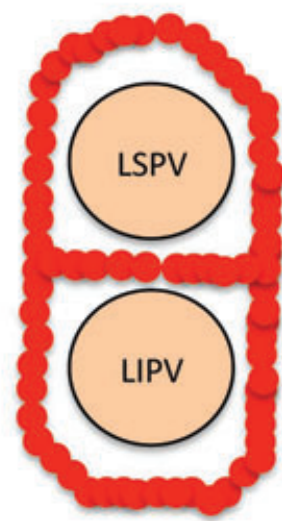

Figure 2. (A) Segmental/ostial isolation: the isolation of PVs is performed at level of the ostium (black ring) and verified by means of a CMC (blue ring) sequentially positioned at each $P V$. The red dots correspond to the application of RF energy. The arrow indicates the CMC. (B) Circumferential/antral PV isolation: the isolation of $P V S$ is performed at level of the antrum and the CMC is moved all around the PVs and the posterior wall of LA. (C) Circumferential $P V$ ablation: the ablation is performed by using a $3 D$ electroanatomical mapping and creating a circumferential lesion around each PV (1-2 cm outside the ostium); verification of PVs isolation by means of a CMC is not strictly required for this technique. (D) Double Lasso technique: the isolation of PVs is performed by means of continuous circular lesions around both ipsilateral PVs and verified by means of 2 CMCs placed within the superior and inferior Pvs. $C M C=$ circular mapping catheter; LIPV = left inferior $P V ; L S P V=$ left superior $P V ; R I P V=$ right inferior $P V ; R S P V=$ right superior $P V ; P V=$ pulmonary vein.

have included the use of cryothermy, ${ }^{33-35}$ laser, ${ }^{36,37}$ ultrasound, ${ }^{38-40}$ and RF energy. ${ }^{41-43}$ Typically these technologies have employed a noncompliant balloon and have suffered from inability to isolate the PVs proximally, particularly at the antrum, but instead achieve isolation more distally at the ostium of the PV or even within the PV itself. ${ }^{44,45}$ This latter issue has been the "Achilles heel" of such balloon technologies, as the resulting lesion delivery at such a distal location has been associated with lower efficacy, by not addressing more proximal sites of triggers, and with an increase in complications such as PV stenosis and phrenic nerve damage. Other balloon-based technologies are under development that would employ a compliant balloon to address these shortcomings. 37

Another new technology has been the development of catheters with various lengths and shapes of the effective ablation delivery region. With use of such catheters, delivery of arcs or lines of lesions might be facilitated. ${ }^{46,47}$

Robotic technologies have been developed for use for catheter navigation. Presently, 2 of such technologies are available. ${ }^{48,49}$ One technology utilizes magnetic fields to navigate special magnetic catheters. The magnetic field can be manipulated at a remote workstation to direct the tip of the catheter. A significant advantage of the magnetic catheter is the physical property of being quite floppy, with virtually no ability to generate excessive contact force against the myocardium to prevent a risk of perforation. This allows for manipulation of the catheter without or at least with much reduced fluoroscopic guidance. A major limitation of this robotic technology is the inability to control additional catheters, such as the CMC and/or the ICE catheter. The use of this magnetic robotic technology for AF catheter ablation has been reported with comparable efficacy and safety to manual techniques. ${ }^{50-52}$ Another robotic technology that has become available is a system that employs a deflectable sheath controlled at a remote workstation. The primary advantage of this system is the ability to use standard catheters rather than specialized catheters as with the magnetic robotic system. However, this system does not offer the safety of the magnetic catheters with regards to potential for excessive forces to the myocardium, so the risk of perforation remains an issue. Reports from centers with extensive experience has demonstrated comparable results to manual methods and reduced fluoroscopy times. ${ }^{53,54}$ 


\section{Electrogram-Based Ablation or CFAEs Ablation}

Different patterns of electrograms have been targeted during radiofrequency catheter ablation of $\mathrm{AF}^{21,55-64}$ Among these, CFAEs have been most widely studied. In the initial report by Nademanee et al., the definition of CFAE included: (1) atrial electrograms composed of 2 deflections or more, and/or perturbations of the baseline with continuous deflections of a prolonged activation complex over a 10 -second recording period, and (2) atrial electrograms with very short cycle lengths $(\leq 120 \mathrm{~ms})$ averaged over a 10-second recording period. Intraoperative mapping of AF has shown that CFAEs are found mostly in areas of slow conduction or at points where the wavelets turn around at the end of arcs of functional block. Such CFAEs have heterogeneous spatial and temporal distribution. Recent studies have attempted to target these CFAEs in order to terminate and prevent recurrence of AF. ${ }^{55,56,61-63,65-67}$

In the study by Nademanee et al., regarding 121 patients with AF (57 paroxysmal), CARTO mapping of both atria was performed during spontaneous or induced AF. CFAEs were identified using bipolar recordings filtered at 30 to $500 \mathrm{~Hz}$ and defined by the presence of voltage $\leq 0.15 \mathrm{mV} .{ }^{55} \mathrm{RF}$ ablation of the area with CFAEs was performed in an attempt to eliminate the CFAEs. According to this report, 92 (76\%) of the 121 patients were free of arrhythmia at 1-year follow-up. However, other studies have shown conflicting results with some improvement or no improvement when ablation of CFAEs alone or in combination with $\mathrm{PV}$ isolation is performed, in patients undergoing AF ablation. ${ }^{56,61-63,65-67}$ According to a recent meta-analysis, the addition of CFAE ablation to PV antral isolation increases the rate of sinus rhythm maintenance in patients with persistent and long-lasting persistent $\mathrm{AF}$, but does not provide supplemental benefit in patients with paroxysmal AF. ${ }^{67}$ Therefore, further randomized studies are needed to clarify the real value of CFAE ablation in patients with AF.

\section{Linear Lesions}

Linear lesions were used initially intraoperatively with the aim of preventing the multiple reentrant wavelets that sustain AF. It is not surprising that catheter-based ablation procedures pursued a similar strategy. The goal of linear lesions is the achievement of bidirectional conduction block. Despite the use of irrigated tip ablation catheters with 3D anatomical guidance, lesion creation remains challenging. ${ }^{68}$

Linear lesions have been reported to be associated with conversion of AF either directly to sinus rhythm or to atrial tachycardia (AT), further demonstrating that such lesions may at least in some patients deeply modify the substrate for AF. ${ }^{69,70}$ Most of these ATs are macroreentrant and require linear lesions to be treated. ${ }^{71}$ Such organized tachycardias may be observed during the index procedure or emerge upon follow-up. Although complete linear lesions can terminate such organized tachycardias, the development of a gap in conduction block along such lines has the potential for a proarrhythmic effect and can facilitate sustained reentry. ${ }^{72}$

For patients in whom atrial flutter has been previously recorded clinically as well as those in whom right atrial flutter is inducible after PV isolation, ablation of the right atrial cavo-tricuspid isthmus ${ }^{73}$ may be appropriate but on long-term follow-up may be of limited added value beyond PV isolation alone. ${ }^{74,75}$ Ablation of the posterolateral mitral isthmus (to the inferior pole of the left PV antrum) has been widely deployed in patients with persistent $\mathrm{AF}^{69,76,77}$ One limitation of the mitral isthmus ablation is that it can require supplemental radiofrequency applications in the distal CS with its intrinsic safety concerns before conduction block is achieved. A number of approaches have been proposed to overcome this requirement, including balloon occlusion of the CS to reduce the heat sink effect of the CS blood flow during endocardial ablation ${ }^{78}$ and modification of the line to a more supero-lateral trajectory.

With wide area circumferential PV antral isolation approach, the distance between the contralateral encirclements is greatly reduced posteriorly. Thus, an LA roof line (which can be created sufficiently superiorly to minimize ablation adjacent to the esophagus) can be achieved with a short transverse lesion connecting the 2 encirclements. More recently the creation of a second transverse linear lesion between the inferior poles of the contralateral encirclements has been deployed in order to complete a box isolation of the posterior LA wall. ${ }^{79}$ This latter technique has the advantage of isolating a large area of high frequency activity where triggers and drivers are more likely to occur than other parts of the atria. Supplemental linear ablation on the anterior wall of the LA appears to be of lesser potential impact. ${ }^{80}$

\section{Catheter Ablation of Left Atrial GP}

Autonomic influences in the heart are produced by the extrinsic (central) and intrinsic cardiac autonomic nervous systems. The intrinsic cardiac autonomic nervous system contains clusters of autonomic GP located in epicardial fat pads on the left and right atria (superior left GP, inferior left GP, anterior right GP, inferior right GP) and in the ligament of Marshall (Marshall tract GP) ${ }^{81-83}$ In patients with AF, endocardial high-frequency stimulation (HFS, cycle length $50 \mathrm{~ms}, 12$ Volt actual output, $10 \mathrm{~ms}$ pulse width) produces a positive vagal response (transient AV block during $\mathrm{AF}$ and hypotension), allowing the identification and localization of left atrial GP. These GP may represent a target of AF ablation.

For endocardial GP ablation, RF energy should be applied to each site exhibiting a positive vagal response to HFS. ${ }^{83,84}$ HFS is repeated after each RF application. If a vagal response is still present, RF energy is reapplied until the vagal response is eliminated. Elimination of the vagal response to HFS at each GP generally requires 3-10 RF applications (usually 30-35-40 Watts for 30-40 seconds but less when close to the esophagus).

In a population of 63 patients with paroxysmal $\mathrm{AF}$ undergoing ablation of the left atrial GP followed by PV antrum isolation, GP ablation alone (prior to PV antrum isolation) decreased the occurrence of PV firing from 47 of 63 patients (75\%) before GP ablation to only 9 of the 63 patients $(14 \%)(\mathrm{P}<0.01)$ after GP ablation. ${ }^{83} \mathrm{PV}$ antrum isolation was then performed, which eliminated PV firing in the remaining 9 patients ( $0 / 63$ patients). The description in this and earlier studies of the elimination of PV firing by $\mathrm{PV}$ isolation, without targeting the sites of firing, ${ }^{85}$ may be explained by the interruption of the axons extending from the GP to the PV myocardium. A similar relationship is present between CFAE ablation ${ }^{86}$ and GP ablation. GP ablation alone often eliminates the majority of CFAE, despite ablating a much smaller area than the overall CFAE area. CFAE ablation may 
eliminate much of the fractionation by ablating the axons without ablation of the GP cell bodies.

\section{Ablation of AF Nests Guided by Real-Time Spectral Mapping in Sinus Rhythm}

Pachon et al. have developed a system for real-time spectral mapping using fast Fourier transform in sinus rhythm. ${ }^{86}$ This mapping strategy identifies sites in which the unfiltered, bipolar atrial electrograms contain unusually high frequencies, namely fibrillar myocardium or the so-called AF Nest. The investigators successfully targeted biatrial AF Nests, without intentional PV isolation, as a novel approach for AF ablation. Oh et al. compared CFAE sites and AF Nests in an animal model of vagally mediated AF and concluded that these sites did not share identical anatomical locations. ${ }^{87}$ Typically for AF Nest ablation, RF delivery for 20-30 seconds abolishes the high-frequency potentials normalizing the spectrum. Arruda et al. evaluated the adjunctive role of AF Nest ablation to antral PV isolation and SVC isolation in a prospective randomized study. The adjunct of AF Nest ablation resulted in a $10 \%$ decrease of recurrence as compared to conventional antral PV isolation and superior vena cava isolation. $^{88}$

\section{Sequential Ablation Strategy}

A stepwise approach has been recently developed in patients with long-lasting persistent AF with different sequences that target multiple atrial areas. ${ }^{89}$ The endpoint of the sequential ablation strategy is termination of AF. This can be achieved by passing directly from AF either to sinus rhythm or, more commonly, to AT, which is then mapped and ablated. The first step consists in PV isolation using antral isolation. As only $12 \%$ of AF will stop at that stage, the second step is frequently needed. It requires ECG-guided ablation targeting continuous electrical activities, focal sources, areas with temporal gradient, etc. The last step uses linear lesions and is used in case of persisting AF/AT after the first 2 steps. The mitral isthmus line is deployed after the roof line as a last resort given the difficulties observed in achieving a complete block. Once sinus rhythm has been restored, PV isolation and linear lesions are checked for completeness and areas re-ablated if needed. It should be emphasized that this approach represents an extensive procedure associated with significant risks and requires careful and individualized riskbenefit assessment. However, it is associated with unprecedented success rate in long-lasting AF, particularly when AF termination is achieved during the index procedure.

\section{Future Technologies}

In order to improve permanent transmural lesion formation, contact force sensing technology (Biosense Webster and Endosense SA) is currently under clinical investigation. The contact force sensor integrates within the distal tip of a conventional mapping and ablation catheter, providing realtime catheter tip-to-tissue contact feedback. Preliminary results using the Endosense catheter demonstrate feasibility and safety in using this new technology for PV isolation. ${ }^{90}$ Several ongoing studies will determine whether the addition of contact force measurement during AF ablation will result also in improved procedural outcome. An alternative means of contact force assessment utilizes local impedance changes between catheter tip and cardiac tissue. The software
TABLE 4

Key Points Regarding the Techniques and Technologies for AF Catheter Ablation

-PV isolation is the cornerstone of current AF catheter ablation techniques. A CMC is the most widespread and reliable method to assess effective PV isolation.

-PV isolation may be performed at different levels, but nowadays it is performed preferentially at level of PV antrum, to include in the lesion important anatomical structures for the initiation and maintenance of $\mathrm{AF}$ (LA posterior wall, GP, rotors, etc.).

-Nonparoxysmal AF patients necessitate a more extensive ablation protocol. Adjuvant ablation of the CFAEs increases the success rate of PV isolation in these patients.

-The incremental therapeutic value of other ablation strategies, such linear lesions, GP ablation, and stepwise approach remains to be established. -New technologies (balloon-based, robotic, contact-force sensing technologies, etc.) are being developed with the principal aim of increasing the effectiveness and safety of catheter ablation of AF, while reducing the operator dependency.

integrates with the Ensite NavX electroanatomical mapping system and initial animal and human studies have shown its clinical utility during mapping and ablation within the LA. ${ }^{91,92}$

The ability to register real-time in-tissue temperature during ablation could potentially facilitate better lesion formation. Using microwave radiometry, very early in-human data demonstrate a correlation between in-tissue temperature and lesion transmurality. Future studies are needed to assess the system's feasibility during AF ablation.

The remote magnetic mapping and ablation system by Magnetecs promises real-time catheter maneuverability within a magnetic field of 1.5 Tesla. The system uses 8 electrical magnets that can be switched off. Hence, no magnetic shielding of the examination room is needed. Studies are under way to test the system's mapping capabilities within humans.

The Amigo robotic arm by Catheter Robotics can be mounted on any conventional examination table and facilitates remote-controlled movement of mapping and ablation catheters. The system is available in Europe and can be integrated with any electroanatomical mapping system. Clinical data are limited with 1 trial currently recruiting patients to assess the system's ability to navigate and map within the human heart.

A new electroanatomical mapping system is currently being developed that uses a basket-shaped mapping catheter to facilitate acquisition of several thousand mapping points within several minutes. Initial clinical data indicate that the system is able to map complex left atrial arrhythmias in humans.

The key points regarding the techniques and technologies for AF catheter ablation are reported in Table 4.

\section{Endpoints of Catheter Ablation for Atrial Fibrillation}

The principal procedural endpoints used for catheter ablation of AF depend on the type of AF being treated. Endpoints include completion of a predetermined lesion set, ${ }^{93}$ termination of AF during ablation, ${ }^{89}$ and noninducibility of AF following ablation. ${ }^{94,95}$ There is still debate surrounding the predictive value of such endpoints, in particular AF termination. 
TABLE 5

Ablation Sites and Ablation Endpoints of the Different Techniques for Catheter Ablation of AF

\begin{tabular}{|c|c|c|}
\hline Ablation Technique & Ablation Site & Ablation Endpoints \\
\hline Segmental/ostial PV isolation & PV ostium & $\begin{array}{l}\text { Complete elimination or dissociation of PV } \\
\text { potentials assessed by a CMC }\end{array}$ \\
\hline Circumferential PV isolation & $1-2 \mathrm{~cm}$ outside $\mathrm{PV}$ ostium & $\begin{array}{l}\text { Abatement of local bipolar voltage by } 90 \% \text { or }<0.05 \\
\mathrm{mV} \text { within encircled areas }\end{array}$ \\
\hline Antral PV isolation & PV antrum & $\begin{array}{l}\text { Complete elimination of PV potentials with } \\
\text { isolation of all PVs and posterior wall of LA } \\
\text { assessed by a CMC }\end{array}$ \\
\hline CFAEs ablation & LA areas where CFAEs are recorded & $\begin{array}{l}\text { Complete elimination of CFAEs Termination of AF } \\
\text { Noninducibility of AF }\end{array}$ \\
\hline Linear lesions & LA roof and mitral isthmus & $\begin{array}{l}\text { Creation and demonstration of line of complete } \\
\text { block }\end{array}$ \\
\hline Autonomic GP ablation & GP located around PVs & Abolition of vagal reflexes induced by HFS \\
\hline AF Nest ablation & $\begin{array}{l}\text { Local high frequency activity or focal and } \\
\text { centrifugal spread of activation or frequency areas }\end{array}$ & $\begin{array}{l}\text { Abolition of these high sites with temporal gradient } \\
\text { between } 2 \text { dipoles }\end{array}$ \\
\hline Other structures and thoracic veins & $\begin{array}{l}\text { CS, LA appendage, superior vena cava, persistent } \\
\text { left superior vena cava, vein of Marshall }\end{array}$ & $\begin{array}{l}\text { Complete elimination or dissociation of other } \\
\text { structures or thoracic veins }\end{array}$ \\
\hline
\end{tabular}

In patients with paroxysmal $\mathrm{AF}$, it is possible that the termination of AF during ablation is coincidental. In these patients noninducibility seems to be associated with an improved outcome. ${ }^{95,96}$ However, there is no current consensus on the definition of noninducibility and the standardization of the induction protocol used. Furthermore, it is likely that the noninducibility of AF might identify a subgroup of patients who have less severe atrial disease and therefore more likely to have a successful outcome. For patients with persistent and long-lasting persistent AF, the procedural endpoint is also unclear. Although restoration of sinus rhythm by ablation, without the use of antiarrhythmic drugs or DC cardioversion, appears to be an intuitively ideal endpoint, this is not always achievable and results regarding clinical outcome are controversial. ${ }^{97-99}$ Until more data are available, completion of a predetermined lesion set incorporating PV isolation remains the basic procedure. ${ }^{100}$ Verification and completion of ablation linear lesion sets is fundamental to minimizing proarrhythmia and arrhythmia recurrence. The ablation endpoints of the principal ablation approaches previously discussed are summarized below and in Table 5 .

\section{PV Isolation}

There is consensus that electrical PV isolation is the optimal endpoint for ablation targeting the LA-PV junction and is now generally incorporated as the initial lesion set in $\mathrm{AF}$ ablation strategies. ${ }^{101,102}$ The most objective procedural endpoint is absence or dissociation of PV potentials recorded from a CMC positioned just inside the $\mathrm{PV}^{28,29,103,104}$ (Table 5). Many consider the same endpoint of electrical PV isolation optimal for wide area circumferential PV ablation. However, reduction of local bipolar amplitude with low peak-to-peak bipolar potentials $(\leq 0.1 \mathrm{mV})$ inside the encircled area as well as local endocardial activation time $>30 \mathrm{~ms}$ between contiguous points lying in the same axial plane on the external and internal side of the line, are still suggested by some authors as a suitable endpoint in order to avoid the necessity for a $\mathrm{CMC}^{26}$ (Table 5). Exit block into the LA can also be proven with pacing maneuvers from inside the PV, but this is not routinely applied. This is due to the technical difficulty of ensuring pacing capture of the muscle sleeves inside the vein without far-field capture of the left or right atrium.
The role of intravenous adenosine as an adjunct to prove permanent abolition of PV conduction has been suggested ${ }^{105}$ and is part of an ongoing prospective study. ${ }^{106}$ As an additional endpoint, nonexcitability of bilateral circumferential lines following PV isolation has been introduced. ${ }^{107,108}$

\section{Electrogram-Based Ablation or CFAEs Ablation}

Endpoints for ablation of sites of CFAEs include: (1) complete elimination of the areas with CFAEs, (2) conversion of AF to normal sinus rhythm for both paroxysmal AF and persistent/long-lasting persistent AF patients, (3) conversion of $\mathrm{AF}$ to an organized atrial tachyarrhythmia (AT or flutter), and (4) noninducibility of AF in paroxysmal AF patients $^{55,56,61-63,65-67}$ (Table 5).

The ablation typically begins at the sites where CFAEs have the shortest local A-A interval. Such sites are unfortunately ubiquitous in persistent AF. It is not known whether ablation of all such sites is necessary or if it is possible to target specific locations and thereby limit the extent of unnecessary ablation and resultant tissue damage. Irrespective of electrogram complexity, ablation all along some structures like the CS, LA appendage, ${ }^{109}$ and septum may also have an impact on $\mathrm{AF}$ perpetuation.

Importantly, after "defragmentation" and prior ablation (PV isolation and eventually linear lesions), electrograms may become discrete or organized, allowing a dominant rate (frequency) and specific activation sequence to be identified. In such situations, parameters other than fragmentations may be used. Local high-frequency activity or focal and centrifugal spread of activation or sites with temporal gradient between 2 bipoles of conventional mapping catheter (representing local circuit, "rotor" or "AF nest") are potential targets for ablation. ${ }^{110}$

\section{Linear Lesions}

In patients with persistent or long-lasting persistent $\mathrm{AF}$, the use of adjunctive linear ablation, mainly at the level of LA roof and mitral isthmus, has been associated with higher success rates. ${ }^{95,111,112}$ The endpoint should be a complete line of linear lesions ${ }^{76,77,113,114}$ because incomplete lesions are associated with recurrence of atrial arrhythmias. ${ }^{72,115,116}$ The electrophysiological endpoint should therefore be demonstration of bidirectional line of block ${ }^{76}$ (Table 5). A complete 
LA roofline may be demonstrated by activation progressing in a caudal-cranial direction on the posterior wall during left appendage pacing. ${ }^{77}$ A complete mitral isthmus line may be demonstrated by an inversion of CS activation sequence from distal-proximal to proximal-distal during pacing from the left appendage. ${ }^{76}$

\section{Autonomic GP Ablation}

Autonomic GP located around PV can be identified by HFS. HFS at these sites leads to induction of bradycardia or AV block due to increased vagal tone. Abolition of inducible vagal reflexes has been proposed as an endpoint of GP ablation ${ }^{117}$ (Table 5). It is unclear whether GP should be specifically targeted given that these sites may be concomitantly ablated in the course of above-described ablation targets. Most centers still do not specifically target such GP, although these may be affected especially when extended ablation approaches are introduced.

\section{CS and Other Thoracic Veins Ablation}

Similar to triggers arising from the muscle sleeves surrounding the PVs, rapid atrial activity from the musculature of the CS may be a driver for persistent or long-lasting persistent AF. The same electrogram-based approach as discussed above can be applied to the CS. ${ }^{118}$

Other potential triggers, such as superior vena cava and persistent left superior vena cava, ${ }^{119,120}$ can be electrically isolated by ablation technique and endpoints similar to PV isolation $^{121}$ (Table 5).

The key points regarding the endpoints of catheter ablation for $\mathrm{AF}$ are reported in Table 6.

\section{Patient Management Pre-, During, and Postablation}

\section{Preablation Management}

\section{Anticoagulation}

Effective anticoagulation therapy is often necessary before an ablation procedure for AF. The modalities and duration of preablation anticoagulation therapy are reported in detail later.

\section{Other drugs}

Drug treatment for nonarrhythmic indications is generally continued. There is no consensus with regard to discontinuing antiarrhythmic drugs (AADs), although to avoid confounding ablation effects with AADs effects, all AADs with the possible exception of amiodarone should be discontinued at least 4 half-lives in advance. However, if symptomatic arrhythmias demand, effective AADs may be continued.

\section{Transesophageal echocardiogram}

A preablation transesophageal echocardiogram (TEE) is used to rule out the presence of a LA thrombus, and should be considered a supplementary and backup strategy to continuous effective anticoagulation leading up to the ablation procedure. It should be performed shortly before the ablation procedure and without an intervening window in effective anticoagulation. In many EP laboratories, TEE is performed only in patients presenting with $\mathrm{AF}$ and off anticoagulation therapy.

\section{Other imaging studies}

Imaging to define the cardiac substrate could include establishing the presence and extent of coronary artery disease (if present) and left ventricular size and function. A transthoracic echocardiogram before the procedure is useful and allows measurement of chamber size and ejection fraction. LA size is an important determinant of rhythm outcome after ablation and may influence the selection of ablation strategies. The most widely used measure, single-plane dimension from the parasternal long-axis view, correlates modestly with LA volumes. Estimation of LA volume from multiple 2-D imaging planes or by volumetric analysis of MR or CT images may be preferable and more accurate. Evaluation of LA emptying and systolic function (ejection fraction) is not part of most standard imaging routines but may have an important role in evaluating the long-term impact of ablation on LA function.

An MR or contrast-enhanced spiral CT scan is obtained as a baseline both for comparison and for formulation of an ablation strategy with variable PV anatomy. ${ }^{122}$ In some laboratories, the ablation is performed with MR or CT image integration. In such situations, both the underlying rhythm and ventricular rate at the time of acquisition are important in order to make effective use of the 3D images. ${ }^{123}$ Preliminary data indicate that preprocedure delayed enhancement MR may be useful in predicting procedural outcome. ${ }^{124}$

\section{Informed consent and preablation fasting}

As for any ablation, an informed consent and appropriate preparation including at least 6 hours of fasting leading up to the procedure are necessary.

\section{Management During Ablation}

\section{Sedation/anesthesia}

Conscious sedation using midazolam combined with analgesia using fentanyl is used in ablation procedures of less complex arrhythmias and can also be applied during AF ablation. However, conscious sedation is often inadequate during $\mathrm{AF}$ ablation, due to long procedure times, pain during RF energy applications, and the need to limit patient motion during the procedure. Therefore, general anesthesia is widely used during AF ablation. General anesthesia may reduce the prevalence of $\mathrm{PV}$ reconnection during repeat ablation when compared with conscious sedation. ${ }^{125}$ Alternatively, deep sedation during continuous infusion of propofol has evolved as a third sedation alternative. This strategy can achieve painless deep sedation without the need for intubation and general anesthesia, and can be guided by the electrophysiologist. ${ }^{126}$

\section{Anticoagulation}

The intensity of anticoagulation during the AF ablation is of critical importance and is described in chapter 6 .

\section{AADs/electrical cardioversion}

Many investigators choose to perform the AF ablation procedure off AADs. The procedure can be performed during either sinus rhythm or AF. In selected cases, AADs may be administered intravenously when sinus rhythm is desired. Alternatively, electrical cardioversion can be applied when sinus rhythm is the preferred rhythm during specific parts of 
TABLE 6

Key Points Regarding the Endpoints of Catheter Ablation for AF

-Primary targets of AF ablation are PVs and/or PV antrum.

-Primary goal is complete and permanent electrical isolation of PVs.

-Careful identification of PV ostia is essential to avoid ablation within the PVs.

-Ablation of focal extra-PV triggers (superior vena cava, vein of Marshall, CS, LA appendage) is recommended.

-In patients with paroxysmal AF, electrical isolation of the PVs is sufficient. In patients with persistent and long-lasting persistent AF, additional lesions are usually required (CFAEs ablation, linear lesions, GP ablation).

-For additional linear lesions (LA roof, mitral isthmus, anterior left septum), verification of line completeness demonstrated by bidirectional block is of fundamental importance to minimize arrhythmia recurrence.

-Ablation of the cavotricuspid isthmus is recommended only with history of typical atrial flutter or inducible cavotricuspid isthmus dependent atrial flutter.

-No consensus on other endpoints exists: use of intravenous isoproterenol to unmask focal extra-PV triggers, role of intravenous adenosine as an adjunct to prove permanent abolition of $\mathrm{PV}$ conduction, $\mathrm{AF}$ termination during ablation and AF inducibility postablation.

the procedure, e.g., verification of conduction block across linear ablation lines and confirmation of PV isolation.

\section{Postprocedural Management}

The immediate postprocedural management consists of continuing and maintaining anticoagulation, maintaining hemostasis at puncture sites, and supportive treatment. Vagal episodes remedied by fluid infusion and/or atropine are not uncommon; however, pericardial tamponade must be excluded in patients with postprocedural hypotension. Pericarditic discomfort may occur during the first 3-5 days, sometimes accompanied by a mild and self-limited febrile syndrome. Aspirin is usually sufficient treatment although uncommonly, continuing symptoms and a nonresolving pericardial effusion may require the administration of systemic steroids. The later occurrence (6-10 days postablation) of a febrile state with or without neurological symptoms should prompt suspicion of an atrio-esophageal fistula and lead to a contrast-enhanced spiral CT to exclude the diagnosis.

Many centers now perform AF ablation while continuing therapeutic anticoagulation with warfarin. ${ }^{127}$ In this case, oral warfarin anticoagulation can simply be continued after ablation. For other practical aspects regarding anticoagulation after $\mathrm{AF}$ ablation, see later.

\section{Rhythm outcome}

Estimating the burden of AF, both symptomatic and asymptomatic, is the key to determining the outcome of the procedure. The ideal outcome would be a zero residual burden with no atrial flutter or AT. The absence of symptoms may not correspond to the stable restoration of sinus rhythm, probably due to ablation-induced denervation or because of the absence of symptoms at baseline. The accuracy of estimating AF burden depends chiefly upon the duration of ECG recording (Table 7). ${ }^{128-135}$ Many laboratories use a clinical definition of successful ablation to mean the absence of symptomatic tachycardia, as well as the absence of documented AF during periodic follow-up visits as well as on periodic $24-48$-hour Holter recordings, typically at 1 , 3 , and 6 months after the ablation. An event recorder may be used to evaluate symptoms not elucidated by the above tests. However, extending the duration of Holter tracings to 7 days has been shown to enhance the sensitivity of detecting recurrent $\mathrm{AF} .{ }^{136}$ Another approach has been to monitor periodic, even daily, transtelephonic ECG recordings supplemented by ECG transmission during symptomatic episodes, although the correlation to AF burden may be difficult to determine. ${ }^{132}$ Finally, more and more implanted devices have sufficient memory and accurate arrhythmia recognition software to provide probably the most accurate measurement of AF burden possible, but of course only in a limited patient population. ${ }^{137,138}$ From a clinical standpoint, when success is defined as the restoration of stable sinus rhythm, this assumes the elimination of (sustained) ATs as well, whether reentrant (flutters) or nonreentrant.

Owing to the difficulty of clinically measuring the AF burden, the temporal evolution of arrhythmias in ablated patients has not been clearly determined. Although some groups have re-ablated patients as soon as they develop recurrent AF, others have advocated waiting for 1-3 months with or without adding AADs treatment in the interim period. An early re-ablation may result (unnecessarily) in a higher incidence of local puncture site complications, a longer hospital stay, and the risks of an additional left-sided procedure. About $30-50 \%$ of patients with documented or symptomatic recurrences during the first 3 months after an $\mathrm{AF}$ ablation have no further AF or flutter even without additional ablation. However, early AF recurrences do portend a worse longterm outcome, and merit heightened awareness of later AF occurrences (see later).

\section{AADs therapy}

It has been demonstrated in a prospective randomized trial that treatment with AADs during the first 6 weeks after AF ablation reduces the incidence of clinically significant atrial arrhythmias and need for cardioversion or hospitalization for arrhythmia management. ${ }^{139}$ However, systematic AADs therapy did not reduce late arrhythmia recurrence during longer-term follow-up in the same population. ${ }^{140}$ Alternatively, AADs are stopped 4 half-lives before ablation and not restarted unless symptomatic or sustained recurrences occur. There are no guidelines for discontinuing AADs therapy after AF ablation. Depending upon the risk of recurrence and the accuracy of determining residual arrhythmias, trial of discontinuation may be offered after 3-6 arrhythmia-free months. According to a recent paper, transient use of small amounts of corticosteroids (prednisolone $0.5 \mathrm{mg} / \mathrm{kg} /$ day) shortly after ablation (first 3 days) may be effective and safe for preventing both immediate and late AF recurrences (14 months follow-up). ${ }^{141}$ Other drugs such as angiotensin-converting enzyme inhibitors, angiotensin receptor blockers, statins, and polyunsaturated fatty acids may potentially prevent AF by a variety of mechanisms, including anti-fibrotic, anti-inflammatory, and anti-oxidant effects. However, the efficacy of these drugs in reducing postablation arrhythmia recurrences has yet to be demonstrated. ${ }^{142}$ 
TABLE 7

Incidence of Asymptomatic AF in Postablation Patients

\begin{tabular}{|c|c|c|c|}
\hline Authors & Total number of patients & Number of patients with asymptomatic AF (\%) & ECG detection method \\
\hline Oral et al. ${ }^{128}$ & 53 & $1(2 \%)$ & Transtelephonic ECG monitoring \\
\hline Hindricks et al. ${ }^{129}$ & 108 & $20(18 \%)$ & 7-day Holter monitoring \\
\hline Senatore et al. ${ }^{130}$ & 72 & $8(11 \%)$ & Transtelephonic ECG monitoring \\
\hline Neumann et al. ${ }^{131}$ & 80 & $11(14 \%)$ & External loop recorder \\
\hline Vasamreddy et al. ${ }^{132}$ & 10 & $2(20 \%)$ & Mobile continuous outpatient telemetry \\
\hline Klemm et al. ${ }^{133}$ & 80 & $7(9 \%)$ & Transtelephonic ECG monitoring \\
\hline Verma et al. ${ }^{134}$ & 86 & $2(2 \%)$ & Pacemaker/ICD memory \\
\hline Steven et al. ${ }^{135}$ & 37 & $0(0 \%)$ & Pacemaker/ICD memory \\
\hline
\end{tabular}

Note: Only the incidence of asymptomatic episodes is reported.

\section{Late surveillance}

Echocardiographic monitoring is useful to detect improvement in left ventricular function and assess reductions in LA size after ablation. ${ }^{143,144}$ In the light of the high rates of symptomatic PV stenosis/occlusion in the early days of ablation targeting the PVs, routine MR or CT imaging was advocated at 3-6 months following the ablation. However, improvements in intra-procedural imaging as well as strategic changes in placing ablation lesions more remote from the PV ostia, has resulted in significant reductions in PV stenosis rates. Furthermore, about $80 \%$ of PV stenoses, including most single PV occlusions, are asymptomatic. ${ }^{145}$ Consequently, routine imaging with MR or CT is often restricted to patients with suggestive symptoms. Finally, a significant risk of very late AF recurrence has been reported in several series. ${ }^{146,147}$ It is therefore advisable to maintain periodic surveillance for arrhythmia recurrence at 6- or 12month intervals, even in patients who are free of arrhythmias during the initial year following ablation.

The key points regarding patient management pre-, during, and postablation are reported in Table 8.

\section{Periprocedural and Long-Term Anticoagulation}

Stroke is by far the most serious adverse consequence of $\mathrm{AF}$, and concern about stroke prevention pervades all decision making related to management of AF, including ablation. Although the primary motivation for PV isolation procedures is to reduce symptoms, nonetheless, stroke prevention needs to be considered before, during and after ablation procedures for $\mathrm{AF}$.

\section{Preablation Anticoagulation and TEE}

Because AF ablation involves not only cardioversion in many patients and the introduction of foreign bodies into the left heart, but also the possibility of a lapse in anticoagulation during sheath removal, the importance of preprocedural anticoagulation is well accepted. However, there are many potential strategies and very little data to guide best practices.

Anticoagulation strategies prior to ablation procedures in high risk patients reflect guidelines for the care of patients with AF in general. Patients with CHADS2 scores of 2 or higher should be anticoagulated in any case, to an INR of 2-3 for at least 3 weeks prior to ablation; if warfarin is stopped prior to the procedure, enoxaparin or heparin may be used for "bridging." There is little consensus regarding the need for anticoagulation in low risk patients. Recent observational studies suggest that a strategy of performing ablation with a therapeutic INR may reduce the risk of ablation-related thromboembolism. ${ }^{127,148,149}$ This strategy has the theoretical advantage of eliminating the lapse in anticoagulation during sheath removal, and has been shown to be associated with a low rate of bleeding complications and of periprocedural stroke. The impact of new oral anticoagulants has not been studied in this application.

Many centers routinely perform TEE prior to ablation to exclude the presence of thrombus in high risk patients, particularly in those with persistent AF. Other strategies to assess the presence of thrombus, such as CT angiography, or intra-procedural ICE, may be reasonable but have not been rigorously compared to TEE, which is the current gold standard. There is little consensus in low risk patients, or those with paroxysmal AF. A recent paper suggested that the incidence of intracardiac thrombus was low in ablation candidates $(0.6 \%)$, but increased with increasing CHADS2 score, history of heart failure and left ventricular ejection fraction $<35 \% .{ }^{150}$

\section{Anticoagulation During the Ablation Procedure}

In the updated worldwide survey of catheter ablation for $\mathrm{AF}$, a $0.94 \%$ incidence of stroke or TIA was reported, ${ }^{151}$ however an 11-14\% incidence of cerebral emboli were observed following catheter ablation in 2 recently published studies. ${ }^{152,153}$ Major bleeding complications such as tamponade, hemothorax, and groin complications such as pseudoaneurysm or AV fistula totaled $2.3 \% .{ }^{151}$ Femoral hematomas are more common, up to $8 \%,{ }^{154}$ and may prolong hospitalization or produce a short period of disability. Achieving the lowest possible thromboembolic complication rate while maintaining an acceptably low bleeding complication rate is the goal of intra-procedural anticoagulation. Thrombus can form within sheaths or on guidewires and catheters, as observed by ICE, particularly in patients with persistent AF, dilated atria, and spontaneous echo contrast. ${ }^{155}$ To prevent thrombus formation within the sheaths, it is common sense to flush them intermittently or use continuous irrigation, which may be more reliable. Since the capacity of the inner lumen for blood is larger without a catheter in place, it may be beneficial to leave catheters in sheaths while in the LA. Endocardial RF catheter ablation may disrupt endothelial integrity and expose a nidus of interstitial tissue, which may promote thrombus formation. Char may form on the electrodes of the ablation catheter if temperatures exceed $100^{\circ} \mathrm{C}$ 
TABLE 8

Key Points Regarding Patient Management Pre-, During, and Postablation

Preablation

-Effective anticoagulation often necessary. TEE recommended to rule out an LA thrombus in patients with persistent/long-lasting persistent AF and/or at high thromboembolic risk (see next chapter).

-No consensus with regard to discontinuing AADs.

-MR or CT scan important for comparison and for formulation of an ablation strategy with variable PV anatomy.

During Ablation

-Conscious sedation, deep sedation, jet ventilation, and general anesthesia are alternative methods for patient sedation during AF ablation.

-The intensity and the type of anticoagulation protocol are of key importance (see next chapter).

Postablation

-Continuation and maintenance of anticoagulation crucial (see next chapter).

-Ambulatory ECG monitoring with 1 of the different ECG detection methods strongly recommended in order to assess the correspondence between symptoms and arrhythmia and to discover asymptomatic episodes of AF.

-No consensus exists for continuing/discontinuing AADs after AF ablation. The use of AADs in the first period after ablation reduces the recurrence rate of early arrhythmias but not the incidence of late arrhythmias.

-The use of ACE inhibitors, statins, and PUFAs does not appear associated with a reduction of arrhythmia recurrences.

-MR or CT imaging at 3-6 months not recommended routinely but only for patients with symptoms suggestive for PV stenosis.

at the electrode-tissue interface that may increase the risk of thrombus formation. A sudden impedance rise during RF energy delivery may indicate the development of char and should prompt withdrawal and inspection of the catheter tip. A catheter tip with open irrigation appears to reduce the risk of char and thrombus formation by cooling the electrodetissue interface. ${ }^{156}$

Unfractionated heparin, delivered by weight/time-based nomograms and/or monitored by frequent measurement of activated clotting time (ACT), is typically given during the ablation procedure, even in the presence of a therapeutic INR (thrombus may form in the right atrium with similar frequency as it does in patients with an INR <2.0). Exchanging short vascular access sheaths for transseptal sheaths should be preceded by careful flushing and heparin delivery should be considered at this point rather than after transseptal puncture, particularly in patients with a higher risk of thromboembolism. The target intensity of anticoagulation is not standardized among experienced investigators, and may vary according to several factors, for example, patient age, type of ablation procedure, catheter used, and energy source. Observational studies have shown using ICE that the incidence of visualized thrombus markedly decreased with an increase in target ACT from 250-300 to >300 seconds. ${ }^{155,157}$ Many experienced operators instruct their patients to maintain a therapeutic INR, as it may be easier to achieve and maintain target ACT values and may reduce the risk of stroke. The risk of major bleeding complications does not appear to increase using this strategy. ${ }^{149,154}$ Additionally, management of cardiac tamponade appears to be equally safe in patients with a therapeutic INR, but reversal agents such as fresh frozen plasma or factor IX should be readily available during the procedure if a therapeutic INR is to be maintained. ${ }^{158}$

\section{Postablation Anticoagulation}

No universally accepted recommendations exist for anticoagulation therapy after successful ablation of AF. Due to the high risk of thromboembolism in the early postprocedural period, ${ }^{159}$ in the many centers, warfarin therapy is started in all patients either the same evening of the ablation procedure or the next morning. In the initial period, LMWH (e.g., enoxaparin at a dosage of $0.5-1.0 \mathrm{mg} / \mathrm{kg}$ twice a day) is often given as bridging therapy by starting 3-4 hours after the ablation. ${ }^{28,160}$ Less frequently, heparin is administered intravenously until the day after the procedure, starting about 3 hours after sheath removal at a rate of 1,000 IU/h. ${ }^{160-162}$ Thereafter, LMWH is administrated until the INR is $\geq 2$. Warfarin is usually continued for at least 3 months.

After this period the anticoagulation strategy is controversial. There have been several reports indicating that a low rate of stroke may occur in patients with successful ablation who do not receive anticoagulation. ${ }^{159,162-166}$ However, these studies have 2 major limitations: (1) they are observational, retrospective, and not randomized; and (2) most enrolled few patients at high thromboembolic risk. The reasons for continuing anticoagulation after ablation mainly concern the risk of long-term recurrence ${ }^{146,147,167-177}$ and in particular, the risk of asymptomatic recurrences. ${ }^{128-135}$ Furthermore, it is generally accepted that there is a continuing risk of stroke in patients receiving AADs therapy even if it appears that therapy has eliminated AF recurrences. Therefore it would appear to be prudent at this point to recommend that long-term anticoagulation be continued in patients even after apparently successful ablation. The use of anticoagulation requires an assessment of stroke risk ${ }^{178}$ and bleeding risk as well as patient values. Aspirin is generally considered a poor substitute for oral anticoagulation. New anticoagulants such as dabigatran, which is easier to use than warfarin, more effective and associated with fewer life-threatening bleeds make the decision to continue an anticoagulant after apparently successful ablation more attractive. ${ }^{179}$

The key points regarding periprocedural and long-term anticoagulation are reported in Table 9.

\section{Peri-Procedural and Late Complications}

Recognition of complications related to AF ablation can help minimize risk. Overall, the rate of major complications ranges from $0.8 \%$ to $5.2 \%$ in recent studies. ${ }^{151,169,180-187}$ The incidence, causes, clinical presentation, diagnostic tools, preventive and therapeutic measures of each of these complications are summarized in Table 10. Death occurs, as a complication of $\mathrm{AF}$ ablation, in 1 of 1,000 patients. ${ }^{188}$ The most frequent causes of death are cardiac tamponade, stroke, and atrio-esophageal fistula. ${ }^{189}$ 
TABLE 9

Key Points Regarding Periprocedural and Long-Term Anticoagulation

Preablation

-In patients at moderate to high risk of stroke, anticoagulation with a Vitamin $\mathrm{K}$ antagonist (INR 2-3, target 2.5) or a new anticoagulant is recommended for 3 weeks prior to ablation. For patients at low risk of stroke, the need for this is unknown.

-TEE or other methods to exclude intracardiac thrombus prior to ablation is recommended in patients with persistent $\mathrm{AF}$ or other high-risk

characteristics.

-If INR has been therapeutic every week for the 4 weeks preceding the ablation, the TEE could be avoided.

During Ablation

-Heparin administration should be initiated at the time of the exchange of short vascular sheaths for transseptal sheaths, and no later than immediately after transseptal puncture is safely accomplished.

-Heparin should be administered as an initial bolus dose of 100-140 IU/kg followed by an infusion of $15-18 \mathrm{IU} / \mathrm{kg} / \mathrm{hour}$ and/or by additional boluses.

For patients with an INR range of 2.0-3.5, the initial bolus dose should be reduced to $80 \mathrm{IU} / \mathrm{kg}$.

-The ACT target should be 350-400 seconds based on limited data. The ACT target does not differ in patients with and without a therapeutic INR.

-Heparin infusion is discontinued in all patients after removal of catheters from the LA. Protamine infusion may be administered (dose 30-50 mg) or

ACT allowed to decrease below 250 seconds prior to sheath removal to minimize the potential for femoral hematoma formation.

-Ablation on therapeutic coumadin could be considered.

Postablation

-Oral anticoagulation should be started after ablation and continued for at least 3 months in all patients.

-Oral anticoagulation should be continued indefinitely in most patients who are at moderate or high risk of stroke (based on a risk stratification system such as $\mathrm{CHADS}_{2}$ or $\mathrm{CHA}_{2} \mathrm{DS}_{2}-\mathrm{VASc}$ ). This recommendation is based on a known risk of AF recurrence, and a lack of randomized, prospectively obtained trial data indicating the safety of anticoagulation discontinuation.

\section{Pericardial Effusion/Cardiac Tamponade}

A risk of $1.3 \%$ for cardiac tamponade has been reported in the last worldwide survey on AF ablation outcome. ${ }^{151}$

Clinical manifestations of acute tamponade include hypotension, tachycardia, paradoxical pulse, jugular venous distension, and shock.

Monitoring with ICE or TEE and direct visualization of the transseptal puncture may help minimize risk. ${ }^{190}$ Cautious LA catheter manipulation and careful titration of RF power delivery seems to reduce direct LA trauma and tissue boiling with endocardial rupture.

Most large effusions can be drained with a percutaneous technique with documentation of the absence of ongoing bleeding. Occasionally, open-heart surgery, including cardio-pulmonary bypass may be required particularly when ongoing bleeding after initial drainage is evident and substantive. ${ }^{191}$

Recently, cases of delayed cardiac tamponade (i.e., occurring after discharge from the EP lab or from hospital) have been reported, sometimes preceded by evidence of pericarditis. ${ }^{192}$

\section{Thromboembolic Events}

The prevalence of thromboembolism during or after AF ablation has been reported to vary from $0 \%$ to $1.1 \%$ in different studies. ${ }^{151,180,183,184,187}$ For the possible causes, prevention and therapy of this complication see the previous section on periprocedural and long-term anticoagulation.

\section{PV Stenosis}

With the evolution of PV isolation techniques and ablation at the PV ostium or even more proximal at the antral level, the incidence of severe PV stenosis has decreased to $0-0.5 \% .^{151,180,183,184,186,187}$ However, PV stenosis may be underreported because most of the patients remain asymptomatic and postablation imaging is no longer routine at most centers. In the updated worldwide AF ablation registry, the rate of PV stenosis requiring intervention was $0.29 \%$. $^{15}$

The clinical manifestation of PV stenosis may be quite insidious. Many people are asymptomatic if only single
PV stenosis is present even when marked $(>70 \%) .{ }^{193}$ The most frequent symptoms of PV stenosis are cough, dyspnea, hemoptysis, or recurrent and drug-resistant pneumonia. ${ }^{194-196}$ Symptoms may develop both early and/or late after the procedure with most patients presenting within 2-6 months. ${ }^{194}$

To reduce the risk of PV stenosis when RF-ablation is performed near the PV ostium, the anatomy should be clearly defined using angiography of the PVs, ICE, or 3D mapping systems with image integration of preprocedure acquired MR or CT imaging. Avoidance of lesion placement within venous structures is critical. ${ }^{194}$ Cryo-energy was promoted to eliminate the risk of PV stenosis. ${ }^{33-35}$ However, the first cases of PV stenosis after cryo-balloon PV isolation have been reported recently. ${ }^{197}$

Significant $(>70 \%)$ PV stenosis in symptomatic patients should be treated by angioplasty and/or stenting. ${ }^{198}$ Angioplasty is associated with high restenosis rate of $45 \% .{ }^{198,199}$ PV stenting with bare metal stents with a size of $\geq 10$ $\mathrm{mm}^{200,201}$ or drug-eluting stents ${ }^{202}$ seem to reduce the restenosis rate. Because of the disappointing surgical results for congenital stenosis, surgery should be considered the treatment of last resort. Whether patients with $1 \mathrm{PV}$ stenosis and no or minimal clinical symptoms should be treated is not yet known. Anticoagulation is typically maintained if severe stenosis is present to prevent acute thrombosis.

\section{Phrenic Nerve Injury}

The estimated incidence of phrenic nerve injury is between $0.1 \%$ and $0.48 \% .{ }^{203,204}$ The right phrenic nerve is vulnerable to collateral injury during energy delivery at or close to right superior PV and superior vena cava. ${ }^{205}$ The left phrenic nerve is susceptible to damage when lesions are applied in the vicinity of the LA appendage. ${ }^{206}$

Phrenic nerve injury appears to be clinically silent in many patients (22-50\%), ${ }^{203,204}$ with the majority of the remaining patients presenting with mild symptoms such as dyspnea, cough, and weakness. However, some patients develop more severe lung complications such as pneumonia, atelectasis, pleural effusion, and respiratory failure. Surgical plication of the paralyzed right diaphragm may be required. The 


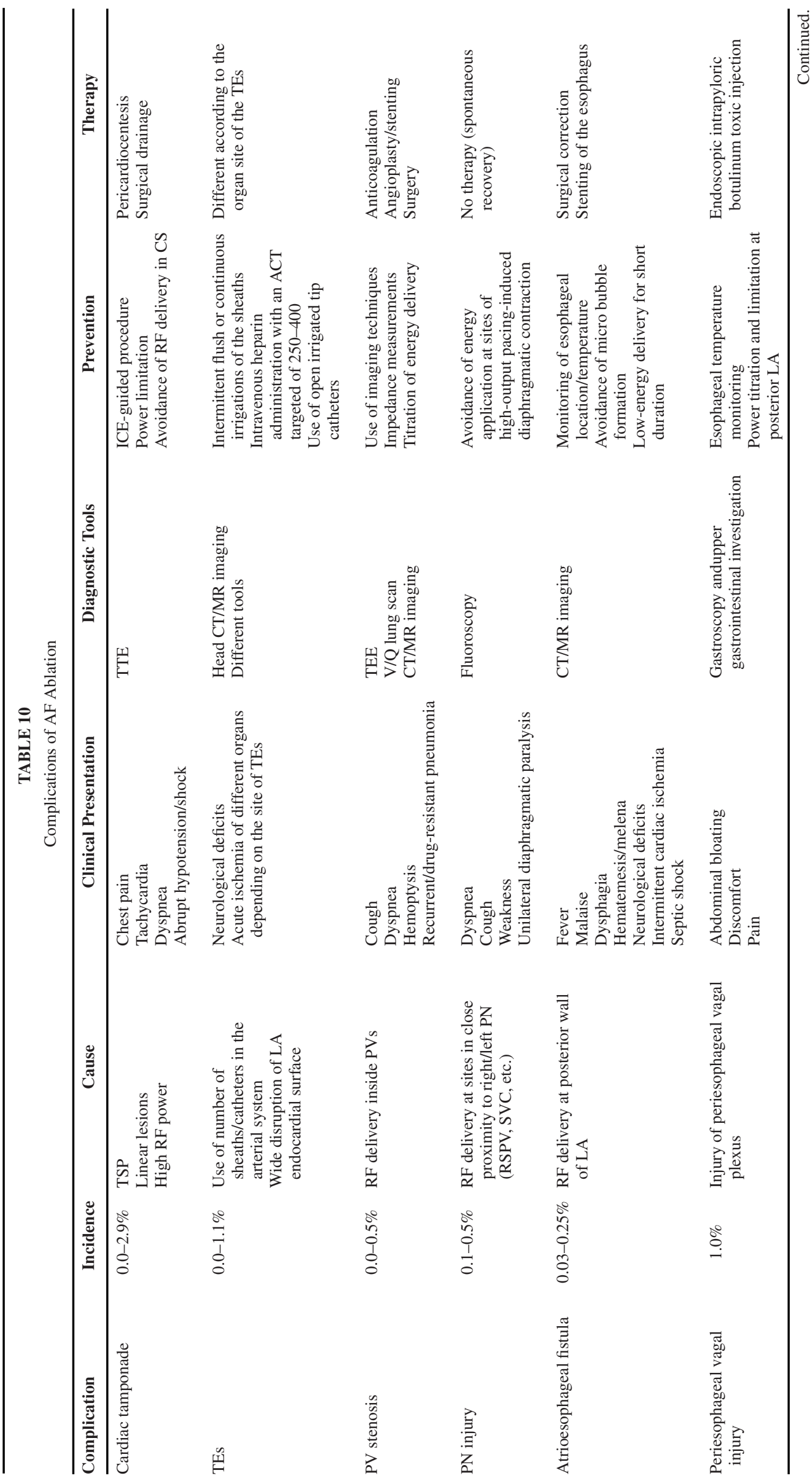




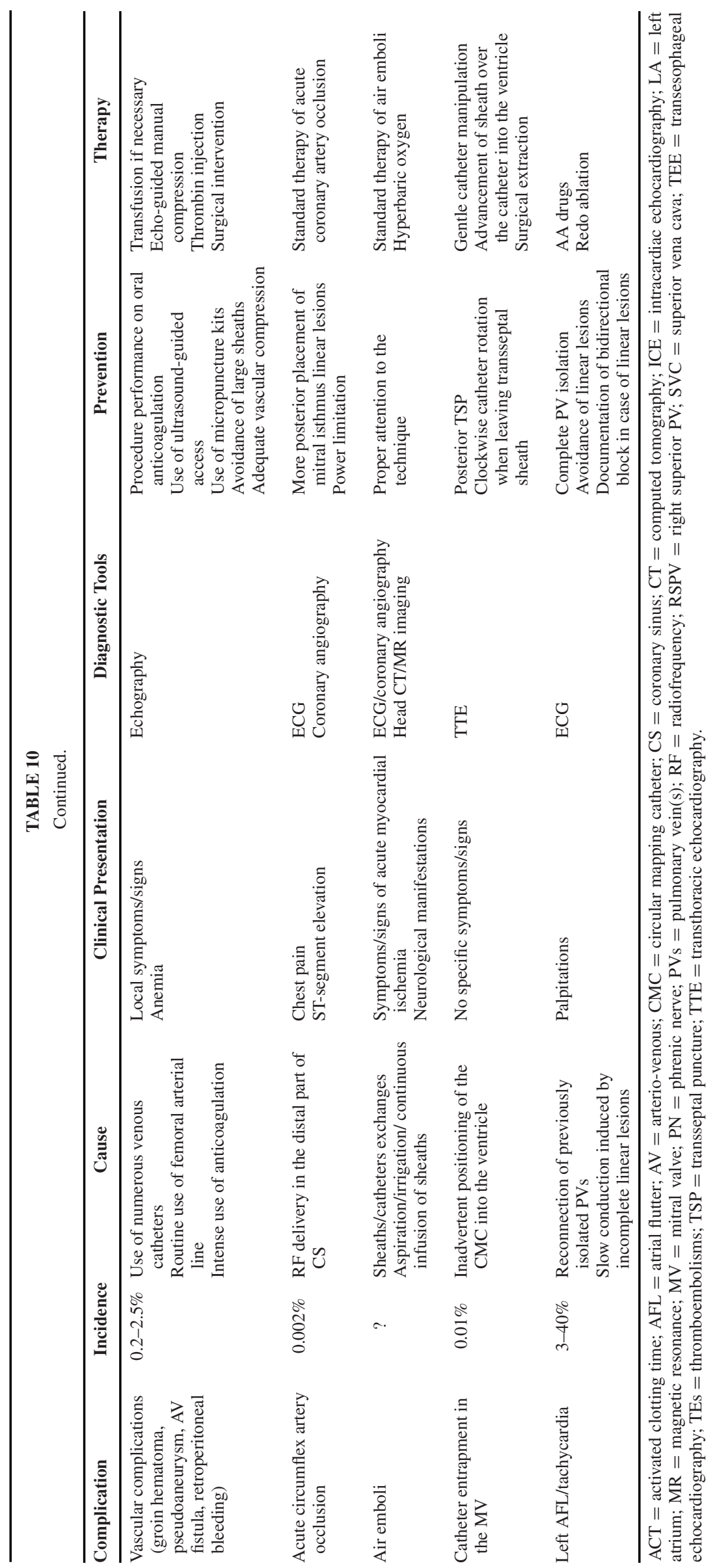


diagnosis of phrenic nerve injury can be confirmed by fluoroscopy demonstrating a positive "sniff test" and the presence of unilateral diaphragmatic paralysis.

Despite the low prevalence and apparent benign course in most patients, prevention of persistent phrenic nerve injury is possible by identification of phrenic nerve location with high-output pacing ( $\geq 30 \mathrm{~mA}, 2 \mathrm{~ms}$ ). ${ }^{203,204,207,208}$ Such a maneuver is recommended before energy delivery at or near the anterior aspect of right superior PV, the superior vena cava, and the LA appendage roof and, in the case of diaphragmatic contraction, ablation should be avoided. Other methods have recently been reported to allow RF delivery in regions where phrenic nerve injury would be expected. Applying an intra-pericardial balloon ${ }^{209,210}$ and progressive infusion of air and saline in the pericardial space ${ }^{211}$ to separate the phrenic nerve from the epicardial surface has allowed successful ablation without phrenic nerve injury. Another option, with greater inherent risk, includes close monitoring of the diaphragmatic excursion with immediate offset of ablation upon its reduction or if hiccups develop.

\section{Atrio-Esophageal Fistula}

Atrio-esophageal fistula formation is a rare but nearly universally fatal complication of $\mathrm{AF}$ ablation. A nationwide survey reported an incidence of 6 cases in 20,425 LA procedures $(0.03 \%)$ with 5 deaths. ${ }^{212}$ The mean time to presentation of this complication is 12.3 days ${ }^{213}$ but it has been described as late as 41 days. ${ }^{214}$

Because of the high risk of death, ${ }^{212,213}$ atrio-esophageal fistula, when occurs, requires rapid and accurate recognition and diagnosis. Fever, malaise, leukocytosis, dysphagia, hematemesis, and neurological symptoms in patients with a recent catheter ablation procedure should raise suspicion of atrio-esophageal fistula. If a fistula is suspected, it is important that endoscopy is avoided because insufflation of the esophagus can cause massive air emboli through the fistula leading to stroke and myocardial infarction. ${ }^{213,215-218}$ Currently, imaging techniques such as MR or CT are used to diagnose an atrio-esophageal fistula. CT of the chest or head revealing intravascular air should immediately suggest the possible diagnosis.

Monitoring of esophageal location/temperature and lowenergy short-duration delivery on the posterior LA are all means utilized to minimize risk of the atrio-esophageal fistula during AF ablation. ${ }^{219}$ However, until now there are no data that clearly favors an approach on another.

Although mortality of atrio-esophageal fistula is very high, previously published reports documented survival following rapid surgical correction or esophageal stenting. ${ }^{220,221}$

\section{Periesophageal Vagal Injury}

An unusual extracardiac complication of AF ablation characterized by abdominal bloating and discomfort occurring within a few hours to 2 days after the procedure has been described. ${ }^{222}$ The incidence of such adverse event was $1 \%$ in a series of 367 patients. ${ }^{222}$ This rare complication is probably due to LA RF energy delivery affecting the periesophageal vagal plexus. Upper gastrointestinal investigation showed a pyloric spasm, gastric hypomotility, and a markedly prolonged gastric emptying time. To avoid this complication, the authors suggested using esophageal temperature moni- toring and avoiding the ablation of LA endocardium directly overlying the esophagus.

\section{Vascular Complications}

Vascular complications including femoral artero-venous fistula, pseudo-aneurysm, and large hematomas are common after AF ablation $(0.2-2.5 \%) .{ }^{151,180-187}$ These complications are due to the numerous vascular access sites required for the procedure and high intensity anticoagulation during and following the procedure. The prevalence of pseudo-aneurysm ranges from $0 \%$ to $1.0 \%$ and the prevalence of $\mathrm{AV}$ fistula from $0 \%$ to $0.97 \%$ in large series. ${ }^{151,180,182-185,187}$ Suggestions for limiting vascular complications include use of smaller gauge needles for venous access, avoid femoral arterial access, perform procedure on warfarin anticoagulation to avoid the need for "bridging" anticoagulation, decreasing number of sheaths in 1 vein, use of micropuncture kits, and use of ultrasound guided access in obese patients. 223,224

Treatment of pseudoaneurysm depends on the size and complexity and can include surgical repair but most are treated with ultrasound guided compression and thrombin injection. ${ }^{225,226}$ Treatment of $\mathrm{AV}$ fistula is also dependent on the size and complexity and includes simple observation, ultrasound guided compression, endovascular stent and surgery, but most can be treated with simple observation. ${ }^{227}$

\section{Acute Coronary Artery Injury}

Linear lesions deployed in the mitral isthmus can create coronary circumflex injury. Fortunately, the incidence of this complication is very low $(0.002 \%$ in a large clinical experience with $71 \%$ of the study group having RF energy delivered in the CS). ${ }^{228}$

Assessing the location of the circumflex coronary vessel and its proximity to the planned ablation sites although not routinely performed should be considered with careful power titration as appropriate.

\section{Air Emboli}

Air emboli may enter the arterial system during transseptal puncture, sheath/catheter exchanges, aspiration, irrigation, intravenous medication administration or continuous infusion of sheaths. ${ }^{229-231}$

An air embolus often travels to the right coronary artery and mimics typical clinical presentations of acute inferior myocardial wall ischemia. Air emboli may also travel to cerebral circulation and may lead to severe neurological manifestations.

Air emboli are best prevented by proper attention to catheter and sheath technique. Caution should be exercised when exchanging the sheaths and catheters. Air filters can be used to minimize the risk of a large air embolus. If sheaths are continuously irrigated throughout the procedure, automatic pumps capable of detecting air in the tubing should be considered.

Air embolus to the coronary arteries often resolves within several minutes without major complications and residual myocardial injury. If the signs of an embolus persist, coronary angiography and, if necessary, aspiration of air from within the coronary artery should be considered. Treatment of large cerebral air emboli with prompt hyperbaric oxygen may have clinical value. ${ }^{232}$ 


\section{Catheter Entrapment in the Mitral Valve or PV}

The original worldwide survey on AF ablation on 7,154 patients reported an incidence of $0.01 \%$ of valve damage due to catheter entrapment in the mitral valve apparatus. ${ }^{233}$ The $\mathrm{CMC}$ is at particular risk for entrapment within the mitral apparatus. ${ }^{234}$

Several recommendations can be made to reduce the risk. First, the CMC should be positioned in the posterior LA during transseptal catheterization. Second, the catheter should be torqued in a clockwise direction when leaving the transseptal sheath. These first 2 tips have allowed for safe catheter manipulation and successful ablation even in the setting of prior mitral surgery and prosthetic mitral valve. ${ }^{235,236}$ Third, it is recommended to advance the catheter and/or the sheath over the catheter when mitral valve entrapment is observed. ${ }^{237} \mathrm{Fi}$ nally, early surgical extraction should be strongly considered before forceful manual extraction. ${ }^{238}$

Rarely the CMC can get entrapped in the PV with the potential risk of laceration and intrapulmonary bleeding. ${ }^{239}$

\section{Organized Left ATs After AF Ablation}

Organized left ATs are common after AF ablation with a reported incidence of $1.2-40 \%$ (Table 11). ${ }^{72,76,96,115,116,240-255}$ The variability in the frequency of occurrence and the mechanism of the tachycardia appears to be clearly dependent on the type of ablation procedure used and the extent of the underlying atrial disease. ${ }^{247,251,252,256,257}$ Centers utilizing circumferential PV ablation combined with additional linear lesions in the LA, targeting of CFAEs and other more extensive LA ablation report a higher prevalence of macro-reentrant atypical flutters and an overall incidence of organized left ATs that is more than 5-10 times that observed with only PV isolation. ${ }^{72,76,96,115,116,240-252,256,257}$ This is especially true if no attempt is made to establish/confirm a line of bidirectional block or anchor clusters of more extensive LA ablation to anatomic obstacles. ${ }^{145,258,259}$

The macro-reentrant circuit of atypical flutter typically moves around a large anatomic barrier such as the mitral annulus or ipsilateral PVs and typically incorporates a zone of slow conduction created by gaps in LA linear lesions. ${ }^{260,261}$ Occasionally circuits can occur around the fossa ovalis, from the CS musculature and adjacent LA or involve smaller circuits around anatomic barriers related to prior surgical or catheter-based lesions. ${ }^{262,263}$ Centers that utilize PV isolation have predominantly localized reentrant left ATs originating from reconnected PVs. ${ }^{244,246,253,257}$

Patients with organized left ATs are frequently very symptomatic because they tend to demonstrate 2:1 AV conduction and a faster ventricular rate than observed in response to AF. Despite the general poor response to medical therapy and frequent recurrence after cardioversion, attempts to temporize are still recommended when the arrhythmia is observed early postablation. This is especially true given the fact that up to $50 \%$ of these tachycardias appear to resolve spontaneously during the "healing phase" postablation. ${ }^{116}$

Depending on the underlying mechanism, the ablation strategy may require isolation of the reconnected PV segment (for focal or local re-entrant tachycardias of PV origin) or may involve targeting the zone of slow conduction or a welldefined anatomic isthmus for macro-reentrant flutter. ${ }^{72,244,257}$ It is routine to re-isolate PVs even if the mechanism of the
LA flutter is macro-reentry to minimize the risk of manifest $\mathrm{AF}$ and recurrent LA flutter if lines of block do not hold long term. Overall, ablation is quite effective for these postablation left ATs with reported long-term success in excess of $80 \% .^{72}$

\section{Adverse Impact on Atrial Contractility}

Reverse remodeling of the left cardiac chambers with improvement in function has been reported after successful RF catheter ablation of paroxysmal and persistent AF. ${ }^{27,143,144,264-273}$ However, the consequences of RF ablation on the LA contractility are still somewhat inconsistent based on published reports.

A recent meta-analysis, including 17 studies and 869 patients, assessed the effects of AF catheter ablation on LA size, volume, and function. Independent of the technique applied there was a significant decrease in LA diameters and volumes during follow-up in patients without $\mathrm{AF}$ recurrence but not in those with AF recurrence. LA ejection fraction and LA active emptying fraction did not decrease in patients without AF recurrence, whereas they decreased in those with $\mathrm{AF}$ recurrence. ${ }^{272}$

It appears that the effects of RF ablation on LA function are dependent on the extent of ablation and time they are assessed. Extensive ablation during PV antral isolation causes initial impairment in atrial function; however, the positive remodeling that occurs with rhythm restoration in patients with a high burden of AF typically outweighs negative effects of ablation. ${ }^{270,271}$

It is important to recognize that studies performed till now have used different protocols to evaluate the LA size, have included different patient populations, and incorporated different ablation techniques. These limitations suggest that more investigation and standardization is required in this important area.

It is also noteworthy that, very recently, a new syndrome, so-called "stiff LA syndrome," has been described as possible complication of AF ablation. ${ }^{274}$ The syndrome, although rare (incidence of $1.4 \%$ ), is clinically significant and characterized by dyspnea, congestive heart failure, LA diastolic dysfunction, and new-onset pulmonary hypertension. ${ }^{274}$

\section{Radiation Exposure During Catheter Ablation of AF}

Catheter ablation of AF frequently requires a long fluoroscopy time. Although single ablation procedure brings a very low cancer risk, repeated procedures are usually associated with a measurable risk increase. Consequently, every effort should be made to abate total radiation time during $\mathrm{AF}$ ablation. ${ }^{275-279}$

Very low frame rate pulsed fluoroscopy systems have become the norm to minimize radiation exposure during ablation procedure. Limiting cine-angiography, avoidance of magnification and changing the angulation of fluoroscopic equipment are other helpful measures to reduce fluoroscopy time. Electro-anatomic and remote navigation systems that facilitate catheter placement and stability further help to reduce radiation exposure. ${ }^{280-282}$ Operator exposure can also be reduced by use of appropriate lead shielding. ${ }^{283}$

Skin radiation "burns," with proper operating equipment, are currently extremely rare as a result of AF ablation. ${ }^{284,285}$

The key points regarding periprocedural and late complications are reported in Table 12. 
TABLE 11

Iatrogenic Postatrial Fribrillation Ablation LAT/FL: Literature Data

\begin{tabular}{|c|c|c|c|c|c|c|c|c|c|}
\hline Author & $\begin{array}{l}\text { Number of } \\
\text { Patients }\end{array}$ & $\begin{array}{c}\mathbf{L A T} / \mathbf{F L} \\
(\%)\end{array}$ & $\begin{array}{c}\text { Time to } \\
\text { LAT/FL (mo) }\end{array}$ & $\begin{array}{c}\text { Mean } \\
\text { TCL }(\mathrm{ms})\end{array}$ & Macroreentry & Focus & $\begin{array}{c}\text { Acute } \\
\text { Success }(\%)\end{array}$ & $\begin{array}{c}\text { Chronic } \\
\text { Success }(\%)\end{array}$ & $\begin{array}{c}\text { Mean } \\
\text { Follow-Up (mo) }\end{array}$ \\
\hline Kanagaratnam et al..$^{240}$ & 71 & $14(20)$ & NR & NR & $5 / 5 \dagger$ & 0 & 100 & 100 & NR \\
\hline Villacastin et al. ${ }^{241}$ & 30 & $2(6.6)$ & 2 & 240 & 2 & 0 & 100 & 100 & 6.5 \\
\hline Oral et al..$^{242}$ & 80 & $1(1.2)$ & NR & NR & 1 & 0 & 100 & 100 & NR \\
\hline Ernst et al. ${ }^{243}$ & 88 & $6(7.0)$ & NR & NR & 6 & 0 & 100 & 100 & NR \\
\hline Gerstenfeld et al. ${ }^{244}$ & 341 & $10(3.4)$ & $5.7 \pm 2.8 \ddagger$ & $253 \pm 33$ & 1 & 8 & 100 & 100 & $6.7 \pm 2.3$ \\
\hline Mesas et al. ${ }^{115}$ & 276 & $13(4.7)$ & $2.6 \pm 1.6 \ddagger$ & $275 \pm 25$ & 11 & 3 & 100 & 87 & $2.5 \pm 1.2$ \\
\hline Pappone et al. ${ }^{245}$ & 560 & $39(7.0) \S$ & $2.4 / 2.9$ & NR & 31 & 8 & 100 & 100 & $6.3 / 8.2$ \\
\hline Jaïs et al. ${ }^{76}$ & 100 & $12(12)$ & NR & NR & 9 & 3 & 100 & 879 & 12 \\
\hline Oral et al. ${ }^{96}$ & 100 & $21(21)$ & NR & NR & NR & NR & NR & NR & NR \\
\hline Ouyang et al. ${ }^{246}$ & 100 & $21(21)$ & 0.21 & 206 & 17 & 2 & 100 & 100 & $5.8 \pm 1.8$ \\
\hline Cummings et al. ${ }^{247}$ & 737 & $23(3.1)$ & NR & NR & 23 & 0 & 100 & 61 & $16.5 \pm 2.9$ \\
\hline Hocini et al. ${ }^{248}$ & 20 & $4(20)$ & $4 \pm 1 \ddagger$ & NR & 4 & 0 & 100 & 100 & NR \\
\hline Chugh et al. ${ }^{116}$ & 349 & $85(24)$ & $1.5 \pm 2.0$ & $238 \pm 35$ & $28 / 28 \dagger$ & 0 & 88 & 82 & $7.5 \pm 4$ \\
\hline Shah et al. ${ }^{249}$ & 207 & $16(8)$ & $2.3 \pm 2.0$ & $271 \pm 45$ & $15 / 15 \dagger$ & 0 & 93 & 87 & $21 \pm 11$ \\
\hline Daoud et al. ${ }^{251}$ & 112 & $28(25)$ & $1.0 \pm 0.5$ & NR & $9 / 9 \dagger$ & 0 & 94 & NR & NR \\
\hline Deisenhofer et al. ${ }^{250}$ & 67 & $21(31)$ & $3.2 \pm 3.1$ & $264 \pm 41$ & $16 / 16 \dagger$ & 0 & 89 & 38 & $10.4 \pm 6.7$ \\
\hline Chae et al..$^{252}$ & 800 & $78(10)$ & NR & $256 \pm 49$ & $137 / 155$ & $18 / 155$ & 86 & 77 & $13 \pm 10$ \\
\hline Sawhnet et al. ${ }^{253}$ & 66 & $8(12)$ & $9.8 \pm 4.9 \dagger \ddagger$ & NR & $9 / 9$ & 0 & 100 & 83 & NR \\
\hline Rostock et al. ${ }^{254}$ & 320 & $128(40)$ & NR †† & $270 \pm 40$ & $44 / 61 \dagger$ & $17 / 61 \dagger$ & 93 & 82 & $21 \pm 4$ \\
\hline Chang et al..$^{255}$ & 452 & 87 (19) & $\mathrm{NR}+\ddagger$ & NR & $84 / 120$ & $36 / 120$ & 90 & 97 & $21 \pm 16$ \\
\hline
\end{tabular}

Adapted from Raviele A, Themistoclakis S, Rossillo A, Bonso A. Iatrogenic postatrial fibrillation ablation left atrial tachycardia/flutter: How to prevent and treat it? J Cardiovasc Electrophysiol 2005;16:298-301. ${ }^{72}$

$\dagger$ Only a limited number of the total population of patients with LAT/FL underwent repeat ablation procedure.

$\ddagger$ Time to LAT/FL ablation.

$\S 28(10 \%)$ in the 280 patients who were randomized to circumferential ablation alone, and $11(3.9 \%)$ in the 280 patients who were randomized to circumferential plus linear lesions ablation.

IRegards both AF and LAT/FL.

TABLE 12

Key Points Regarding Periprocedural and Late Complications

-Recognition of common and unique complications related to AF ablation can minimize the risk and optimize the outcome of ablation procedure. -In order to reduce the risk, operators must be familiar with risk factors, clinical signs, and symptoms of early as well as delayed occurring complications.

- The rate of major complications of $\mathrm{AF}$ ablation ranges from $0.8 \%$ to $5.2 \%$ according to the ablation strategy used, lesion extension, patient characteristics, and center experience.

-Death occurs, as complication of AF, in 1 of 1,000 patients.

-The most common complications of AF ablation are vascular lesions, cardiac tamponade, and thromboembolic events. Other complications (e.g., atrio-esophageal fistula), although rare, may be very serious and life-threatening.

\section{Short- and Long-Term Efficacy of Catheter Ablation for $\mathbf{A F}$}

Since the Venice Chart International Consensus Document in $2007,{ }^{1}$ more data have become available describing the acute, mid/long-term and very long-term efficacy of catheter ablation for AF. In order to define the success rates of any given procedure, there must be a consistent approach to the technique, a well-accepted method of followup, and a strict definition of success. Fortunately, over the last few years, a fairly good agreement has been reached on all the above-mentioned criteria. For most studies in patients with paroxysmal AF, PV isolation is considered a sufficient endpoint for ablation. Additional linear ablation and/or targeting of CFAEs has largely been reserved for patients with more persistent AF. Most studies have conformed to the HRS/EHRA/ECAS Expert Consensus Statement recommen- dations that follow-up postablation should be a minimum of 12 months with ECGs and 24-hour Holter monitors at least every 3 months. ${ }^{101}$ Finally, the definition of success has become more standardized. For the most part, early recurrences occurring within the first 3 months after the procedure are discounted as being due to inflammatory changes and/or incomplete healing of the lesion sets, part of the so-called "blanking period." Recurrences after 3 months have been defined as episodes of AF lasting $>30$ seconds for reporting purposes, although the relevance of such short episodes of $\mathrm{AF}$ is not known. ${ }^{101}$

\section{Acute Efficacy of AF Ablation}

Acute recurrences of AF are not uncommon within the first 2-3 months postablation. Studies suggest that the incidence of early AF recurrence ranges from $35 \%$ to $50 \%{ }^{286-288}$ These studies also show that most patients who go on to have late recurrence have usually had recurrence within the first 3 months. However, as many as $50 \%$ of patients who have early recurrences will not continue to have $\mathrm{AF}$ in the longer term. ${ }^{286,287}$ While most studies use a 3-month blanking, as recommended by the HRS/EHRA/ECAS Expert Consensus Statement, other data have suggested that 2 months may be long enough. ${ }^{289}$ Many studies have also used temporary AADs therapy during the blanking period to prevent early recurrences, supported by the $5 \mathrm{~A}$ trial. ${ }^{139}$

\section{Mid- to Long-Term Efficacy of AF Ablation}

In patients with paroxysmal $\mathrm{AF}$ and minimal structural heart disease, consistent success rates for catheter ablation can be achieved. In these patients, the success rate at 1 year off AADs is $60-75 \%$ after single procedure and $65-90 \%$ after 
multiple procedures. ${ }^{151,290}$ A number of recent systematic reviews have been published comparing the efficacy of catheter ablation of AF to AADs therapy. ${ }^{291-294}$ The technique used in these studies was a PV isolation technique with little to no adjuvant ablation performed. The results of all of these reviews showed superiority of RF ablation over AADs therapy with a success rate of $75.7-77 \% .{ }^{291,294} \mathrm{~A}$ single repeat ablation procedure was required in $10-25 \%$ of patients, increasing the chance of off-drug success by an additional $5-15 \% .295$ The results of single prospective randomized trials published after the first Venice Chart International Consensus Document were similar. ${ }^{296-302}$ In the 4A study, Jais et al. showed an $89 \%$ success rate at 1 year with catheter ablation (mean $1.8 \pm 0.8$ procedures) compared to $23 \%$ success for AADs (P $<0.001 ; \mathrm{n}=112) .{ }^{300}$ In a large, multicenter, randomized trial with RF ablation and an intensive postablation monitoring regimen, Wilber et al. reported a $66 \%$ single-procedure success rate at 1 year compared with only $16 \%$ with AADs $(\mathrm{P}<$ $0.001 ; \mathrm{n}=167) .{ }^{301}$ Finally, in the STOP-AF trial, which utilized cryo-ablation balloon technology for PV isolation, 245 patients were enrolled and the ablation group had a $69.9 \%$ success rate at 1 year (after 1 or more procedures) compared with only $7.3 \%$ success rate with AADs $(\mathrm{P}<0.001){ }^{302}$

\section{Very Long-Term Efficacy of AF Ablation}

Data on very long-term outcomes from AF ablation, beyond 1 year, are more limited and largely restricted to singlecenter experiences (Table 13). ${ }^{146,147,167-177}$ A few studies have shown that outcome of $\mathrm{AF}$ ablation beyond 1 year is preserved. Weerasooriya et al. described 1 high-volume center's experience over 5 years of follow-up in both paroxysmal (63\%) and persistent AF patients, showing that the majority of recurrences occur within 6 months of the ablation procedure. Success rates at 1,2 , and 5 years were $87 \%, 81 \%$, and $63 \%$, respectively, with a median of 2 procedures per patient. ${ }^{176}$ Other authors reported similar results. ${ }^{167,169,172,177}$ Risk factors for very late recurrence appear to be nonparoxysmal AF, valvular heart disease, cardiomyopathy, and advanced age. ${ }^{176}$ Other studies, however, have published less optimistic results. ${ }^{146,147,168}$ Wokhlu et al. reported that the risk of recurrence increased in absolute terms by $12 \%$ in paroxysmal patients and $20 \%$ in persistent patients from year 1 to year 2.5. ${ }^{147}$ Bertaglia et al. published that the actuarial atrial arrhythmia recurrence rate was $13.0 \%$ at 2 years, $21.8 \%$ at 3 years, $35.0 \%$ at 4 years, $46.8 \%$ at 5 years, and $54.6 \%$ at 6 years. ${ }^{146}$ However, in both of these studies, the initial success rates were substantially lower than those reported in the previous section. Perhaps a difference in ablation technique is resulting in a higher late recurrence rate. Furthermore, although recurrences may be common, performing an additional procedure may still provide very long-term success, as described by Sawhney et al. ${ }^{170}$

\section{Efficacy in Nonparoxysmal AF}

In general, the success rate of AF ablation is lower in patients with persistent or long-lasting persistent $\mathrm{AF}$ compared to paroxysmal AF. ${ }^{303}$ Many studies show success rates of 40-70\% in nonparoxysmal AF and many have suggested the need for supplemental substrate modification in addition to $\mathrm{PV}$ isolation. ${ }^{35}$ In a recently published meta-analysis of ablation in persistent AF, the pooled, single procedure, drug-free success rate was only $44 \%$ in 211 patients who underwent wide antral PV isolation alone. ${ }^{303}$ With repeat procedures
TABLE 13

Very Long-Term Efficacy of AF Ablation

\begin{tabular}{|c|c|c|c|c|c|}
\hline Authors & $\begin{array}{c}\text { Patients } \\
\text { (No.) }\end{array}$ & $\begin{array}{c}\text { Follow-Up } \\
\text { (Months) }\end{array}$ & $\begin{array}{c}\text { Recurrences } \\
\text { After } \\
\text { Single } \\
\text { Procedure } \\
(\%)\end{array}$ & & $\begin{array}{c}\text { Recurrences } \\
\text { After } \\
\text { Repeat } \\
\text { Procedures } \\
(\%)\end{array}$ \\
\hline Shah et al. ${ }^{167}$ & $264 \dagger$ & $28 \pm 12$ & $8.7 \%$ & & $3 \%$ \\
\hline Katritsis et al. ${ }^{168}$ & 35 & $42 \pm 6$ & $79 \%$ & & $34 \%$ \\
\hline Bhargava et al. ${ }^{169}$ & 1,404 & $57 \pm 17$ & $27 \%$ & & $10 \%$ \\
\hline Sawhney et al. ${ }^{170}$ & 71 & $63 \pm 5$ & $44 \%$ & & $16 \%$ \\
\hline Bertaglia et al. ${ }^{146}$ & $177 \dagger$ & $49 \pm 13$ & \multicolumn{3}{|c|}{$42 \%$} \\
\hline Wokhlu et al. ${ }^{147}$ & 774 & $36 \pm 23$ & & & $36 \%$ \\
\hline Miyazaki et al. ${ }^{172}$ & 574 & $27 \pm 14$ & & $34 \%$ & $16 \%$ \\
\hline Tzou et al. ${ }^{173}$ & $123 \dagger$ & 60 & & $29 \%$ & \\
\hline Ouyang et al. ${ }^{174}$ & 161 & 54 & $53 \%$ & & $20 \%$ \\
\hline Medi et al. ${ }^{175}$ & 100 & $39 \pm 10$ & $51 \%$ & & $18 \%$ \\
\hline Weerasooriya et al. ${ }^{176}$ & 100 & 60 & $71 \%$ & & $37 \%$ \\
\hline Pappone et al. ${ }^{177}$ & 99 & 48 & \multicolumn{3}{|c|}{$27 \%$} \\
\hline
\end{tabular}

$\dagger$ Patients free of arrhythmic recurrences at 1-year follow-up.

\section{TABLE 14}

Key Points Regarding the Short and Long-Term Efficacy of Catheter Ablation for $\mathrm{AF}$

-Early recurrences of AF are not uncommon during the first 2-3 months postablation (35-50\%). These arrhythmias tend to disappear after the initial period in $50 \%$ of the cases and not necessarily express procedural failure.

$-\mathrm{AF}$ ablation is an effective therapy over the mid/long term. In the first year following ablation, the success rate after multiple procedures is 65-90\% for paroxysmal AF and 40-70\% for nonparoxysmal AF.

-Outcome for AF ablation seems to be preserved also beyond 1 year with only few very late recurrences; additional data, however, are required to this regard to confirm the robustness of the therapy.

-Prospective randomized trials conducted in a limited number of patients with paroxysmal AF have systematically shown that $\mathrm{AF}$ ablation is superior to AADs therapy in controlling AF; however, whether this translates into reduced morbidity and mortality remains to be assessed. -Clinical factors predictive of procedural failure include nonparoxysmal AF, advanced age, hypertension, diabetes, sleep apnea syndrome, LA enlargement, LA scarring, and structural heart disease, such as cardiomyopathy or valvular heart disease.

and concomitant AADs therapy, the success rates increase to $59 \%$ and $77 \%$, respectively. Addition of adjuvant ablation may further improve outcome. The drug-free, 1 procedure success rate of PV isolation + linear ablation ranges from $48 \%$ to $57 \%, 303$ which is better than that of PV isolation alone. Similarly, the success rate of PV isolation + CFAEs is higher than that of PV isolation alone: 51\% with 1 procedure and $77 \%$ with 2 procedures. ${ }^{63,66,304}$

\section{Mechanisms of AF Ablation Failure}

Studies have shown that the mechanism for long-term recurrence is linked to the recovery of electrical conduction between the PVs and the LA both in patients with paroxysmal and nonparoxysmal AF. ${ }^{305}$ Recurrence, particularly atrial flutters, may also be related to incomplete scars created by the initial ablation. ${ }^{253}$ Re-isolation of the PVs is quite often effective in treating recurrent $\mathrm{AF}$ or atrial flutters. ${ }^{247}$ However, performance of additional ablation may be required, such as linear ablation or ablation of CFAEs, particularly in nonparoxysmal AF. ${ }^{306}$ The mechanism of very late recurrences beyond 1 year may also involve development 


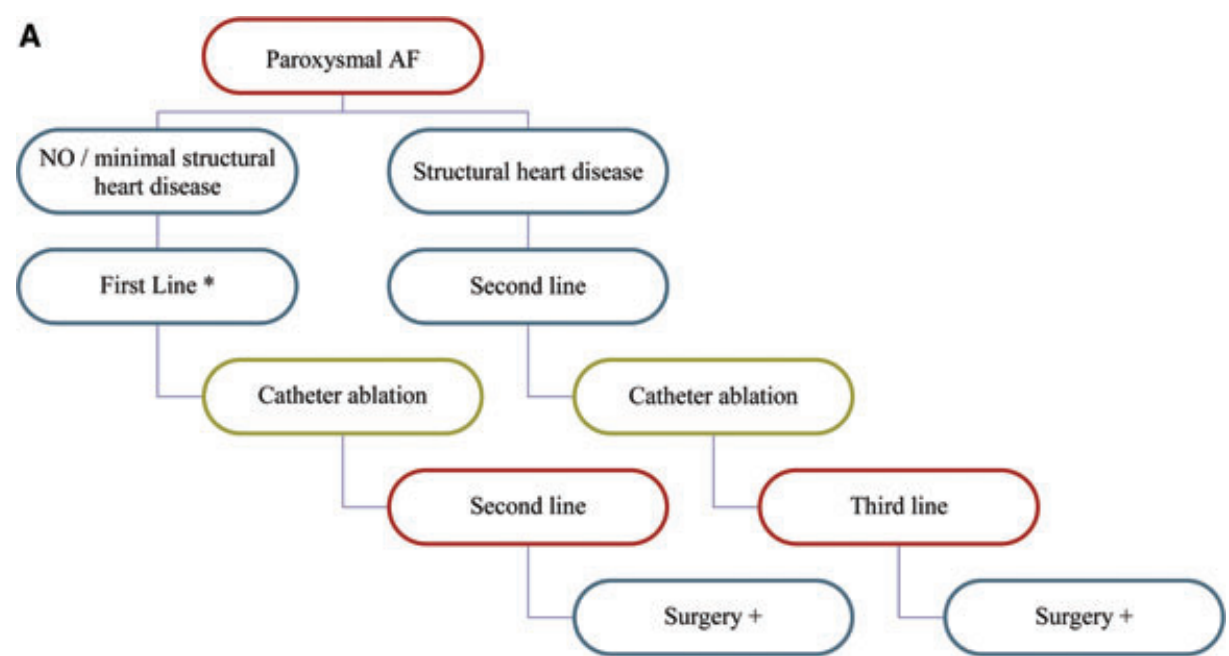

B

Figure 3. Indications to catheter ablation of AF. (A) Patients with paroxysmal $A F$. (B) Patients with persistent $A F$ and
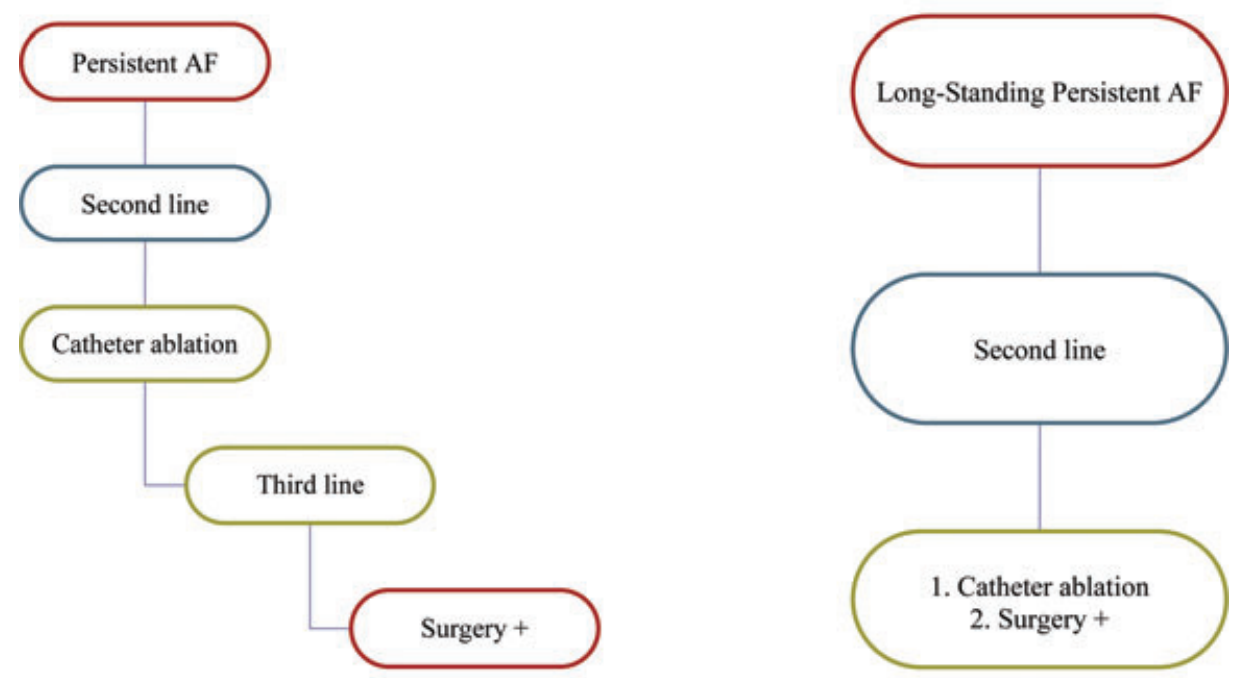

* Selected patients (See text)

+ first line may be considered if the patient is undergoing eardiac surgery long-lasting persistent $A F$.

of non-PV triggers, either outside of the PV antra in the LA, or even within the $\mathrm{CS}$ and right atrium. ${ }^{172,307}$

A number of clinical factors predict late failure of $\mathrm{AF}$ ablation. In particular, LA scarring may be the strongest predictor of procedural failure. ${ }^{124,308}$ Other risk factors include significant LA enlargement, advanced age, nonparoxysmal $\mathrm{AF}$, and structural heart disease, such as cardiomyopathy or valvular heart disease. ${ }^{147,176}$ Diabetes, hypertension, and sleep apnea syndrome have also been reported as risk factors for late recurrence. ${ }^{146,287,309}$

The key points regarding the short- and long-term efficacy of catheter ablation for AF are reported in Table 14.

\section{Indications to Catheter Ablation of AF and Cost-Effectiveness}

\section{Indications to Catheter Ablation of AF}

Several studies from high-volume centers have demonstrated the efficacy of catheter ablation for AF, mainly in patients with paroxysmal AF. ${ }^{113,169,170,174,296-301,310,311}$ Therefore, catheter ablation of paroxysmal $A F$ in symptomatic patients is an established indication in experienced centers after failure of AADs therapy (second-line therapy) (Fig. 3A) and LA size and left ventricular function are important to define the class of recommendation according to latest US guidelines for the management of patients with $\mathrm{AF}^{312,313}$ Class I, level of evidence A, is now recommended for patients with normal or mildly dilated LA and normal or mildly reduced left ventricular function without severe pulmonary disease. ${ }^{313}$ Class IIa, level of evidence A, is recommended for patients with dilated LA or reduced left ventricular function and class IIb is recommended for patients with significant LA enlargement or significant LV dysfunction. ${ }^{313}$ Ablation of persistent $A F$ is feasible as second-line therapy after failure of medical treatment (Class IIa, level of evidence A) (Fig. 2B), ${ }^{313}$ but there is no real consensus since the procedure is more complex with a lower success rate. For these reasons, catheter ablation of persistent AF requires a more accurate selection of patients and, particularly among patients with long-standing persistent $A F$, multiple interventions are frequently necessary to increase the success rate. ${ }^{169}$ Thus, more data are needed to determine the most suitable candidates with long-standing AF for ablation (Fig. 3B). A new 
Class I first-line indication for catheter ablation of $\mathrm{AF}$ is proposed for selected patients with very symptomatic paroxysmal AF (Fig. 3A). ${ }^{296}$ This approach will require an accurate selection of candidates that includes patient preference for nonpharmacologic therapy, the absence (lone AF) or the presence of "minimal" structural heart disease, relatively frequent AF, e.g., > 2 episodes/month, and with operators that are very experienced. For these highly selected patients the ablative procedure may be performed at an earlier stage of the disease $\mathrm{e}^{296,311}$ to avoid or limit arrhythmia progression to more persistent forms, ${ }^{311}$ which is associated with lower success rate and with an increased need for repeat procedures.

\section{Cost-Effectiveness}

Whereas several studies have reported the costs of AF ablation, limited information is available on cost-effectiveness of the procedure. ${ }^{314-320}$ The issue is further complicated by the fact that cost-effectiveness of AF ablation is influenced by several factors, the most relevant of whom being the type of AF, the clinical characteristics of patient population, the duration of the follow-up, the intensity of ECG monitoring, the success and complication rates of the procedure, the experience of the ablation centers, the costs of ablation tools and drug therapy and the differences in resource utilization. ${ }^{321,322}$ In general, cost-effectiveness is better in patients with paroxysmal AF, with no or minimal heart disease, highly symptomatic with higher $\mathrm{CHADS}_{2}$ score, treated in high-volume centers and followed for a sufficiently long period of time. ${ }^{321,322}$ Under these conditions, the initial higher costs of ablation procedure are usually offset by the subsequent higher costs of AADs within a period of time ranging from 2 to 5 years or more. ${ }^{314,318}$ In a recent study, the incremental cost-effectiveness ratio for AF ablation versus AADS was 51.431 \$ per quality-adjusted life-year. ${ }^{319}$ This suggests that AF ablation is a reasonably cost-effective therapy.

The key points regarding indications and costeffectiveness of catheter ablation of $\mathrm{AF}$ are reported in Table 15 .

\section{Clinical Trials on AF/Future Perspectives}

Available randomized studies of AF comparing catheter ablation and AADs have essentially focused on recurrences of AF, either clinically or electrocardiographically, and only to a lesser extent on measurements of quality of life. ${ }^{296-302}$ Moreover, in these studies, no attempts were made to evaluate the effect on hospitalization, long-term survival, and thromboembolic complications, as the number of patients included was too small and the follow-up too short. The scientific evidence is also insufficient for drawing definitive conclusions about the cost-effectiveness of the AF ablation therapy, since its long-term effects are still uncertain. Therefore, further large randomized trials are needed to better clarify the real impact of AF ablation on these clinically relevant issues. Several ongoing trials have been planned to this regard. ${ }^{323}$ Some (e.g., CABANA, EAST, and CASTLE-AF) are focused on mortality, hospitalization and stroke, others (e.g., RAAFT-2 and MANTRA-PAF) will test the effectiveness of catheter ablation early in the treatment of AF, and some more will assess the role of AF ablation in patients with heart failure (e.g., AATAC-HF, AMICA and ARC-HF) or with persistent

\section{TABLE 15}

Key Points Regarding Indications and Cost-Effectiveness of Catheter Ablation of $\mathrm{AF}$

Paroxysmal AF

-As second-line therapy, after failure of AADs, catheter ablation is an established indication in symptomatic patients. The class of recommendation depends on LA size and left ventricular function. -As first-line therapy, catheter ablation may be indicated in a very selected group of highly symptomatic patients with no or minimal heart disease and relatively frequent episodes of AF.

Persistent/Long-Lasting Persistent AF

-As second-line therapy, after failure of AADs, catheter ablation is feasible in symptomatic patients, but the selection has to be accurate because the procedure is more complex and associated with lower success rate and higher need for repeat interventions.

Cost-Effectiveness

-Catheter ablation of AF is a reasonably cost-effective therapy provided that the selection of patients is appropriate.

\section{TABLE 16}

Key Points Regarding Clinical Trials on AF/Future Perspectives

-Multiple randomized trials have demonstrated a superiority of AF ablation over AADs therapy in patients with drug-refractory symptomatic paroxysmal AF. Catheter ablation significantly reduces AF recurrences and hospitalizations, and improves quality of life.

-The effects of catheter ablation on hard endpoints such as mortality or thromboembolic events remain to be established.

-Ongoing trials are evaluating effectiveness of catheter ablation in broader patient populations, such as patients with nonparoxysmal $\mathrm{AF}$ and left ventricular dysfunction, as well as the effects of ablation on hard endpoints such as mortality.

and long-standing persistent AF (e.g., SARA). ${ }^{323-326}$ The results of these trials will further improve our understanding of the clinical value of AF ablation.

The key points regarding clinical trials on AF/future perspectives are reported in Table 16.

\section{Surgical Approach/Ablation of AF}

\section{Historical Aspects and Surgical Ablation Technologies}

The surgical ablation era for the treatment of AF began in the early 1980s. In 1987, the Cox-Maze (C-M) procedure was introduced and then progressively modified over time. ${ }^{327}$ The last version, the C-M III procedure, proved to be highly effective in eliminating AF with $97 \%$ of the patients free from symptomatic AF at a mean late follow-up of $5.4 \pm 2.9$ years. ${ }^{328}$ However, it was technically difficult, highly invasive, and associated with significant risks. With the introduction of ablation devices in the last decades, only a small number of cardiac surgeons still perform the cut-and-sew operation today. Ablation devices have transformed the field of AF surgery by decreasing procedural difficulty and operative time, thus allowing for an application to a broader patient population and for the development of minimally invasive techniques. ${ }^{329}$ Many devices using different energy sources have been proposed and employed for surgical treatment of AF. They include RF (unipolar and bipolar), cryo-ablation (nitrous oxide and argon-based technology), and high intensity frequency ultrasound devices. Each ablation technology has its own advantages and disadvantages. It is imperative for surgeons to develop a complete understanding of the effects of each specific ablation technology on atrial hemodynamic, 
function, and electrophysiology. This will allow for more appropriate use of devices in the operating room.

\section{Surgical Techniques and Outcome}

There are a myriad of different surgical ablation procedures that are presently performed. They can be grouped into 4 broad categories: the C-M procedure, PV isolation alone, $\mathrm{PV}$ isolation with left atrial lesion sets, and hybrid approach.

\section{$C$ - $M$ procedure}

The original cut-and-sew C-M III procedure is only rarely performed today. At most centers, the surgical incisions have been replaced with lines of ablation using a variety of energy sources. The most widely adopted variation has been the C-M IV procedure, which utilizes bipolar RF energy to replace most of the surgical incisions. ${ }^{330}$ This RF ablationassisted procedure incorporates most of the lesions of the $\mathrm{C}-\mathrm{M}$ III and is performed on cardiopulmonary bypass. The operation can be done either through a median sternotomy or a less-invasive right mini-thoracotomy. ${ }^{331}$ The PVs are isolated with the bipolar clamps on the beating heart. It is imperative to document entrance and/or exit block at the time of surgery. In a large C-M IV series, the freedom from $\mathrm{AF}$ was $89 \%$ and the freedom from $\mathrm{AF}$ off $\mathrm{AADs}$ was $78 \%$ at 1 year, in the entire population of patients. ${ }^{332}$ In patients undergoing a stand-alone $\mathrm{C}-\mathrm{M}$ IV procedure for lone $\mathrm{AF}$, the results were even better with a freedom from $\mathrm{AF}$ of $90 \%$ and freedom from AF off AADs of $84 \%$ at 2 years with no intraoperative mortality and no postoperative strokes. ${ }^{333}$ There was no difference in success rates for patients with paroxysmal AF compared to those with persistent or long-lasting persistent AF. Similar results have been obtained using cryoablation or high intensity frequency ultrasound.

\section{PV isolation alone}

The PVs have been isolated either separately or as a large box lesion incorporating the posterior LA. This procedure may be performed through thoroscopy with a minimally invasive surgical approach ${ }^{334}$ and may be associated with GP ablation. In a recent study using this technique, the success rate at 1 year was $65 \%$ with a low incidence of postoperative complications. ${ }^{335}$ However, a number of studies support the contention that PV isolation alone or associated to autonomic denervation ${ }^{335,336}$ is inadequate for persistent and long-lasting persistent AF due to the substrate changes induced by electrical remodeling.

\section{Expanded lesion sets}

When connection lines to the mitral annulus are added, the success rates are more satisfactory and comparable to those of the cut and sew maze. Jeanmart and colleagues reported an AF-free rate of $69.7 \%$ with an endocardial box lesion plus a connecting line to the mitral annulus. ${ }^{337}$ However, incorporation of the mitral valve isthmus can be challenging. To overcome this problem and to replicate the LA lesions of the C-M III, the Dallas lesion set was developed. ${ }^{338}$ With this approach the connection to the mitral valve is made to the anterior annulus at the left fibrous trigone. ${ }^{339}$ The other lesions include a line from the right superior PV to the left superior PV and a line from the left superior PV to the base of the amputated LA appendage. ${ }^{340}$ In a multicenter registry, including 124 patients treated with the Dallas lesion set, a high success rate was measured: $63 \%$ in a group that had previously undergone catheter ablation $(\mathrm{n}=21)$ and $86 \%$ in patients who had not been ablated before (unpublished data provided by Edgerton JR).

\section{Hybrid approach}

Further frontiers include the use of hybrid approach, combining the strengths of epicardial and endocardial ablation. ${ }^{341}$ Lesions are more likely to be transmural when burning inside and outside simultaneously. The potential for improved outcomes through hybrid ablation also derives from combining expertise levels. The demonstration of the efficacy of this approach awaits the completion of currently underway trials.

\section{Indications}

The current indications for surgical ablation as defined in the HRS/EHRA/ECAS expert consensus statement ${ }^{101}$ on AF ablation include: (1) all symptomatic patients with documented AF undergoing other cardiac surgical procedures; and (2) selected asymptomatic patients with AF undergoing cardiac surgery in which the ablation can be performed with minimal risk in experienced centers. Moreover, surgical ablation is indicated, as stand-alone procedure, in symptomatic patients who either prefer a surgical approach, have failed 1 or more attempts at catheter ablation or are not candidates for catheter ablation (Fig. 4). However, there are other relative indications for surgery, in particular for a stand-alone procedure, that were not included in the HRS/EHRA/ECAS expert consensus statement that should be taken into consideration as first-line therapy in lieu of less invasive catheter ablation. The following are examples: (1) AF patients who develop a contraindication to long-term anticoagulation and have a high risk for stroke $\left(\mathrm{CHADS}_{2}\right.$ score $\left.\geq 2\right)$ are excellent candidates for surgery. The C-M procedure both eliminates $\mathrm{AF}$ in most of these patients, and also amputates the LA appendage. The stroke rate following the procedure off anticoagulation has been remarkably low, even in patients with high $\mathrm{CHADS}_{2}$ scores; $^{342}$ (2) surgical treatment for AF also should be considered in patients with long-lasting AF who have suffered a cerebrovascular accident despite adequate anticoagulation. These patients are at high risk for repeat neurological events. In a series of over 200 patients with a stand-alone C-M procedure there was only 1 late stroke, and over $80 \%$ of patients were off anticoagulation at last followup; ${ }^{343,344}$ (3) finally, symptomatic AF patients with a clot in the LA appendage who have failed medical therapy are not candidates for catheter ablation and should be referred for surgical ablation.

The key points regarding surgical approach/ablation are reported in Table 17.

\section{Hospital Equipment and Facilities, Personnel, Training Requirements, and Competences}

\section{Hospital Equipment, Facilities, and Technological Requirements}

Centers involved in $\mathrm{AF}$ ablation procedures should be equipped with state-of-the-art equipment. These should include the following: 


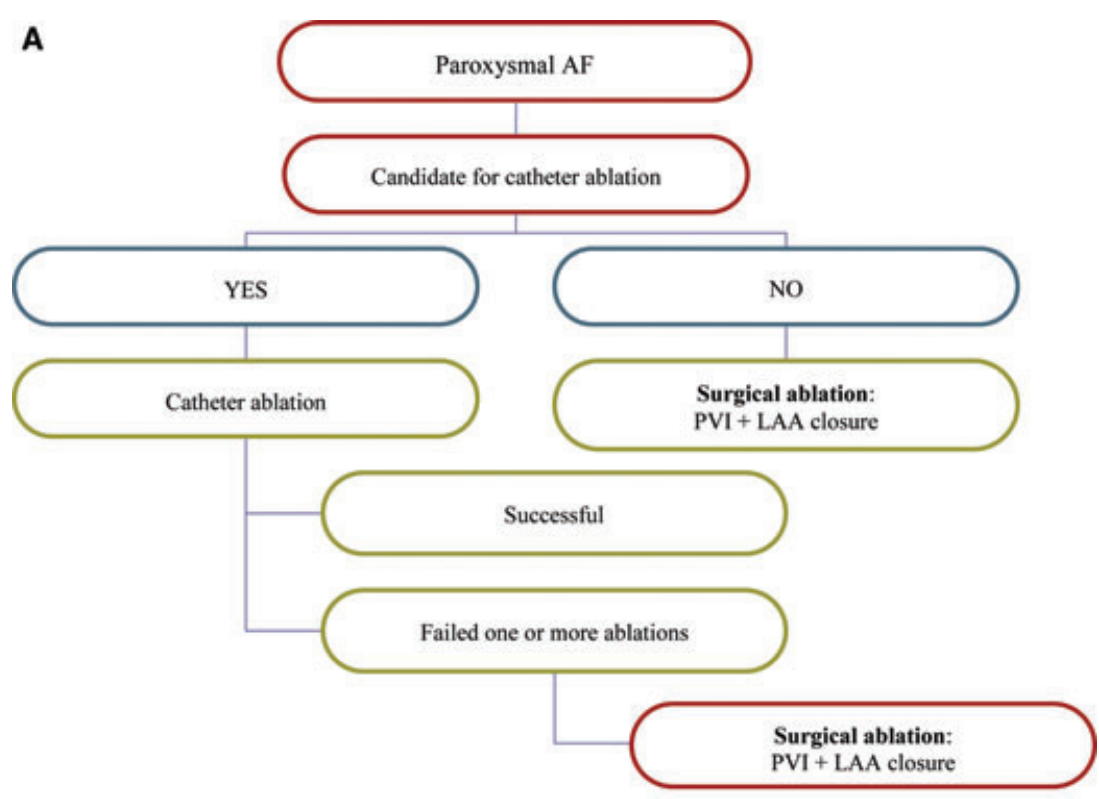

B
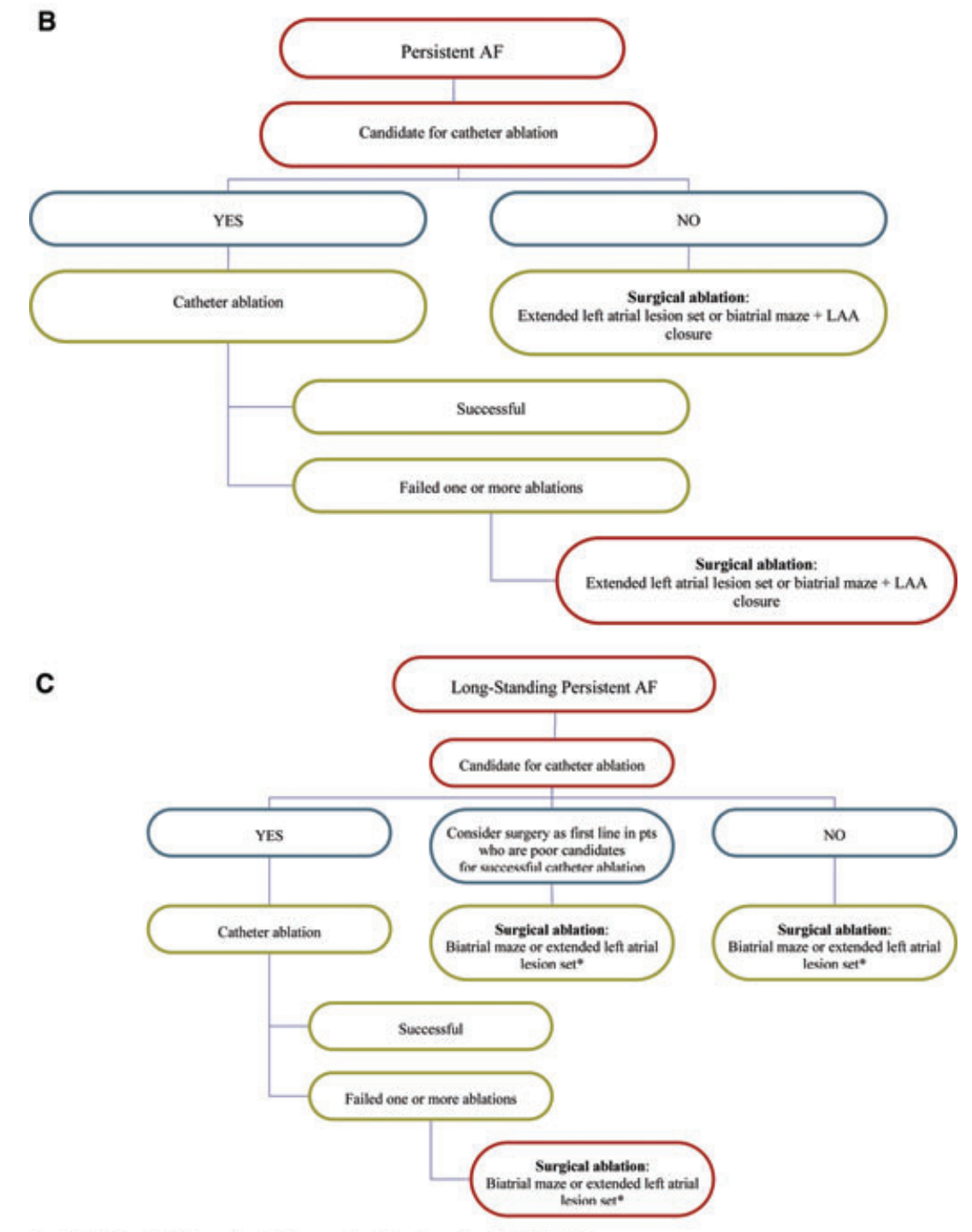

" extended left atrial lesion set - only in experienced centres with established AF team.

Figure 4. Indications to surgical ablation of AF. (A) Patients with paroxysmal AF. (B) Patients with persistent AF. (C) Patients with long-lasting AF. 
TABLE 17

Key Points Regarding Surgical Approach/Ablation of AF

-Surgical techniques for AF include Cox-Maze procedure, $\mathrm{PV}$ isolation alone, PV isolation with LA lesion sets, and hybrid approach.

-The original "cut and sew" Cox-Maze procedure is only performed rarely today. At most centers the surgical incisions have been replaced with lines of AF ablation using a variety of energy sources (especially bipolar RF).

-The surgical procedures can be done either through sternotomy or through thoracoscopy with a minimally invasive surgical approach. -Success rates of surgical AF ablation vary between $65 \%$ and $90 \%$ during follow-up. This great range can be attributed to many factors including type of AF, patient characteristics, the use of different ablation devices and energy sources, differing lesion sets, and surgeon experience.

-Surgical AF ablation is indicated in all symptomatic patients as well as in selected asymptomatic patients with documented AF who undergo other cardiac surgical procedures.

-Surgical AF ablation is also indicated, as stand-alone procedure, in symptomatic patients with AF who either prefer a surgical approach, have failed 1 or more attempts at or are not candidates to catheter ablation.

- Sedation, anesthesia and resuscitation equipment, including pericardiocentesis materials, biphasic defibrillator, and a mechanical ventilator.

- Up-to-date ECG, blood pressure, oxygen saturation, and ACT monitoring equipment.

- Modern catheterization laboratories, including X-ray systems allowing dose-reduction and image optimization and staff protection.

- A multichannel recording system (at least a 16-channel recording system) and a multi-programmable stimulator.

- 3D electro-anatomical mapping: at least 1 system.

- RF power generators and/or cryoablation console.

- Cardiac imaging techniques, including at least transthoracic echocardiography and TEE and preferably also a multislice-CT scanner or MR scanner.

- Intracardiac echocardiography (recommended but not mandatory).

Other equipments, such as magnetic and robotic navigation systems and single-shot device systems, are promising but their impact and superiority compared to the conventional approach of AF ablation is unclear and remains speculative.

\section{Training and Knowledge}

\section{Indications and patient selection}

The physician (i.e., electrophysiologist) should be competent in counseling patients and evaluating the potential risks and benefits of catheter ablation and should be able to direct current recommendations to the specific needs of individual patients.

\section{Anatomical knowledge}

The detailed knowledge of cardiac anatomy with specific attention to LA and its adjacent structures is highly required for performing the technical aspects of transseptal puncture, cannulation of the LA and navigation and to avoid or reduce the risk of procedure-related complications.

\section{Interpretation of electrograms/knowledge in basic EP studies}

Every electrophysiologist performing catheter ablation of AF must have achieved a proficiency in the ECG and intracavitary electrograms interpretation. Recognition of PV

\section{TABLE 18}

Basic Technical Skills to be Proficient for an Atrial Fibrillation Procedure

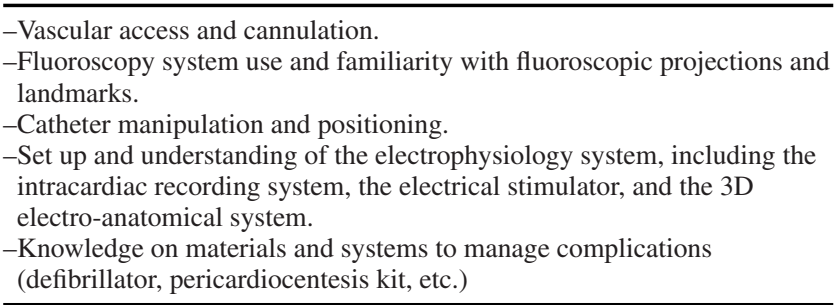

potentials both at baseline and during CS pacing and when $\mathrm{PV}$ electrical disconnection is achieved remains the cornerstone of the ablation procedure. Correct identification and interpretation of CFAEs is also important, because these potentials may be a target for ablation in patients with persistent and long-lasting persistent AF.

\section{Knowledge of 3D mapping systems}

An electrophysiologist who performs AF ablation procedures must be familiar with the handling and interpretation, as well as with the limitations of different 3D mapping systems. Therefore trainees should be able to perform and interpret the different types of electrophysiological analysis like activation mapping for the treatment of left-atrial macroreentrant tachycardia, voltage mapping for substrate guided ablation approaches and purely anatomical maps for conventional AF ablation procedures.

\section{Technical competence}

Technical competence and skills in catheter, sheath and guide wire manipulation are required.

\section{Basic technical skills}

Basic technical skills to be proficient for an atrial fibrillation procedure are listed in Table 18.

\section{Transseptal puncture}

A good knowledge of transseptal puncture techniques is mandatory for all electrophysiologists involved in PV isolation and other left-sided procedures.

\section{Competence in performing basic EP studies and ablation procedures}

The European Heart Rhythm Association (EHRA) presently recommends receiving formal training for at least 1 year in conventional electrophysiology procedures and simpler ablations before being involved in AF ablation procedures. ${ }^{345}$ Following this first year, the trainee should receive formal training for at least another year in more complex procedures, 1 of them being AF ablation. According to this scientific organization the trainee should be directly involved in a minimum number of 150 ablation procedures (35 to be performed as the primary operator) and 10 transseptal catheterizations ( 5 to be performed as the primary operator) at the end of this 2-year period. ${ }^{345}$ The American Accreditation Council of Graduate Medical Education (ACGME) recommends involvement in a minimum of 75 catheter ablation procedures. ${ }^{346}$ However, these requirements are the basis to be trained in ablation procedures in general and 


\section{TABLE 19}

Key Points Regarding Hospital Equipment and Facilities, Personnel, Training Requirements and Competences

-Centers involved in AF ablation procedures should be equipped with state-of-the-art equipment.

-The physicians should be competent in counseling patients and evaluating the potential risks and benefits of catheter ablation on individual basis. -Every electrophysiologist performing AF catheter ablation should have a detailed anatomical knowledge of LA and its adjacent structures, must have achieved a proficiency in the ECG and intracavitary electrograms interpretation, and must be familiar with the handling and interpretation of different 3D mapping systems.

-Moreover, technical competence and skills in catheter, sheath, and guide wire are required.

-Although no scientific organization has established precise criteria, participation in at least 30-50 mentored $\mathrm{AF}$ ablations and 10 transseptal punctures is considered the minimum requirement to be considered trained for AF ablation.

possibly more practical experience, especially in transseptal catheterization, should be required to be fully competent to perform AF ablation procedures as independent operator and to manage potential complications, such as macroreentrant left AT. ${ }^{101}$ To date, no scientific organization has established a minimum number of AF procedures to be performed as primary operator in order to be considered fully trained for this task. The American College of Cardiology and the American Heart Association recommend participation in 30 to 50 mentored AF ablations. ${ }^{347}$ The former committee also recommends involvement in 10 transseptal punctures. ${ }^{347}$ Anyhow, some reports suggested that results improved in centers with experience in more than $100 \mathrm{AF}$ ablations. ${ }^{233}$

\section{Management of Complications}

Trainees must be familiar with risk factors, clinical signs, and symptoms of potential early as well as delayed occurring complications. Backup of an experienced physician with skills in emergency needle pericardiocentesis is necessary and training in pericardiocentesis definitely necessary. Awareness of risks of conscious sedation (including hypoventilation, aspiration, and respiratory arrest) as well as management of those should be trained.

\section{Follow-Up}

Trainees must be familiar with the principles of adequate rhythm monitoring following AF catheter ablation with clinical trials necessitating more intense AF monitoring than in clinical practice. ${ }^{101,348}$ The trainee must be familiar with indications and contraindications for cardioversion, concomitant AADs use and timing of repeat ablation. Furthermore the use of anticoagulation regimes must be set in the right context with adequate risk-benefit evaluation of thromboembolic and bleeding risks.

The key points regarding hospital equipment and facilities, personnel, training requirements and competences are reported in Table 19.

\section{References}

1. Natale A, Raviele A, Arentz T, Calkins H, Chen SA, Haïssaguerre M, Hindricks G, Ho Y, Kuck KH, Marchlinski F, Napolitano C, Packer D, Pappone C, Prystowsky EN, Schilling R, Shah D, Themistoclakis S, Verma A: Venice Chart international consensus document on atrial fibrillation ablation. J Cardiovasc Electrophysiol 2007;18:560-580.

2. Tzeis S, Andrikopoulos G, Deisenhofer I, Ho SY, Theodorakis G: Transseptal catheterization: Considerations and caveats. Pacing Clin Electrophysiol 2010;33:231-242.
3. Knecht S, Jaïs P, Nault I, Wright M, Matsuo S, Madaffari A, Lellouche N, O'Neill MD, Derval N, Deplagne A, Bordachar P, Sacher F, Hocini M, Clémenty J, Haïssaguerre M: Radiofrequency puncture of the fossa ovalis for resistant transseptal access. Circ Arrhythmia Electrophysiol 2008;1:169-174.

4. Zaker-Shahrak R, Fuhrer J, Meier B: Transseptal puncture for catheter ablation of atrial fibrillation after device closure of patent foramen ovale. Catheter Cardiovasc Interv 2008;71:551-552.

5. Anselmino M, Blandino A, Beninati S, Rovera C, Boffano C, Belletti M, Caponi D, Scaglione M, Cesarani F, Gaita F: Morphologic analysis of left atrial anatomy by magnetic resonance angiography in patients with atrial fibrillation: A large single center experience. J Cardiovasc Electrophysiol 2011;22:1-7.

6. Cabrera JA, Ho, SY, Climent V, Fuertes B, Murillo M, Sanchez-Quintana D: Morphological evidence of muscular connections between contiguous pulmonary venous orifices: Relevance of the interpulmonary isthmus for catheter ablation in atrial fibrillation. Heart Rhythm 2009;6:1192-1198.

7. Po SS, Nakagawa H, Jackman WM: Localization of left atrial ganglionated plexi in patients with atrial fibrillation. J Cardiovasc Electrophysiol 2009;20:1186-1189.

8. Udyavar AR, Huang SH, Chang SL, Lin YJ, Tai CT, Lo LW, Tuan TC, Hu YF, Wongcharoen W, Tsao HM, Higa S, Chen SA: Acute effect of circumferential pulmonary vein isolation on left atrial substrate. J Cardiovasc Electrophysiol 2009;20:715-722.

9. Platonov PG, Ivanov V, Ho SY, Mitrofanova L: Left atrial posterior wall thickness in patients with and without atrial fibrillation: Data from 298 consecutive autopsies. J Cardiovasc Electrophysiol 2008;19:689-692.

10. Sánchez-Quintana D, Ho SY, Climent V, Murillo M, Cabrera JA: Anatomic evaluation of the left phrenic nerve relevant to epicardial and endocardial catheter ablation: Implications for phrenic nerve injury. Heart Rhythm 2009;6:764-768

11. Ausma J, Wijffels M, Thone F, Wouters L, Allessie M, Borgers M: Structural changes of atrial myocardium due to sustained atrial fibrillation in the goat. Circulation 1997;96:3157-3163.

12. Darbar D, Herron KJ, Ballew JD, Jahangir A, Gersh BJ, Shen WK, Hammill SC, Packer DL, Olson TM: Familial atrial fibrillation is a genetically heterogeneous disorder. J Am Coll Cardiol 2003;41:2185-2192.

13. Lubitz SA, Yi BA, Ellinor PT: Genetics of atrial fibrillation. Heart Fail Clin 2010;6:239-247.

14. Campuzano O, Brugada R: Genetics of familial atrial fibrillation. Europace 2009;11:12671271 .

15. Haissaguerre M, Jais P, Shah DC, Takahashi A, Hocini M, Quiniou G, Garrigue S, Le Mouroux A, LeMetayer P, Clementy J: Spontaneous initiation of atrial fibrillation by ectopic beats originating in the pulmonary veins. N Engl J Med 1998;339:659-666.

16. Lin WS, Tai CT, Hsieh MH, Tsai CF, Lin YK, Tsao HM, Huang JL, Yu WC, Yang SP, Ding YA, Chang MS, Chen SA: Catheter ablation of paroxysmal atrial fibrillation initiated by non-pulmonary vein ectopy. Circulation 2003;107:3176-183.

17. Klos M, Calvo D, Yamazaki M, Zlochiver S, Mironov S, Cabrera JA, Sanchez-Quintana D, Jalife J, Berenfeld O, Kalifa J: Atrial septopulmonary bundle of the posterior left atrium provides a substrate for atrial fibrillation initiation in a model of vagally mediated pulmonary vein tachycardia of the structurally normal heart. Circ Arrhythm Electrophysiol 2008;1:175-183.

18. Patterson E, Po SS, Scherlag BJ, Lazzara R: Triggered firing in pulmonary veins initiated by in vitro autonomic nerve stimulation. Heart Rhythm 2005;2:624-631.

19. Patterson E, Lazzara R, Szabo B, Liu H, Tang D, Li YH, Scherlag BJ, Po SS: Sodium-calcium exchange initiated by the $\mathrm{Ca} 2+$ transient: An arrhythmia trigger within pulmonary veins. J Am Coll Cardiol 2006;47:1196-1206.

20. Burashnikov A, Antzelevitch C: Reinduction of atrial fibrillation immediately after termination of the arrhythmia is mediated by late phase 3 early afterdepolarization-induced triggered activity. Circulation 2003;107:2355-2360.

21. Lemery R, Birnie D, Tang AS, Green M, Gollob M: Feasibility study of endocardial mapping of ganglionated plexuses during catheter ablation of atrial fibrillation. Heart Rhythm 2006;3:387396.

22. Pokushalov E, Romanov A, Artyomenko S, Turov A, Shirokova N, Katritsis DG: Left atrial ablation at the anatomic areas of ganglionated plexi for paroxysmal atrial fibrillation. Pacing Clin Electrophysiol 2010;33:1231-1238.

23. Wijffels MC, Kirchhof CJ, Dorland R, Allessie MA: Atrial fibrillation begets atrial fibrillation. A study in awake chronically instrumented goats. Circulation 1995;92:1954-1968.

24. Morillo CA, Klein GJ, Jones DL, Guiraudon CM: Chronic rapid atrial pacing. Structural, functional, and electrophysiological characteristics of a new model of sustained atrial fibrillation. Circulation 1995;91:1588-1595

25. Haissaguerre M, Shah DC, Jais P, Hocini M, Yamane T, Deisenhofer I, Chauvin M, Garrigue S, Clementy J: Electrophysiological breakthroughs from the left atrium to the pulmonary veins. Circulation 2000;102:2463-2465.

26. Pappone C, Rosanio S, Oreto G, Tocchi M, Gugliotta F, Vicedomini G, Salvati A, Dicandia C, Mazzone P, Santinelli V, Gulletta S, Chierchia S: Circumferential radiofrequency ablation of pulmonary vein ostia: A new anatomic approach for curing atrial fibrillation. Circulation 2000;102:2619-2628

27. Pappone C, Oreto G, Rosanio S, Vicedomini G, Tocchi M, Gugliotta F, Salvati A, Dicandia C, Calabrò MP, Mazzone P, Ficarra E, Di Gioia C, Gulletta S, Nardi S, Santinelli V, Benussi S, Alfieri O: Atrial electroanatomic remodeling after circumferential radiofrequency pulmonary vein ablation: Efficacy of an anatomic approach in a large cohort of patients with atrial fibrillation. Circulation 2001;104:2539-2544.

28. Verma A, Marrouche NF, Natale A: Pulmonary vein antrum isolation: Intracardiac echocardiography-guided technique. J Cardiovasc Electrophysiol 2004;15:1335-1340.

29. Ouyang F, Bansch D, Ernst S, Schaumann A, Hachiya H, Chen M, Chun J, Falk P, Khanedani A, Antz M, Kuck KH: Complete isolation of left atrium surrounding the pulmonary veins: New insights from the double-Lasso technique in paroxysmal atrial fibrillation. Circulation 2004;110:2090-2096

30. Marrouche NF, Martin DO, Wazni O, Gillinov AM, Klein A, Bhargava M, Saad E, Bash D, Yamada H, Jaber W, Schweikert R, Tchou P, Abdul-Karim A, Saliba W, Natale A: Phasedarray intracardiac echocardiography monitoring during pulmonary vein isolation in patients with atrial fibrillation: Impact on outcome and complications. Circulation 2003;107:2710-2716

31. Wood MA, Shaffer KM, Ellenbogen AL, Ownby ED: Microbubbles during radiofrequency catheter ablation: Composition and formation. Heart Rhythm 2005;2:397-403. 
32. Schmidt B, Chun KR, Metzner A, Ouyang F, Kuck KH: Balloon catheters for pulmonary vein isolation. Herz 2008;33:580-584.

33. Ahmed H, Neuzil P, Skoda J, D'Avila A, Donaldson DM, Laragy MC, Reddy VY: The permanency of pulmonary vein isolation using a balloon cryoablation catheter. J Cardiovasc Electrophysiol 2010;21:731-737.

34. Klein G, Oswald H, Gardiwal A, Lusebrink U, Lissel C, Yu H, Drexler H: Efficacy of pulmonary vein isolation by cryoballoon ablation in patients with paroxysmal atrial fibrillation. Heart Rhythm 2008:5:802-806.

35. Neumann T, Vogt J, Schumacher B, Dorszewski A, Kuniss M, Neuser H, Kurzidim K, Berkowitsch A, Koller M, Heintze J, Scholz U, Wetzel U, Schneider MA, Horstkotte D, Hamm CW, Pitschner HF: Circumferential pulmonary vein isolation with the cryoballoon technique: Results from a prospective 3-center study. J Am Coll Cardiol 2008;52:273-278.

36. Reddy VY, Neuzil P, Themistoclakis S, Danik SB, Bonso A, Rossillo A, Raviele A, Schweikert R, Ernst S, Kuck KH, Natale A: Visually-guided balloon catheter ablation of atrial fibrillation: Experimental feasibility and first-in-human multicenter clinical outcome. Circulation 2009;120:12-20.

37. Dukkipati SR, Neuzil P, Skoda J, Petru J, d'Avila A, Doshi SK, Reddy VY: Visual balloonguided point-by-point ablation: Reliable, reproducible, and persistent pulmonary vein isolation. Circ Arrhythm Electrophysiol 2010;3:266-273.

38. Metzner A, Chun KR, Neven K, Fuernkranz A, Ouyang F, Antz M, Tilz R, Zerm T, Koektuerk B, Wissner E, Koester I, Ernst S, Boczor S, Kuck KH, Schmidt B: Long-term clinical outcome following pulmonary vein isolation with high-intensity focused ultrasound balloon catheters in patients with paroxysmal atrial fibrillation. Europace 2010;12:188-193.

39. Natale A, Pisano E, Shewchik J, Bash D, Fanelli R, Potenza D, Santarelli P, Schweikert R, White R, Saliba W, Kanagaratnam L, Tchou P, Lesh M: First human experience with pulmonary vein isolation using a through-the-balloon circumferential ultrasound ablation system for recurrent atrial fibrillation. Circulation 2000;102:1879-1882.

40. Schmidt B, Chun KR, Metzner A, Fuernkranz A, Ouyang F, Kuck KH: Pulmonary vein isolation with high-intensity focused ultrasound: Results from the HIFU $12 \mathrm{~F}$ study. Europace 2009; 11:1281-1288

41. Arruda MS, He DS, Friedman P, Nakagawa H, Bruce C, Azegami K, Anders R, Kozel P, Chiavetta A, Marad P, MacAdam D, Jackman W, Wilber DJ: A novel mesh electrode catheter for mapping and radiofrequency delivery at the left atrium-pulmonary vein junction: A single-catheter approach to pulmonary vein antrum isolation. J Cardiovasc Electrophysiol 2007; 18:206-2011.

42. Mansour M, Forleo GB, Pappalardo A, Heist EK, Avella A, Laurenzi F, De Girolamo P, Bencardino G, Dello Russo A, Mantica M, Ruskin JN, Tondo C: Initial experience with the Mesh catheter for pulmonary vein isolation in patients with paroxysmal atrial fibrillation. Heart Rhythm 2008;5:1510-1516.

43. Neumann T, Kuniss M, Erkapic D, Zaltsberg S, Berkowitsch A, Pajitnev D, Wojcik M, Janin S, Hamm CW, Pitschner HF: Acute and long-term results of PVI at antrum using a novel high-density mapping catheter without help of $3 \mathrm{D}$ electro-anatomic mapping in patients with paroxysmal and chronic atrial fibrillation. J Interv Card Electrophysiol 2010;27:101-108.

44. Phillips KP, Schweikert RA, Saliba WI, Themistoclakis S, Raviele A, Bonso A, Rossillo A, Burkhardt JD, Cummings J, Natale A: Anatomic location of pulmonary vein electrical disconnection with balloon-based catheter ablation. J Cardiovasc Electrophysiol 2008;19:1418

45. Reddy VY, Neuzil P, d'Avila A, Laragy M, Malchano ZJ, Kralovec S, Kim SJ, Ruskin JN: Balloon catheter ablation to treat paroxysmal atrial fibrillation: What is the level of pulmonary venous isolation? Heart Rhythm 2008;5:353-360.

46. Boersma LV, Wijffels MC, Oral H, Wever EF, Morady F: Pulmonary vein isolation by dutycycled bipolar and unipolar radiofrequency energy with a multielectrode ablation catheter. Heart Rhythm 2008;5:1635-1642.

47. Scharf C, Boersma L, Davies W, Kanagaratnam P, Peters NS, Paul V, Rowland E, Grace A, Fynn S, Dang L, Oral H, Morady F: Ablation of persistent atrial fibrillation using multielectrode catheters and duty-cycled radiofrequency energy. J Am Coll Cardiol 2009;54:1450-1456.

48. Ernst S: Magnetic and robotic navigation for catheter ablation: "joystick ablation." J Interv Card Electrophysiol 2008;23:41-44

49. Schmidt B, Chun KR, Tilz RR, Koektuerk B, Ouyang F, Kuck KH: Remote navigation systems in electrophysiology. Europace 2008;10 (Suppl 3):iii57-61.

50. Bauernfeind T, Akca F, Schwagten B, de Groot N, Van Belle Y, Valk S, Ujvari B, Jordaens L, Szili-Torok T: The magnetic navigation system allows safety and high efficacy for ablation of arrhythmias. Europace 2011;13:1015-1021

51. Chun KR, Wissner E, Koektuerk B, Konstantinidou M, Schmidt B, Zerm T, Metzner A, Tilz R, Boczor S, Fuernkranz A, Ouyang F, Kuck KH: Remote-controlled magnetic pulmonary vein isolation using a new irrigated-tip catheter in patients with atrial fibrillation. Circ Arrhythm Electrophysiol 2010;3:458-464.

52. Katsiyiannis WT, Melby DP, Matelski JL, Ervin VL, Laverence KL, Gornick CC: Feasibility and safety of remote-controlled magnetic navigation for ablation of atrial fibrillation. Am J Cardiol 2008:102:1674-1676.

53. Di Biase L, Wang Y, Horton R, Gallinghouse GJ, Mohanty P, Sanchez J, Patel D, Dare M, Canby R, Price LD, Zagrodzky JD, Bailey S, Burkhardt JD, Natale A: Ablation of atrial fibrillation utilizing robotic catheter navigation in comparison to manual navigation and ablation: Singlecenter experience. J Cardiovasc Electrophysiol 2009;20:1328-1335.

54. Hlivak P, Mlcochova H, Peichl P, Cihak R, Wichterle D, Kautzner J: Robotic navigation in catheter ablation for paroxysmal atrial fibrillation: Midterm efficacy and predictors of postablation arrhythmia recurrences. J Cardiovasc Electrophysiol 2011;22:534-540.

55. Nademanee K, McKenzie J, Kosar E, Schwab M, Sunsaneewitayakul B, Vasavakul C, Ngarmukos T: A new approach for catheter ablation of atrial fibrillation: Mapping of the electrophysiologic substrate. J Am Coll Cardiol 2004:43:2044-2053.

56. Rostock T, Rotter M, Sanders P, Takahashi Y, Jaïs P, Hocini M, Hsu LF, Sacher F, Clémenty J, Haïssaguerre M: High-density activation mapping of fractionated electrograms in the atria of patients with paroxysmal atrial fibrillation. Heart Rhythm 2006;3:27-34.

57. Po SS, Scherlag BJ, Yamanashi WS, Edwards J, Zhou J, Wu R, Geng N, Lazzara R, Jackman WM: Experimental model for paroxysmal atrial fibrillation arising at the pulmonary vein-atrial junctions. Heart Rhythm 2006;3:201-208.
58. Tan AY, Li H, Wachsmann-Hogiu S, Chen LS, Chen PS, Fishbein MC: Autonomic innervation and segmental muscular disconnections at the human pulmonary vein-atrial junction: Implications for catheter ablation of atrial-pulmonary vein junction. J Am Coll Cardiol 2006; 48:132-143

59. Pappone C, Santinelli V, Manguso F, Vicedomini G, Gugliotta F, Augello G, Mazzone P, Tortoriello V, Landoni G, Zangrillo A, Lang C, Tomita T, Mesas C, Mastella E, Alfieri $\mathrm{O}$ : Pulmonary vein denervation enhances long-term benefit after circumferential ablation for paroxysmal atrial fibrillation. Circulation 2004:109:327-334.

60. Scanavacca M, Pisani CF, Hachul D, Lara S, Hardy C, Darrieux F, Trombetta I, Negrão CE, Sosa E: Selective atrial vagal denervation guided by evoked vagal reflex to treat patients with paroxysmal atrial fibrillation. Circulation 2006;114:876-885.

61. Verma A, Patel D, Famey T, Martin DO, Burkhardt JD, Elayi SC, Lakkireddy D, Wazni O, Cummings J, Schweikert RA, Saliba W, Tchou PJ, Natale A: Efficacy of adjuvant anterior left atrial ablation during intracardiac echocardiography-guided pulmonary vein antrum isolation for atrial fibrillation. J Cardiovasc Electrophysiol 2007;18:151-156.

62. Oketani N, Lockwood E, Nademanee K: Incidence and mode of AF termination during substrate ablation of AF guided solely by complex fractionated atrial electrogram mapping (abstr) Circulation 2008;118(Suppl):S925.

63. Oral H, Chugh A, Yoshida K, Sarrazin JF, Kuhne M, Crawford T, Chalfoun N, Wells D, Boonyapasit W, Veerareddy S, Billakanty S, Wong WS, Good E, Jongnarangsin K, Pelosi F Jr, Bogun F, Morady F: A randomized assessment of the incremental role of ablation of complex fractionated atrial electrograms after antral pulmonary vein isolation for long-lasting persistent atrial fibrillation. J Am Coll Cardiol 2009;53:782-789.

64. Takahashi Y, O'Neill M, Hocini M, Dubois R, Matsuo S, Knecht S, Mahapatra S, Lim KT, Jaï P, Jonsson A, Sacher F, Sanders P, Rostock T, Bordachar P, Clémenty J, Klein GJ, Haïssaguerre $\mathrm{M}$ : Characterization of electrograms associated with termination of chronic atrial fibrillation by catheter ablation. J Am Coll Cardiol 2008;51:1003-1010.

65. Di Biase L, Elayi CS, Fahmy TS, Martin DO, Ching CK, Barrett C, Bai R, Patel D, Khaykin Y, Hongo R, Hao S, Beheiry S, Pelargonio G, Dello Russo A, Casella M, Santarelli P, Potenza D, Fanelli R, Massaro R, Wang P, Al-Ahmad A, Arruda M, Themistoclakis S, Bonso A, Rossillo A, Raviele A, Schweikert RA, Burkhardt DJ, Natale A: Atrial fibrillation ablation strategies for paroxysmal patients: Randomized comparison between different techniques. Circ Arrhythm Electrophysiol 2009;2:113-119.

66. Verma A, Mantovan R, Macle L, De Martino G, Chen J, Morillo CA, Novak P, Calzolari V, Guerra PG, Nair G, Torrecilla EG, Khaykin Y: Substrate and Trigger Ablation for Reduction of Atrial Fibrillation (STAR AF): A randomized, multicentre, international trial. Eur Heart J 2010;31:1344-1356

67. Li WJ, Bai YY, Zhang HY, Tang RB, Miao CL, Sang CH, Yin XD, Dong JZ, Ma CS: Additional ablation of complex fractionated atrial electrograms after pulmonary vein isolation in patients with atrial fibrillation. A meta-analysis. Circ Arrhythm Electrophysiol 2011;4:143-148.

68. Lavergne T, Jais P, Haissaguerre M, Bruszewski W, Shah D, Bruneval P, Clementy J: Evaluation of a single passage RF ablation line in animal atria using an irrigated tip catheter. Circulation 1997;96(8S Suppl):259-I.

69. Kottkamp H, Hindricks G, Autschbach R, Krauss B, Strasser B, Schirdewahn P, Fabricius A, Mohr FW: Specific linear left atrial lesions in atrial fibrillation: Intraoperative radiofrequency ablation using minimally invasive surgical techniques. J Am Coll Cardiol 2002;40: 475-480.

70. Jass P, Shah DC, Haissaguerre M, Takahashi A, Lavergne T, Hocini M, Garrigue S, Barold SS, Le Métayer P, Clementy J: Efficacy and safety of septal and left-atrial linear ablation for atrial fibrillation. Am J Cardiol 1999;84:139R-146R.

71. Jaïs $P$, Shah D, Haïssaguerre M, Hocini M, Peng JT, Takahashi A, Garrigue S, Le Métayer P, Clémenty J: Mapping and ablation of left atrial flutters. Circulation 2000;101:2928-2934.

72. Raviele A, Themistoclakis S, Rossillo A, Bonso A: Iatrogenic postatrial fibrillation ablation left atrial tachycardia/flutter: How to prevent and treat it? J Cardiovasc Electrophysiol 2005;16:298301.

73. Scharf C, Veerareddy S, Ozaydin M, Chugh A, Hall B, Cheung P, Good E, Pelosi F Jr, Morady $\mathrm{F}$, Oral $\mathrm{H}$ : Clinical significance of inducible atrial flutter during pulmonary vein isolation in patients with atrial fibrillation. J Am Coll Cardiol 2004;43:2057-2062.

74. Wazni O, Marrouche N, Martin D, Gillinov M, Saliba W, Saad E, Klein A, Bhargava M, Bash D, Schweikert R, Erciyes D, Abdul-Karim A, Brachman J, Gunther J, Pisano E, Potenza D, Fanelli R, Natale A: Randomized study comparing combined pulmonary vein-left atrial junction disconnection and cavotricuspid isthmus ablation versus pulmonary vein-left atrial junction disconnection alone in patients presenting with typical atrial flutter and atrial fibrillation. Circulation 2003;108:2479-2483.

75. Schmidt M, Daccarett M, Segerson N, Airey K, Gunther J, Marshang H, Fish E, Rittger H, Sinha AM, Ritscher G, Brachman J, Marrouche N: Atrial flutter ablation in inducible patients during pulmonary vein antrum isolation: A randomized comparison. Pacing Clin Electrophysiol 2008;31:1592-1597.

76. Jaïs P, Hocini M, Hsu LF, Sanders P, Scavee C, Weerasooriya R, Macle L, Raybaud F, Garrigue S, Shah DC, Le Metayer P, Clémenty J, Haïssaguerre M: Technique and results of linear ablation at the mitral isthmus. Circulation 2004;110:2996-3002.

77. Hocini M, Jais P, Sanders P, Takahashi Y, Rotter M, Rostock T, Hsu LF, Sacher F, Reuter S, Clementy J, Haissaguerre M: Techniques, evaluation, and consequences of linear block at the left atrial roof in paroxysmal atrial fibrillation: A prospective randomized study. Circulation 2005; 112:3688-3696.

78. Reddy VY, Ruskin JN, D'Avila A: Balloon occlusion of the coronary sinus to facilitate mitral isthmus ablation. J Cardiovasc Electrophysiol 2008;19:651.

79. Kumagai K, Nakashima H: Noncontact mapping-guided catheter ablation of atrial fibrillation. Circ J 2009; 73:233-241.

80. Verma A, Patel D, Famy T, Martin D, Burkhardt D, Elayi C, Lakkireddy D, Wazni O, Cummings J, Schweikert R, Saliba W, Tchou P, Natale A: Efficacy of adjuvant anterior LA ablation during pulmonary vein antrum isolation for AF. J Cardiovasc Electrophysiol 2007;18:151-156.

81. Armour JA, Yuan BX, Macdonald S, Hopkins DA: Gross and microscopic anatomy of the human intrinsic cardiac nervous system. Anat Rec 1997;247:289-298.

82. Pauza DH, Skripka V, Pauziene N, Stropous R: Morphology, distribution, and variability of the epicardiac neural ganglionated subplexuses in the human heart. Anat Rec 2000;259:353-382. 
83. Nakagawa H, Scherlag BJ, Patterson E, Ikeda A, Lockwood D, Jackman WM: Pathophysiologic basis of autonomic ganglionated plexi ablation in patients with atrial fibrillation. Heart Rhythm 2009;6:S26-S34

84. Nakagawa H, Yokoyama K, Scherlag BJ, Katari V, Aoyama H, Foresti S, Jackman N: Ablation of autonomic ganglia. In: Calkins H, Jais P, Steinberg JS, eds. A Practical Approach to Catheter Ablation of Atrial fibrillation. Philadelphia, PA: Wolters Kluwer/Lippincott Williams \& Wilkins, 2008, pp. 218-230.

85. Macle L, Jais P, Scavee C, Weerasoorija R, Shah DC, Hocini M, Choi KJ, Raybaud F, Clementy J, Haissaguerre M: Electrophysiologically guided pulmonary vein isolation during sustained atrial fibrillation. J Cardiovasc Electrophysiol 2003;14:255-260.

86. Pachon MJ, Pachon ME, Lobo TJ, Pachon MZ, Vargas RN, Pachon DQ, Lopez MF, Jatene AD: A new treatment for atrial fibrillation based on spectral analysis to guide the catheter RF-ablation. Europace 2004;6:590-601.

87. Oh S, Kong H, Choi E, Kim HC, Choi Y: Complex fractionated electrograms and AF nests in vagally mediated atrial fibrillation. Pacing Clinical Electrophysiol 2010;33:1497-1503.

88. Arruda M, Natale A: Ablation of permanent AF: Adjunctive strategies to pulmonary veins isolation: Targeting AF NEST in sinus rhythm and CFAE in AF. J Interv Card Electrophysiol 2008;23:51-57.

89. Haissaguerre M, Sanders P, Hocini M, Takahashi Y, Rotter M, Sacher F, Rostock T, Hsu LF, Bordachar P, Reuter S, Rondant R, Clementy J, Jais P: Catheter ablation of long-lasting persistent atrial fibrillation: Critical structures for termination. J Cardiovasc Electrophysiol 2005; $16: 1125-1137$.

90. Kuck KH, Reddy VY, Schmidt B, Natale A, Neuzil P, Saoudi N, Kautzner J, Herrera C, Hindricks G, Jais P, Nakagawa H, Lambert H, Shah DC: A novel radiofrequency ablation catheter using contact force sensing: Toccata study. Heart Rhythm 2012;9:18-23.

91. Piorkowski C, Sih H, Sommer P, Miller SP, Gaspar T, Teplitsky L, Hindricks G: First in human validation of impedance-based catheter tip-to-tissue contact assessment in the left atrium. J Cardiovasc Electrophysiol 2009;20:1366-1373.

92. Holmes D, Fish JM, Byrd IA, Dando JD, Fowler SJ, Cao H, Jensen JA, Puryear HA, Chinitz LA: Contact sensing provides a highly accurate means to titrate radiofrequency ablation lesion depth. J Cardiovasc Electrophysiol 2011;22:684-690.

93. Pappone C, Santinelli V: Atrial fibrillation ablation: State of the art. Am J Cardiol 2005;96:5964

94. Oral H, Chugh A, Good E, Sankaran S, Reich SS, Igic P, Elmouchi D, Tschopp D, Crawford T, Dey S, Wimmer A, Lemola K, Jongnarangsin K, Bogun F, Pelosi F Jr, Morady F: A tailored approach to catheter ablation of paroxysmal atrial fibrillation. Circulation 2006;113:18241831.

95. Jais P, Hocini M, Sanders P, Hsu LF, Takahashi Y, Rotter M, Rostock T, Sacher F, Clementy J, Haissaguerre M: Long-term evaluation of atrial fibrillation ablation guided by noninducibility. Heart Rhythm 2006;3:140-145.

96. Oral H, Chugh A, Lemola K, Cheung P, Hall B, Good E, Han J, Tamirisa K, Bogun F, Pelosi F $\mathrm{Jr}$, Morady F: Noninducibility of atrial fibrillation as an end point of left atrial circumferential ablation for paroxysmal atrial fibrillation: A randomized study. Circulation 2004;110:27972801

97. O'Neill MD, Wright M, Knecht S, Jaïs P, Hocini M, Takahashi Y, Jönsson A, Sacher F, Matsuo S, Lim KT, Arantes L, Derval N, Lellouche N, Nault I, Bordachar P, Clémenty J, Haïssaguerre M: Long-term follow-up of persistent atrial fibrillation ablation using termination as a procedural endpoint. Eur Heart J 2009;9:1105-12.

98. Rostock T, Steven D, Hoffmann B, Servatius H, Drewitz I, Sydow K, Müllerleile K, Ventura R, Wegscheider K, Meinertz T, Willems S: Chronic atrial fibrillation is a biatrial arrhythmia Data from catheter ablation of chronic atrial fibrillation aiming arrhythmia termination using a sequential ablation approach. Circ Arrhythm Electrophysiol 2008;1:344-53.

99. Elayi CS, Di Biase L, Barrett C, Ching CK, al Aly M, Lucciola M, Bai R, Horton R, Fahmy TS, Verma A, Khaykin Y, Shah J, Morales G, Hongo R, Hao S, Beheiry S, Arruda M, Schweikert RA, Cummings J, Burkhardt JD, Wang P, Al-Ahmad A, Cauchemez B, Gaita F, Natale A: Atria fibrillation termination as aprocedural endpoint during ablation in longstanding persistent atrial fibrillation. Heart Rhythm 2010;9:1216-1223.

100. Tilz RR, Chun KR, Schmidt B, Fuernkranz A, Wissner E, Koester I, Baensch D, Boczor S, Koektuerk B, Metzner A, Zerm T, Ernst S, Antz M, Kuck KH, Ouyang F: Catheter ablation of long-standing persistent atrial fibrillation: A lesson from circumferential pulmonary vein isolation. J Cardiovasc Electrophysiol 2010;10:1085-1093.

101. Calkins H, Brugada J, Packer DL, Cappato R, Chen SA, Crijns HJ, Damiano RJ Jr, Davies DW, Haines DE, Haissaguerre M, Iesaka Y, Jackman W, Jais P, Kottkamp H, Kuck KH, Lindsay BD, Marchlinski FE, McCarthy PM, Mont JL, Morady F, Nademanee K, Natale A, Pappone C, Prystowsky E, Raviele A, Ruskin JN, Shemin RJ: HRS/EHRA/ECAS expert consensus statement on catheter and surgical ablation of atrial fibrillation: Recommendations for personnel, policy, procedures and follow-up. Heart Rhythm 2007;4:816-861.

102. Keane D, Reddy V, Ruskin J: Emerging concepts on catheter ablation of atrial fibrillation from the Tenth Annual Boston Atrial Fibrillation Symposium. J Cardiovasc Electrophysiol 2005; 16:1025-1028.

103. Hocini M, Sanders P, Jaïs P, Hsu LF, Takahashi Y, Rotter M, Clémenty J, Haïssaguerre M: Techniques for curative treatment of atrial fibrillation. J Cardiovasc Electrophysiol 2004;15:14671471.

104. Sauer WH, McKernan ML, Lin D, Gerstenfeld EP, Callans DJ, Marchlinski FE: Clinical predictors and outcomes associated with acute return of pulmonary vein conduction during pulmonary vein isolation for treatment of atrial fibrillation. Heart Rhythm 2006;3:1024-1028

105. Arentz T, Macle L, Kalusche D, Hocini M, Jais P, Shah D, Haissaguerre M: 'Dormant' pulmonary vein conduction revealed by adenosine after ostial radiofrequency catheter ablation. J Cardiovasc Electrophysiol 2004;15:1041-1047.

106. Macle L, Khairy P, Atul Verma A, Weerasooriya R, Willems S, Arentz T, Novak P, Veenhuyzen G, Scavée C, Skanes A, Puererfellner H, Jaïs P, Khaykin Y, Rivard L, Guerra PC, Dubuc M, Thibault B, Talajic M, Roy D, Nattel S; ADVICE Study Investigators: Adenosine following pulmonary vein isolation to target dormant conduction elimination (ADVICE): Methods and rationale. Can J Cardiol 2012;28:184-190.

107. Eitel C, Hindricks G, Sommer P, Gaspar T, Kircher S, Wetzel U, Dagres N, Esato M, Bollmann A, Husser D, Hilbert S, Zaker-Shahrak R, Arya A, Piorkowski C: Circumferential pulmonary vein isolation and linear left atrial ablation as a single-catheter technique to achieve bidirectional conduction block: The pace-and-ablate approach. Heart Rhythm 2010;7:157-164.

108. Steven D, Reddy VY, Inada K, Roberts-Thomson KC, Seiler J, Stevenson WG, Michaud GF: Loss of pace capture on the ablation line: A new marker for complete radiofrequency lesions to achieve pulmonary vein isolation. Heart Rhythm 2010;7:323-330.

109. Di Biase L, Burkhardt JD, Mohanty P, Sanchez J, Mohanty S, Horton R, Gallinghouse GJ, Bailey SM, Zagrodzky JD, Santangeli P, Hao S, Hongo R, Beheiry S, Themistoclakis S, Bonso A, Rossillo A, Corrado A, Raviele A, Al-Ahmad A, Wang P, Cummings JE, Schweikert RA, Pelargonio G, Dello Russo A, Casella M, Santarelli P, Lewis WR, Natale A: Left atrial appendage: An underrecognized trigger site of atrial fibrillation. Circulation 2010;122:109-118

110. Jais P, O’Neill MD, Takahashi Y, Jönsson A, Hocini M, Sacher F, Sanders P, Jodali S, Rostock T, Rotter M, Clémenty J, Haïssaguerre M: Stepwise catheter ablation of chronic atrial fibrillation: Importance of discrete anatomic sites for termination. J Cardiovasc Electrophysiol 2006; 17:S28-S36

111. Willems S, Klemm H, Rostock T, Brandstrup B, Ventura R, Steven D, Risius T, Lutomsky B, Meinertz T: Substrate modification combined with pulmonary vein isolation improves outcome of catheter ablation in patients with persistent atrial fibrillation: A prospective randomized comparison. Eur Heart J 2006;27:2871-2878.

112. Gaita F, Caponi D, Scaglione M, Montefusco A, Corleto A, Di Monte F, Coin D, Di Donna $P$, Giustetto C: Long term results of 2 different ablation strategies in patients with paroxysmal and persistent atrial fibrillation. Circ Arrhythm Electrophysiol 2008;1:269-275.

113. Hsu LF, Jaïs P, Sanders P, Garrigue S, Hocini M, Sacher F, Takahashi Y, Rotter M, Pasquié JL, Scavée C, Bordachar P, Clémenty J, Haïssaguerre M: Catheter ablation for atrial fibrillation in congestive heart failure. N Engl J Med 2004;351:2373-2383.

114. Cauchemez B, Haissaguerre M, Fischer B, Thomas O, Clementy J, Coumel P: Electrophysiological effects of catheter ablation of inferior vena cava tricuspid annulus isthmus in common atrial flutter. Circulation 1996;93:284-294

115. Mesas CE, Pappone C, Lang CC, Gugliotta F, Tomita T, Vicedomini G, Sala S, Paglino G, Gulletta S, Ferro A, Santinelli V: Left atrial tachycardia after circumferential pulmonaryvein ablation for atrial fibrillation: Electroanatomic characterization and treatment. J Am Coll Cardiol 2004:44:1071-1079.

116. Chugh A, Oral H, Lemola K, Hall B, Cheung P, Good E, Tamirisa K, Han J, Bogun F, Pelosi F Jr, Morady F: Prevalence, mechanisms, and clinical significance of macroreentrant atrial tachycardia during and following left atrial ablation for atrial fibrillation. Heart Rhythm 2005;2:464-473.

117. Scherlag BJ, Yamanashi W, Patel U, Lazzara R, Jackman WM: Autonomically induced conversion of pulmonary vein focal firing into atrial fibrillation. J Am Coll Cardiol 2005;45:1878-1886.

118. Sanders P, Jais P, Hocini M, Haissaguerre M: Electrial disconnection of the coronary sinus by radiofrequency catheter ablation to isolate a trigger of atrial fibrillation. J Cardiovasc Electrophysiol 2004;15:364-368.

119. Tsai CF, Tai CT, Hsieh MH, Lin WS, YU WC, Ueng KC, Ding YA, Chang MS, Chen SA: Initiation of atrial fibrillation by ectopic beats originating from the superior vena cava: Electrophysiological characteristics and results of radiofrequency ablation. Circulation 2000;102:67

120. Hsu LF, Jaïs P, Keane D, Wharton JM, Deisenhofer I, Hocini M, Shah DC, Sanders P, Scavée C, Weerasooriya R, Clémenty J, Haïssaguerre M: Atrial fibrillation originating from persistent left superior vena cava. Circulation 2004;109:828-832.

121. Corrado A, Bonso A, Madalosso M, Rossillo A, Themistoclakis S, Di Biase L, Natale A, Raviele A: Impact of systematic isolation of superior vena cava in addition to pulmonary vein antrum isolation on the outcome of paroxysmal, persistent, and permanent atrial fibrillation ablation: Results from a randomized study. J Cardiovasc Electrophysiol 2010;21:1-5.

122. Jongbloed MR, Bax JJ, Lamb HJ, Dirksen MS, Zeppenfeld K, van der Wall EE, de Roos A, Schalij MJ: Multislice computed tomography versus intracardiac echocardiography to evaluate the pulmonary veins before radiofrequency catheter ablation of atrial fibrillation: A head-tohead comparison. J Am Coll Cardiol 2005;45:343-350.

123. Dong J, Calkins H, Solomon SB, Lai S, Dalal D, Lardo AC, Brem E, Preiss A, Berger RD, Halperin H, Dickfeld T: Integrated electroanatomical mapping with three-dimensional computed tomographic images for real-time guided ablations. Circulation 2006;113:186-194.

124. Oakes RS, Badger TJ, Kholmovski EG, Akoum N, Burgon NS, Fish EN, Blauer JJ, Rao SN, DiBella EV, Segerson NM, Daccarett M, Windfelder J, McGann CJ, Parker D, MacLeod RS, Marrouche NF: Detection and quantification of left atrial structural remodeling with delayed-enhancement magnetic resonance imaging in patients with atrial fibrillation. Circulation 2009;119:1758-1767.

125. Di Biase L, Conti S, Mohanty P, Bai R, Sanchez J, Walton D, John A, Santangeli P, Elayi CS, Beheiry S, Gallinghouse GJ, Mohanty S, Horton R, Bailey S, Burkhardt JD, Natale A: General anesthesia reduces the prevalence of pulmonary vein reconnection during repeat ablation when compared with conscious sedation: Results from a randomized study. Heart Rhythm 2011;8:368-372.

126. Kottkamp H, Hindricks G, Eitel C, Müller K, Siedziako A, Koch J, Anastasiou-Nana M, Varounis C, Aria A, Sommer P, Gaspar T, Piorkowski C, Dagres N: Deep sedation for cathete ablation of atrial fibrillation: A prospective study in 650 consecutive patients. J Cardiovasc Electrophysiol 2011;22:1339-1343.

127. Wazni OM, Beheiry S, Fahmy T, Barrett C, Hao S, Patel D, Di Biase L, Martin DO, Kanj M, Arruda M, Cummings J, Schweikert R, Saliba W, Natale A: Atrial fibrillation ablation in patients with therapeutic international normalized ratio: Comparison of strategies of anticoagulation management in the periprocedural period. Circulation 2007;116:2531-2534.

128. Oral H, Veerareddy S, Good E, Hall B, Cheung P, Tamirisa K, Han J, Fortino J, Chugh A, Bogun F, Pelosi F Jr, Morady F: Prevalence of asymptomatic recurrences of atrial fibrillation after successful radiofrequency catheter ablation. J Cardiovasc Electrophysiol 2004;15:920-924.

129. Hindricks G, Piorkowski C, Tanner H, Kobza R, Gerds-Li JH, Carbucicchio C, Kottkamp H: Perception of atrial fibrillation before and afgter radiofrequency catheter ablation: Relevance of asymptomatic arrhythmia recurrence. Circulation 2005;112:307-313.

130. Senatore G, Stabile G, Bertaglia E, Donnici G, De Simone A, Zoppo F, Turco P, Pascotto $\mathrm{P}$, Fazzari M: Role of transtelephonic electrocardiographic monitoring in detecting short-term arrhythmia recurrences after radiofrequency ablation in patients with atrial fibrillation. J Am Coll Cardiol 2005;45:873-876 
131. Neumann T, Erdogan A, Dill T, Greiss H, Berkowitsch A, Sperzel J, Kuniss M, Kurzidim K, Hamm CW, Pitschner HF: Asymptomatic recurrences of atrial fibrillation after pulmonary vein isolation. Europace 2006;8:495-498.

132. Vasamreddy CR, Dalal D, Dong J, Cheng A, Spragg D, Lamiy SZ, Meininger G, Henrikson CA, Marine JE, Berger R, Calkins H: Symptomatic and asymptomatic atrial fibrillation in patients undergoing radiofrequency catheter ablation. J Cardiovasc Electrophysiol 2006;17:134-139.

133. Klemm HU, Ventura R, Rostock T, Brandstrup B, Risius T, Meinertz T, Willems S: Correlation of symptoms to ECG diagnosis following atrial fibrillation ablation. J Cardiovasc Electrohysiol 2006; $17: 146-150$

134. Verma A, Minor S, Kilicaslan F, Patel D, Hao S, Beheiry S, Lakkireddy D, Elayi SC, Cummings J, Martin DO, Burkhardt JD, Schweikert RA, Saliba W, Tchou PJ, Natale A: Incidence of atrial arrhythmias detected by permanent pacemakeers (PPM) post-pulmonary vein antrum isolation (PVAI) for atrial fibrillation (AF): Correlation with symptomatic recurrence. J Cardiovasc Electrophysiol 2007;18:601-606.

135. Steven D, Rostock T, Lutomsky B, Klemm H, Servatius H, Drewitz I, Friedrichs K, Ventura $\mathrm{R}$, Meinertz T, Willems S: What is the real atrial fibrillation burden after catheter ablation of atrial fibrillation? A prospective rhythm analysis in pacemaker patients with continuous atrial monitoring. Eur Heart J 2008;29:1037-1042.

136. Kottkamp H, Tanner H, Kobza R, Schirdewahn P, Dorszewski A, Gerds-Li JH, Carbucicchio C, Piorkowski C, Hindricks G: Time course and quantitative analysis of atrial fibrillation episode number and duration after circular plus linear left atrial lesions: Trigger elimination or substrate modification; early or delayed cure? J Am Coll Cardiol 2004;44:869-877.

137. Capucci A, Santini M, Padeletti L, Gulizia M, Botto G, Boriani G, Ricci R, Favale S, Zolezzi F, Di Belardino N, Molon G, Drago F, Villani GQ, Mazzini E, Vimercati M, Grammatico A: Italian AT500 Registry Investigators. Monitored atrial fibrillation duration predicts arterial embolic events in patients suffering from bradycardia and atrial fibrillation implanted with antitachycardia pacemakers. J Am Coll Cardiol 2005;46:1913-1920.

138. Healey JS, Connolly SJ, Gold MR, Israel CW, Van Gelder IC, Capucci A, Lau CP, Fain E, Yang S, Bailleul C, Morillo CA, Carlson M, Themeles E, Kaufman ES, Hohnloser SH; ASSERT Investigators: Subclinical atrial fibrillation and the risk of stroke. N Engl J Med 2012;366:120-129.

139. Roux JF, Zado E, Callans DJ, Garcia F, Lin D, Marchlinski FE, Bala R, Dixit S, Riley M, Russo AM, Hutchinson MD, Cooper J, Verdino R, Patel V, Joy PS, Gerstenfeld EP: Antiarrhythmics after ablation of atrial fibrillation (5A Study). Circulation 2009;120:1036-1040.

140. Leong-Sit P, Roux JF, Zado E, Callans DJ, Garcia F, Lin D, Marchlinski FE, Bala R, Dixit S, Riley M, Hutchinson MD, Cooper J, Russo AM, Verdino R, Gerstenfeld EP: Antiarrhythmics after ablation of atrial: fibrillation (5A Study): Six-month follow-up study. Circ Arrhythm Electrophysiol 2011;4:11-14.

141. Koyama T, Tada H, Sekiguchi Y, Arimoto T, Yamasaki H, Kuroki K, Machino T, Tajiri K, Zhu XD, Kanemoto-Igarashi M, Sugiyasu A, Kuga K, Nakata Y, Aonuma K: Prevention of atrial fibrillation recurrence with corticosteroids after radiofrequency catheter ablation: A randomized controlled trial. J Am Coll Cardiol 2010;56:1463-1472.

142. Savelieva I, Kakouros N, Kourliouros A, Camm AJ: Upstream therapies for management of atrial fibrillation: Review of clinical evidence and implications for European Society of Cardiology guidelines. Part II: Secondary prevention. Europace 2011;13:610-625.

143. Verma A, Kilicaslan F, Adams JR, Hao S, Beheiry S, Minor S, Ozduran V, Claude Elayi S, Martin DO, Schweikert RA, Saliba W, Thomas JD, Garcia M, Klein A, Natale A: Extensive ablation during pulmonary vein antrum isolation has no adverse impact of left atrial function: An echocardiography and cine computed tomography analysis. J Cardiovasc Electrophysiol 2006;7:741-746.

144. Reant P, Lafitte S, Jaïs P, Serri K, Weerasooriya R, Hocini M, Pillois X, Clementy J, Haïssaguerre M, Roudaut R: Reverse remodelling of the left cardiac chambers after catheter ablation after 1 year in a series of patients with isolated atrial fibrillation. Circulation 2005;112:2896-2903.

145. Di Biase L, Fahmy TS, Wazni OM, Bai R, Patel D, Lakkireddy D, Cummings JE, Schweikert RA, Burkhardt JD, Elayi CS, Kanj M, Popova L, Prasad S, Martin DO, Prieto L, Saliba W, Tchou P, Arruda M, Natale A: Pulmonary vein total occlusion following catheter ablation for atrial fibrillation: Clinical implications after long-term follow-up. J Am Coll Cardiol 2006; 48:2493-2499.

146. Bertaglia E, Tondo C, De Simone A, Zoppo F, Mantica M, Turco P, Iuliano A, Forleo G, La Rocca V, Stabile G: Does catheter ablation cure atrial fibrillation? Single-procedure outcome of drug-refractory atrial fibrillation ablation: A 6-year multicentre experience. Europace 2010;12:181-187.

147. Wokhlu A, Hodge DO, Monahan KH, Asirvatham SJ, Friedman PA, Munger TM, Cha YM, Shen WK, Brady PA, Bluhm CM, Haroldson JM, Hammill SC, Packer DL: Long-term outcome of atrial fibrillation ablation: Impact and predictors of very late recurrence. J Cardiovasc Electrophysiol 2010;21:1071-1078.

148. Hussein AA, Martin DO, Saliba W, Patel D, Karim S, Batal O, Banna M, Williams-Andrews M, Sherman M, Kanj M, Bhargava M, Dresing T, Callahan T, Tchou P, Di Biase L, Beheiry S, Lindsay B, Natale A, Wazni O: Radiofrequency ablation of atrial fibrillation under therapeutic international normalized ratio: A safe and efficacious periprocedural anticoagulation strategy. Heart Rhythm 2009;6:1425-1429

149. Di Biase L, Burkhardt JD, Mohanty P, Sanchez J, Horton R, Gallinghouse GJ, Lakkireddy D, Verma A, Khaykin Y, Hongo R, Hao S, Beheiry S, Pelargonio G, Dello Russo A, Casella M, Santarelli P, Santangeli P, Wang P, Al-Ahmad A, Ptel D, Themistoclakis S, Bonso A, Rossillo A, Corrado A, Raviele A, Cummings JE, Schweikert RA, Lewis WR, Natale A: Periprocedural stroke and management of major bleeding complications in patients undergoing catheter ablation of atrial fibrillation: The impact of periprocedural therapeutic international normalized ratio. Circulation 2010;121:2550-2556.

150. Puwanant S, Varr BC, Shrestha K, Hussain SK, Tang WHW, Gabriel RS, Wazni OM, Bhargava M, Saliba WI, Thomas JD, Lindsay BD, Klein AL: Role of the CHADS2 score in the evaluation of thromboembolic risk in patients with atrial fibrillation undergoing transesophogeal echocardiography before pulmonary vein isolation. J Am Coll Cardiol 2009;54:20322039 .

151. Cappato R, Calkins H, Chen SA, Davies W, Iesaka Y, Kalman J, Kim YH, Klein G, Natale A, Packer D, Skanes A, Ambrogi F, Biganzoli E: Updated worldwide survey on the methods, effi- cacy, and safety of catheter ablation for human atrial fibrillation. Circ Arrhythm Electrophysiol 2010;3:32-38.

152. Schrickel JW, Lickfett L, Lewalter T, Mittman-Braun E, Selbach S, Strach K, Nähle CP, Schwab JO, Linhart M, Andrié R, Nickenig G, Sommer T: Incidence and predictors of silent cerebral embolism during pulmonary vein catheter ablation for atrial fibrillation. Europace 2010;12:52-57.

153. Gaita F, Caponi D, Pianelli M, Scaglione M, Toso E, Cesarani F, Boffano C, Gandini G, Valentini MC, De Ponti R, Halimi F, Leclercq JF: Radiofrequency catheter ablation of atrial fibrillation: A cause of silent thromboembolism? Magnetic resonance imaging assessment of cerebral thromboembolism in patients undergoing ablation of atrial fibrillation. Circulation 2010;122:1667-1673.

154. Gautam S, John RM, Stevenson WG, Jain R, Epstein LM, Tedrow U, Koplan BA, McClennen S, Michaud GF: Effect of therapeutic INR on activated clotting times, heparin dosage and bleeding risk during ablation of atrial fibrillation. J Cardiovasc Electrophysiol 2011;22:248-254.

155. Ren JF, Marchlinski FE, Callans DJ, Gerstenfeld EP, Dixit S, Lin D, Nayak HM, Hsia HH: Increased intensity of anticoagulation may reduce risk of thrombus during atrial fibrillation ablation procedures in patients with spontaneous echo contrast. J Cardiovasc Electrophysiol 2005; $16: 474-477$

156. Yokoyama K, Nakagawa H, Wittkampf FH, Pitha JV, Lazzara R, Jackman WM: Comparison of electrode cooling between internal and open irrigation in radiofrequency ablation lesion depth and incidence of thrombus and steam pop. Circulation 2006;113:11-19.

157. Wazni OM, Rossillo A, Marrouche NF, Saad EB, Martin DO, Bhargava M, Bash D, Beheiry S, Wexman M, Potenza D, Pisano E, Fanelli R, Bonso A, Themistoclakis S, Erciyes D, Saliba WI, Schweikert RA, Brachmann J, Raviele A, Natale A: Embolic events and char formation during pulmonary vein isolation in patients with atrial fibrillation: Impact of different anticoagulation regimens and importance of intracardiac echo imaging. J Cardiovasc Electrophysiol 2005; $16: 576-581$

158. Latchamsetty R, Gautam S, Bhakta D, Chugh A, John RM, Epstein LM, Miller JM, Michaud GF, Oral H, Morady F, Jongnarangsin K: Management and outcomes of cardiac tamponade during atrial fibrillation ablation in the presence of therapeutic anticoagulation with warfarin. Heart Rhythm 2011;8:805-808.

159. Oral H, Chugh A, Ozaydin M, Good E, Fortino J, Sankaran S, Reich S, Igic P, Elmouchi D, Tschopp D, Wimmer A, Dey S, Crawford T, Pelosi F Jr, Jongnarangsin K, Bogun F, Morady F: Risk of thromboembolic events after percutaneous left atrial radiofrequency ablation of atrial fibrillation. Circulation 2006;114:759-765.

160. Haïssaguerre M, Hocini M, Sanders P, Sacher F, Rotter M, Takahashi Y, Rostock T, Hsu LF, Bordachar P, Reuter S, Roudaut R, Clémenty J, Jaïs P: Catheter ablation of long-lasting persistent atrial fibrillation: Clinical outcome and mechanisms of subsequent arrhythmias. J Cardiovasc Electrophysiol 2005;16:1138-1147.

161. Pappone C, Santinelli V: How to perform encircling ablation of the left atrium. Heart Rhythm 2006:3:1105-1109.

162. Nademanee K, Schwab MC, Kosar EM, Karwecki M, Moran MD, Visessook N, Michael AD, Ngarmukos T: Clinical outcomes of catheter substrate ablation for high-risk patients with atrial fibrillation. J Am Coll Cardiol 2008;51:843-849.

163. Corrado A, Patel D, Riedlbauchova L, Fahmy TS, Themistoclakis S, Bonso A, Rossillo A, Hao S, Schweikert RA, Cummings JE, Bhargava M, Burkhardt D, Saliba W, Raviele A, Natale A: Efficacy, safety, and outcome of atrial fibrillation ablation in septuagenarians. J Cardiovasc Electrophysiol 2008;19:807-811.

164. Themistoclakis S, Corrado A, Marchlinski FE, Jais P, Zado E, Rossillo A, Di Biase L, Schweikert RA, Saliba WI, Horton R, Mohanty P, Patel D, Burkhardt DJ, Wazni OM, Bonso A, Callans DJ, Haissaguerre M, Raviele A, Natale A: The risk of thromboembolism and need for oral anticoagulation after successful atrial fibrillation ablation. J Am Coll Cardiol 2010;55:735743.

165. Saad EB, d'Avila A, Costa IP, Aryana A, Slater C, Costa RE, Inácio LA Jr, Maldonado P, Neto DM, Camiletti A, Camanho LE, Polanczyk CA: Very low risk of thromboembolic events in patients undergoing successful catheter ablation of atrial fibrillation with a CHADS2 score $\leq 3$ : A long-term outcome study. Circ Arrhythm Electrophysiol 2011;4:615-621.

166. Hunter RJ, McCready J, Diab I, Page SP, Finlay M, Richmond L, French A, Earley MJ, Sporton S, Jones M, Joseph JP, Bashir Y, Betts TR, Thomas G, Staniforth A, Lee G, Kistler P, Rajappan $\mathrm{K}$, Chow A, Schilling RJ: Maintenance of sinus rhythm with an ablation strategy in patients with atrial fibrillation is associated with a lower risk of stroke and death. Heart 2012;98:48-53.

167. Shah AN, Mittal S, Sichrovsky TC, Cotiga D, Arshad A, Maleki K, Pierce WJ, Steinberg JS: Long-term outcome following successful pulmonary vein isolation: Pattern and prediction of very late recurrence. J Cardiovasc Electrophysiol 2008;19:661-667.

168. Katritsis D, Wood MA, Giazitzoglou E, Shepard RK, Kourlaba G, Ellenbogen KA: Long-term follow-up after radiofrequency catheter ablation for atrial fibrillation. Europace 2008;10:419424 .

169. Bhargava M, Di Biase L, Mohanty P, Prasad S, Martin DO, Williams-Andrews M, Wazni OM, Burkhardt JD, Cummings JE, Khaykin Y, Verma A, Hao S, Beheiry S, Hongo R, Rossillo A, Raviele A, Bonso A, Themistoclakis S, Stewart K, Saliba WI, Schweikert RA, Natale A Impact of type of atrial fibrillation and repeat catheter ablation on long-term freedom from atrial fibrillation: Results from a multicenter study. Heart Rhythm 2009;6:1403-1412.

170. Sawhney N, Anousheh R, Chen WC, Narayan S, Feld GK: Five-year outcomes after segmental pulmonary vein isolation for paroxysmal atrial fibrillation. Am J Cardiol 2009; 104:366-372.

171. Hunter RJ, Berriman TJ, Diab I, Baker V, Finlay M, Richmond L, Duncan E, Kamdar R, Thomas G, Abrams D, Dhinoja M, Sporton S, Earley MJ, Schilling RJ: Long-term efficacy of catheter ablation for atrial fibrillation: Impact of additional targeting of fractionated electrograms. Heart 2010;96:1372-1378

172. Miyazaki S, Kuwahara T, Kobori A, Takahashi Y, Takei A, Sato A, Isobe M, Takahashi A: Long-term clinical outcome of extensive pulmonary vein isolation-based catheter ablation therapy in patients with paroxysmal and persistent atrial fibrillation. Heart 2010;97:668-673.

173. Tzou WS, Marchlinski FE, Zado ES, Lin D, Dixit S, Callans DJ, Cooper JM, Bala R, Garcia F, Hutchinson MD, Riley MP, Verdino R, Gerstenfeld EP: Long-term outcome after successful catheter ablation of atrial fibrillation. Circ Arrhythm Electrophysiol 2010;3:237-242.

174. Ouyang F, Tilz R, Chun J, Schmidt B, Wissner E, Zerm T, Neven K, Köktürk B, Konstantinidou M, Metzner A, Fuernkranz A, Kuck KH: Long-term results of catheter ablation in 
paroxysmal atrial fibrillation: Lessons from a 5-year follow-up. Circulation 2010;122:23682377.

175. Medi C, Sparks PB, Morton JB, Kistler PM, Halloran K, Rosso R, Vohra JK, Kumar S, Kalman JM: Pulmonary vein antral isolation for paroxysmal atrial fibrillation: Results from long-term follow-up. J Cardiovasc Electrophysiol 2011;22:137-141.

176. Weerasooriya R, Khairy P, Litalien J, Macle L, Hocini M, Sacher F, Lellouche N, Knecht S, Wright M, Nault I, Miyazaki S, Scavee C, Clementy J, Haissaguerre M, Jais P: Catheter ablation for atrial fibrillation: are results maintained at 5 years of follow-up? J Am Coll Cardiol 2011;57:160-166.

177. Pappone C, Vicedomini G, Augello G, Manguso F, Saviano M, Baldi M, Petretta A, Giannelli L, Calovic Z, Guluta V, Tavazzi L, Santinelli V: Radiofrequency catheter ablation and antiarrhythmic drug therapy: A prospective, randomized, 4-year follow-up trial: The APAF study. Circ Arrhythm Electrophysiol 2011;4:808-814.

178. Chao TF, Lin YJ, Tsao HM, Tsai CF, Lin WS, Chang SL, Lo LW, Hu YF, Tuan TC, Suenari K, Li CH, Hartono B, Chang HY, Ambrose K, Wu TJ, Chen SA: CHADS(2) and CHA(2)DS(2)VASc scores in the prediction of clinical outcomes in patients with atrial fibrillation after catheter ablation. J Am Coll Cardiol 2011;58:2380-2385.

179. Winkle RA, Mead RH, Engel G, Kong MH, Patrawala RA: The use of dabigatran immediately after atrial fibrillation ablation. J Cardiovasc Electrophysiol 2011;23:264-268.

180. Bertaglia E, Zoppo F, Tondo C, Colella A, Mantovan R, Senatore G, Bottoni N, Carreras G, Corò L, Turco P, Mantica M, Stabile G: Early complications of pulmonary vein catheter ablation for atrial fibrillation: A multicenter prospective registry on procedural safety. Heart Rhythm. 2007;4:1265-1271.

181. Spragg DD, Dalal D, Cheema A, Scherr D, Chilukuri K, Cheng A, Henrikson CA, Marine JE, Berger RD, Dong J, Calkins H: Complications of catheter ablation for atrial fibrillation: Incidence and predictors. J Cardiovasc Electrophysiol 2008;19:627-631.

182. Dagres N, Hindricks G, Kottkamp H, Sommer P, Gaspar T, Bode K, Arya A, Husser D, Rallidis LS, Kremastinos DT, Piorkowski C: Complications of atrial fibrillation ablation in a high-volume center in 1,000 procedures: Still cause for concern? J Cardiovasc Electrophysiol 2009;20:1014-1019.

183. Leong-Sit P, Zado E, Callans DJ, Garcia F, Lin D, Dixit S, Bala R, Riley MP, Hutchinson MD, Cooper J, Gerstenfeld EP, Marchlinski FE: Efficacy and risk of atrial fibrillation ablation before 45 years of age. Circ Arrhythm Electrophysiol 2010;3:452-457.

184. Lee G, Sparks PB, Morton JB, Kistler PM, Vohra JK, Medi C, Rosso R, Teh A, Halloran $\mathrm{K}$, Kalman JM: Low risk of major complications associated with pulmonary vein antral isolation for atrial fibrillation: Results of 500 consecutive ablation procedures in patients with low prevalence of structural heart disease from a single center. J Cardiovasc Electrophysiol 2011;22:163-168.

185. Bohnen M, Stevenson WG, Tedrow UB, Michaud GF, John RM, Epstein LM, Albert CM, Koplan BA: Incidence and predictors of major complications from contemporary catheter ablation to treat cardiac arrhythmias. Heart Rhythm 2011;8:1661-1666.

186. Baman TS, Jongnarangsin K, Chugh A, Suwanagool A, Guiot A, Madenci A, Walsh S, Ilg KJ, Gupta SK, Latchamsetty R, Bagwe S, Myles JD, Crawford T, Good E, Bogun F, Pelosi F $\mathrm{Jr}$, Morady F, Oral H: Prevalence and predictors of complications of radiofrequency catheter ablation for atrial fibrillation. J Cardiovasc Electrophysiol 2011;22:626-631.

187. Hoyt H, Bhonsale A, Chilukuri K, Alhumaid F, Needleman M, Edwards D, Govil A, Nazarian S, Cheng A, Henrikson CA, Sinha S, Marine JE, Berger R, Calkins H, Spragg DD: Complications arising from catheter ablation of atrial fibrillation: Temporal trends and predictors. Heart Rhythm 2011;8:1869-1874.

188. Shah RU, Freeman JV, Shilane D, Wang PJ, Go AS, Hlatky MA: Procedural complications, rehospitalizations, and repeat procedures after catheter ablation for atrial fibrillation. J Am Coll Cardiol. 2012;59:143-149

189. Cappato R, Calkins H, Chen SA, Davies W, Iesaka Y, Kalman J, Kim YH, Klein G, Natale A, Packer D, Skanes A: Prevalence and causes of fatal outcome in catheter ablation of atrial fibrillation. J Am Coll Cardiol 2009;53:1798-1803.

190. Ren JF, Marchlinski FE, Callans DJ, Herrmann HC: Clinical use of AcuNav diagnostic ultrasound catheter imaging during left heart radiofrequency ablation and transcatheter closure procedures. J Am Soc Echocardiogr 2002;15(10 pt 2):1301-1308

191. Hargrove M, Marshall CB, Jahanjir S, Hinchion J: Emergency bypass postpercutaneous atrial ablation: A case report. Perfusion 2010;25:423-424

192. Lambert T, Steinwender C, Leisch F, Hofmann R: Cardiac tamponade following pericarditis 18 days after catheter ablation. Clin Res Cardiol 2010;99:595-597.

193. Arentz T, Jander N, von Rosenthal J, Blum T, Fürmaier R, Görnandt L, Josef Neumann F, Kalusche D: Incidence of pulmonary vein stenosis 2 years after radiofrequency catheter ablation of refractory atrial fibrillation. Eur Heart J 2003;24:963-969.

194. Packer DL, Keelan P, Munger TM, Breen JF, Asirvatham S, Peterson LA, Monahan KH, Hauser MF, Chandrasekaran K, Sinak LJ, Holmes DR Jr: Clinical presentation, investigation, and management of pulmonary vein stenosis complicating ablation for atrial fibrillation. Circulation 2005;111:546-554.

195. Saad EB, Rossillo A, Saad CP, Martin DO, Bhargava M, Erciyes D, Bash D, Williams-Andrews M, Beheiry S, Marrouche NF, Adams J, Pisanò E, Fanelli R, Potenza D, Raviele A, Bonso A, Themistoclakis S, Brachmann J, Saliba WI, Schweikert RA, Natale A: Pulmonary vein stenosis after radiofrequency ablation of atrial fibrillation: Functional characterization, evolution, and influence of the ablation strategy. Circulation 2003;108:3102-3107.

196. Di Biase L, Fahmy TS, Wazni OM, Bai R, Patel D, Lakkireddy D, Cummings JE, Schweikert RA, Burkhardt JD, Elayi CS, Kanj M, Popova L, Prasad S, Martin DO, Prieto L, Saliba W, Tchou P, Arruda M, Natale A: Pulmonary vein total occlusion following catheter ablation for atrial fibrillation: Clinical implications after long-term follow-up. J Am Coll Cardiol 2006;48:24932499.

197. Thomas D, Katus HA, Voss F: Asymptomatic pulmonary vein stenosis after cryoballoon catheter ablation of paroxysmal atrial fibrillation. J Electrocardiol 2011;44:473-476.

198. Qureshi AM, Prieto LR, Latson LA, Lane GK, Mesia CI, Radvansky P, White RD, Marrouche NF, Saad EB, Bash DL, Natale A, Rhodes JF: Transcatheter angioplasty for acquired pulmonary vein stenosis after radiofrequency ablation. Circulation 2003;108:1336-1342.

199. Ren JF, Marchlinski FE, Callans DJ, Zado ES: Intracardiac Doppler echocardiographic quantification of pulmonary vein flow velocity: An effective technique for monitoring pulmonary vein ostia narrowing during focal atrial fibrillation ablation. J Cardiovasc Electrophysiol 2002;13:1076-1081.

200. Prieto LR, Schoenhagen P, Arruda MJ, Natale A, Worley SE: Comparison of stent versus balloon angioplasty for pulmonary vein stenosis complicating pulmonary vein isolation. J Cardiovasc Electrophysiol 2008; 19:673-678.

201. Neumann T, Kuniss M, Conradi G, Sperzel J, Berkowitsch A, Zaltsberg S, Wojcik M, Erkapic D, Dill T, Hamm CW, Pitschner HF: Pulmonary vein stenting for the treatment of acquired severe stenosis after pulmonary vein isolation. Clinical implications after long-term follow-up of 4 years. J Cardiovasc Electrophysiol 2009;20:251-257.

202. De Potter TJ, Schmidt B, Chun KR, Schneider C, Malisius R, Nuyens D, Ouyang F, Kuck KH: Drug eluting stents for the treatment of pulmonary vein stenosis after atrial fibrillation ablation. Europace 2011;13:57-61.

203. Sacher F, Monahan KH, Thomas SP, Davidson N, Adragao P, Sanders P, Hocini M, Takahashi Y, Rotter M, Rostock T, Hsu LF, Clémenty J, Hässaguerre M, Ross DL, Packer DL, Jaïs P Phrenic nerve injury after atrial fibrillation catheter ablation: Characterization and outcome in a multicenter study. J Am Coll Cardiol 2006;47:2498-2503.

204. Bai R, Patel D, Di Biase L, Fahmy TS, Kozeluhova M, Prasad S, Schweikert R, Cummings J, Saliba W, Andrews-Williams M, Themistoclakis S, Bonso A, Rossillo A, Raviele A, Schmitt C, Karch M, Uriarte JA, Tchou P, Arruda M, Natale A: Phrenic nerve injury after catheter ablation: Should we worry about this complication? J Cardiovasc Electrophysiol 2006;17:944-948.

205. Lachman N, Syed FF, Habib A, Kapa S, Bisco SE, Venkatachalam KL, Asirvatham SJ: Correlative anatomy for the electrophysiologist, part ii: Cardiac ganglia, phrenic nerve, coronary venous system. J Cardiovasc Electrophysiol 2011;22:104-110.

206. Sanchez-Quintana D, Ho SY, Climent V, Murillo M, Cabrera JA: Anatomic evaluation of the left phrenic nerve relevant to epicardial and endocardial catheter ablation: Implications for phrenic nerve injury. Heart Rhythm 2009;6:764-768.

207. Bunch TJ, Bruce GK, Mahapatra S, Johnson SB, Miller DV, Sarabanda AV, Milton MA, Packer DL: Mechanisms of phrenic nerve injury during radiofrequency ablation at the pulmonary vein orifice. J Cardiovasc Electrophysiol 2005;16:1318-1325.

208. Horton R, Di Biase L, Reddy V, Neuzil P, Mohanty P, Sanchez J, Nguyen T, Mohanty S, Gallinghouse GJ, Bailey SM, Zagrodzky JD, Burkhardt JD, Natale A: Locating the right phrenic nerve by imaging the right pericardiophrenic artery with computerized tomographic angiography: Implications for balloon-based procedures. Heart Rhythm 2010;7:937-941.

209. Lee JC, Steven D, Roberts-Thomson KC, Raymond JM, Stevenson WG, Tedrow UB: Atrial tachycardias adjacent to the phrenic nerve: Recognition, potential problems, and solutions. Heart Rhythm 2009;6:1186-1191.

210. Nakahara S, Ramirez RJ, Buch E, Michowitz Y, Vaseghi M, de Diego C, Boyle NG, Mahajan A, Shivkumar K: Intrapericardial balloon placement for prevention of collateral injury during catheter ablation of the left atrium in a porcine model. Heart Rhythm 2010;7:81-87.

211. Di Biase L, Burkhardt JD, Pelargonio G, Dello Russo A, Casella M, Santarelli P, Horton R, Sanchez J, Gallinghouse JG, Al-Ahmad A, Wang P, Cummings JE, Schweikert RA, Natale A: Prevention of phrenic nerve injury during epicardial ablation: Comparison of methods for separating the phrenic nerve from the epicardial surface. Heart Rhythm 2009;6:957961.

212. Ghia KK, Chugh A, Good E, Pelosi F, Jongnarangsin K, Bogun F, Morady F, Oral H: A nationwide survey on the prevalence of atrio-esophageal fistula after left atrial radiofrequency catheter ablation. J Interv Card Electrophysiol 2009;24:33-36.

213. Cummings JE, Schweikert RA, Saliba WI, Burkhardt JD, Kilikaslan F, Saad E, Natale A: Brief communication: Atrial-esophageal fistulas after radiofrequency ablation. Ann Intern Med 2006;144:572-574

214. Gilcrease GW, Stein JB: A delayed case of fatal atrioesophageal fistula following radiofrequency ablation for atrial fibrillation. J Cardiovasc Electrophysiol 2010;21:708-711.

215. Gillinov AM, Pettersson G, Rice TW: Esophageal injury during radiofrequency ablation for atrial fibrillation. J Thorac Cardiovasc Surg 2001;122:1239-1240.

216. Doll N, Borger MA, Fabricius A, Stephan S, Gummert J, Mohr FW, Hauss J, Kottkamp H, Hindricks G: Esophageal perforation during left atrial radiofrequency ablation: Is the risk too high? J Thorac Cardiovasc Surg 2003;125:836-842.

217. Pappone C, Oral H, Santinelli V, Vicedomini G, Lang CC, Manguso F, Torracca L, Benussi S, Alfieri O, Hong R, Lau W, Hirata K, Shikuma N, Hall B, Morady F: Atrio-esophageal fistula as a complication of percutaneous transcatheter ablation of atrial fibrillation. Circulation 2004;109:2724-2726

218. Scanavacca MI, D'Avila A, Parga J, Sosa E: Left atrial-esophageal fistula following radiofrequency catheter ablation of atrial fibrillation. J Cardiovasc Electrophysiol 2004;15:960-962.

219. Cummings JE, Schweikert RA, Saliba WI, Burkhardt JD, Brachmann J, Gunther J, Schibgilla V, Verma A, Dery M, Drago JL, Kilicaslan F, Natale A: Assessment of temperature, proximity, and course of the esophagus during radiofrequency ablation within the left atrium. Circulation 2005;112:459-464

220. Zellerhoff S, Ullerich H, Lenze F, Meister T, Wasmer K, Mönnig G, Köbe J, Milberg P, Bittner A, Domschke W, Breithardt G, Eckardt L: Damage to the esophagus after atrial fibrillation ablation: Just the tip of the iceberg? High prevalence of mediastinal changes diagnosed by endosonography. Circ Arrhythm Electrophysiol 2010;3:155-159.

221. Bunch TJ, Nelson J, Foley T, Allison S, Crandall BG, Osborn JS, Weiss JP, Anderson JL, Nielsen P, Anderson L, Lappe DL, Day JD: Temporary esophageal stenting allows healing of esophageal perforations following atrial fibrillation ablation procedures. J Cardiovasc Electrophysiol 2006;17:435-439.

222. Shah D, Dumonceau JM, Burri H, Sunthorn H, Schroft A, Gentil-Baron P, Yokoyama Y, Takahashi A: Acute pyloric spasm and gastric hypomotility: An extracardiac adverse effect of percutaneous radiofrequency ablation for atrial fibrillation. J Am Coll Cardiol 2005;46:327330.

223. Santangeli P, Di Biase L, Horton R, Burkhardt JD, Sanchez J, Al-Ahmad A, Hongo R, Beheiry S, Bai R, Mohanty P, Lewis WR, Natale A: Ablation of atrial fibrillation under therapeutic warfarin reduces periprocedural complications: Evidence from a meta-analysis. Circ Arrhythm Electrophysiol 2012;5:302-311

224. Abhishek F, Heist EK, Barrett C, Danik S, Blendea D, Correnti C, Khan Z, Ruskin JN, Mansour M: Effectiveness of a strategy to reduce major vascular complications from catheter ablation of atrial fibrillation. J Interv Card Electrophysiol 2011;30:211-215. 
225. Olsen DM, Rodriguez JA, Vranic M, Ramaiah V, Ravi R, Diethrich EB: A prospective study of ultrasound scan-guided thrombin injection of femoral pseudoaneurysm: A trend toward minimal medication. J Vasc Surg 2002;36:779-782

226. Sackett WR, Taylor SM, Coffey CB, Viers KD, Langan EM 3rd, Cull DL, Snyder BA, Sullivan TM: Ultrasound-guided thrombin injection of iatrogenic femoral pseudoaneurysms: A prospective analysis. Am Surg 2000;66:937-940.

227. Ohlow MA, Secknus MA, von Korn H, Neumeister A, Wagner A, Yu J, Lauer B: Incidence and outcome of femoral vascular complications among 18,165 patients undergoing cardiac catheterisation. Int J Cardiol 2009;135:66-71.

228. Takahashi Y, Jaïs P, Hocini M, Sanders P, Rotter M, Rostock T, Sacher F, Jaï C, Clémenty J, Haiissaguerre M: Acute occlusion of the left circumflex coronary artery during mitral isthmus linear ablation. J Cardiovasc Electrophysiol 2005;16:1104-1107.

229. Hinkle DA, Raizen DM, McGarvey ML, Liu GT: Cerebral air embolism complicating cardiac ablation procedures. Neurology 2001;56:792-794

230. Lesh MD, Coggins DL, Ports TA: Coronary air embolism complicating transseptal radiofrequency ablation of left free-wall accessory pathways. Pacing Clin Electrophysiol 1992;15:11051108 .

231. Le BH, Black JN, Huang SK: Transient ST-segment elevation during transseptal catheterization for atrial fibrillation ablation. Tex Heart Inst J 2010;37:717-721.

232. Mofrad P, Choucair W, Hulme P, Moore H: Case report: Cerebral air embolization in the electrophysiology laboratory during transseptal catheterization: Curative treatment of acute left hemiparesis with prompt hyperbaric oxygen therapy. J Interv Card Electrophysiol 2006;16:105109.

233. Cappato R, Calkins H, Chen SA, Davies W, Iesaka Y, Kalman J, Kim YH, Klein G, Packer D, Skanes A: Worldwide survey on the methods, efficacy, and safety of catheter ablation for human atrial fibrillation. Circulation 2005;111:1100-1105.

234. Wu RC, Brinker JA, Yuh DD, Berger RD, Calkins HG: Circular mapping catheter entrapment in the mitral valve apparatus: A previously unrecognized complication of focal atrial fibrillation ablation. J Cardiovasc Electrophysiol 2002;13:819-821.

235. Lakkireddy D, Nagarajan D, Di Biase L, Vanga SR, Mahapatra S, Bunch TJ, Day JD, Burkhardt DJ, Umbarger L, Dendi R, Pimentel R, Berenbom L, Emert M, Gerken A, Bommana S, Ray W, Atkins D, Murray C, Dawn B, Natale A: Radiofrequency ablation (RFA) of atrial fibrillation in patients with mitral or aortic mechanical prosthetic valves - A feasibility, safety and efficacy study. Heart Rhythm 2011;8:975-980.

236. Mountantonakis S, Frankel D, Hutchinson M, Dixit S, Riley M, Callans DJ, Garcia F, Lin D, Tzou W, Bala R, Marchlinski FE, Gerstenfeld EP: Feasibility of catheter ablation of mitral annular flutter in patients with prior mitral valve surgery. Heart Rhythm 2011;8:809-814

237. Mansour M, Mela T, Ruskin J, Keane D: Successful release of entrapped circumferential mapping catheters in patients undergoing pulmonary vein isolation for atrial fibrillation. Heart Rhythm 2004;1:558-661

238. Je HG, Kim JW, Jung SH, Lee JW: Minimally invasive surgical release of entrapped mapping catheter in the mitral valve. Circ J 2008;72:1378-1380.

239. Monney P, Pascale P, Fromer M, Pruvot E: Catheter entrapment in a pulmonary vein: A unique complication of pulmonary vein isolation. Chest 2010;138:422-425.

240. Kanagaratnam L, Tomassoni G, Schweikert R, Pavia S, Bash D, Beheiry S, Lesh M, Niebauer M, Saliba W, Chung M, Tchou P, Natale A: Empirical pulmonary vein isolation in patients with chronic atrial fibrillation using a three-dimensional nonfluoroscopic mapping system: Long-term follow-up. Pacing Clin Electrophysiol 2001;24:1774-1779.

241. Villacastín J, Pérez-Castellano N, Moreno J, González R: Left atrial flutter after radiofrequency catheter ablation of focal atrial fibrillation. J Cardiovasc Electrophysiol 2003;14:417-421

242. Oral H, Scharf C, Chugh A, Hall B, Cheung P, Good E, Veerareddy S, Pelosi F Jr, Morady F: Catheter ablation for paroxysmal atrial fibrillation: Segmental pulmonary vein ostial ablation versus left atrial ablation. Circulation 2003;108:2355-2360.

243. Ernst S, Ouyang F, Löber F, Antz M, Kuck KH: Catheter-induced linear lesions in the left atrium in patients with atrial fibrillation: An electroanatomic study. J Am Coll Cardiol 2003;42:12711282

244. Gerstenfeld EP, Callans DJ, Dixit S, Russo AM, Nayak H, Lin D, Pulliam W, Siddique S, Marchlinski FE: Mechanisms of organized left atrial tachycardias occurring after pulmonary vein isolation. Circulation 2004;110:1351-1357.

245. Pappone C, Manguso F, Vicedomini G, Gugliotta F, Santinelli O, Ferro A, Gulletta S, Sala S, Sora N, Paglino G, Augello G, Agricola E, Zangrillo A, Alfieri O, Santinelli V: Prevention of iatrogenic atrial tachycardia after ablation of atrial fibrillation: A prospective randomized study comparing circumferential pulmonary vein ablation with a modified approach. Circulation 2004; 110:3036-3042.

246. Ouyang F, Antz M, Ernst S, Hachiya H, Mavrakis H, Deger FT, Schaumann A, Chun J, Falk P, Hennig D, Liu X, Bänsch D, Kuck KH: Recovered pulmonary vein conduction as a dominant factor for recurrent atrial tachyarrhythmias after complete circular isolation of the pulmonary veins: Lessons from double Lasso technique. Circulation 2005;111:127-135.

247. Cummings JE, Schweikert R, Saliba W, Hao S, Martin DO, Marrouche NF, Burkhardt JD, Kilicaslan F, Verma A, Beheiry S, Belden W, Natale A: Left atrial flutter following pulmonary vein antrum isolation with radiofrequency energy: Linear lesions or repeat isolation. J Cardiovasc Electrophysiol 2005;16:293-297.

248. Hocini M, Sanders P, Jaïs P, Hsu LF, Weerasoriya R, Scavée C, Takahashi Y, Rotter M, Raybaud F, Macle L, Clémenty J, Haïssaguerre M: Prevalence of pulmonary vein disconnection after anatomical ablation for atrial fibrillation: Consequences of wide atrial encircling of the pulmonary veins. Eur Heart J 2005;26:696-704.

249. Shah D, Sunthorn H, Burri H, Gentil-Baron P, Pruvot E, Schlaepfer J, Fromer M: Narrow, slow-conducting isthmus dependent left atrial reentry developing after ablation for atrial fibrillation: ECG characterization and elimination by focal RF ablation. J Cardiovasc Electrophysiol 2006;17:508-515.

250. Deisenhofer I, Estner H, Zrenner B, Schreieck J, Weyerbrock S, Hessling G, Scharf K, Karch MR, Schmitt C: Left atrial tachycardia after circumferential pulmonary vein ablation for atrial fibrillation: Incidence, electrophysiological characteristics, and results of radiofrequency ablation. Europace 2006;8:573-582.

251. Daoud EG, Weiss R, Augostini R, Hummel JD, Kalbfleisch SJ, Van Deren JM, Dawson G, Bowman K: Proarrhythmia of circumferential left atrial lesions for management of atrial fibrillation. J Cardiovasc Electrophysiol 2006;17:157-65.
252. Chae S, Oral H, Good E, Dey S, Wimmer A, Crawford T, Wells D, Sarrazin JF, Chalfoun N, Kuhne M, Fortino J, Huether E, Lemerand T, Pelosi F, Bogun F, Morady F, Chugh A: Atrial tachycardia after circumferential pulmonary vein ablation of atrial fibrillation: Mechanistic insights, results of catheter ablation, and risk factors for recurrence. J Am Coll Cardiol 2007;50:1781-1787.

253. Sawhney N, Anousheh R, Chen W, Feld GK: Circumferential pulmonary vein ablation with additional linear ablation results in an increased incidence of left atrial flutter compared with segmental pulmonary vein isolation as an initial approach to ablation of paroxysmal atrial fibrillation. Circ Arrhythm Electrophysiol 2010;3:243-248.

254. Rostock T, Drewitz I, Steven D, Hoffmann BA, Salukhe TV, Bock K, Servatius H, Aydin MA, Meinertz T, Willems S: Characterization, mapping, and catheter ablation of recurrent atrial tachycardias after stepwise ablation of long-lasting persistent atrial fibrillation. Circ Arrhythm Electrophysiol 2010;3:160-169.

255. Chang SL, Tsao HM, Lin YJ, Lo LW, Hu YF, Tuan TC, Tsai WC, Chang CJ, Suenari K, Huang SY, Tai CT, Li CH, Chao TF, Wu TJ, Chen SA: Differentiating macroreentrant from focal atrial tachycardias occurred after circumferential pulmonary vein isolation. J Cardiovasc Electrophysiol 2011;22:748-755.

256. Brooks A, Stiles M, Laborderie J, Lau D, Kuklik P, Shipp N, Hsu LF, Sanders P: Outcomes of long-standing persistent atrial fibrillation ablation: A systematic review. Heart Rhythm 2010;7:835-846.

257. Gerstenfeld EP, Marchlinski FE: Mapping and ablation of left atrial tachycardias occurring after atrial fibrillation ablation. Heart Rhythm 2007;4:S65-72

258. Karch MR, Zrenner B, Deisenhofer I, Schreieck J, Ndrepepa G, Dong J, Lamprecht K, Barthel P, Luciani E, Schömig A, Schmitt C: Freedom from atrial tachyarrhythmias after catheter ablation of atrial fibrillation: A randomized comparison between 2 current ablation strategies. Circulation 2005;111:2875-2880

259. Anousheh R, Sawhney N, Panutich M, Tate C, Chen WC, Feld G: Effect of mitral isthmus block on development of atrial tachycardia following ablation for atrial fibrillation. Pacing Clin Electrophysiol 2010;33:460-468.

260. Perez FJ, Wood MA, Schubert CM: Effects of gap geometry on conduction through discontinuous radiofrequency lesions. Circulation 2006;113:1723-1729.

261. Thomas SP, Wallace EM, Ross DL: The effect of a residual isthmus of surviving tissue on conduction after linear ablation in atrial myocardium. J Interv Card Electrophysiol 2000;4:273281.

262. Lim TW, Koay CH, McCall R, See V, Ross DL, Thomas S: Atrial arrhythmias after single-ring isolation of the posterior left atrium and pulmonary veins for atrial fibrillation: Mechanisms and management. Circ Arrhythm Electrophysiol 2008;1:120-126.

263. Chugh A, Oral H, Good E, Han J, Tamirisa K, Lemola K, Elmouchi D, Tschopp D, Reich S, Igic P, Bogun F, Pelosi F Jr, Morady F: Catheter ablation of atypical atrial flutter and atrial tachycardia within the coronary sinus after left atrial ablation for atrial fibrillation. J Am Coll Cardiol 2005;46:83-91.

264. Lemola K, Desjardins B, Sneider M, Case I, Chugh A, Good E, Han J, Tamirisa K, Tsemo A, Reich S, Tschopp D, Igic P, Elmouchi D, Bogun F, Pelosi F Jr, Kazerooni E, Morady F, Oral $\mathrm{H}$. Effect of left atrial circumferential ablation for atrial fibrillation on left atrial transport function. Heart Rhythm 2005;2:923-928.

265. Beukema WP, Elvan A, Sie HT, Misier AR, Wellens HJ: Successful radiofrequency ablation in patients with previous atrial fibrillation results in a significant decrease in left atrial size. Circulation 2005;112:2089-2095.

266. Tops LF, Bax JJ, Zeppenfeld K, Jongbloed MR, van der Wall EE, Schalij MJ: Effect of radiofrequency catheter ablation for atrial fibrillation on left atrial cavity size. Am J Cardiol 2006;97:1220-1222.

267. Takahashi Y, O'Neill MD, Hocini M, Reant P, Jonsson A, Jais P, Sanders P, Rostock T, Rotter M, Sacher F, Laffite S, Roudaut R, Clémenty J, Haïssaguerre M: Effects of stepwise ablation of chronic atrial fibrillation on atrial electrical and mechanical properties. J Am Coll Cardiol 2007;49:1306-1314.

268. Sacher F, Corcuff JB, Schraub P, Le Bouffos V, Georges A, Jones SO, Lafitte S, Bordachar P, Hocini M, Clémenty J, Haissaguerre M, Bordenave L, Roudaut R, Jaïs P: Chronic atrial fibrillation ablation impact on endocrine and mechanical cardiac functions. Eur Heart J 2008;29:12901295 .

269. Marsan NA, Tops LF, Holman ER, Van de Veire NR, Zeppenfeld K, Boersma E, van der Wall EE, Schalij MJ, Bax JJ: Comparison of left atrial volumes and function by real-time threedimensional echocardiography in patients having catheter ablation for atrial fibrillation with persistence of sinus rhythm versus recurrent atrial fibrillation three months later. Am J Cardiol 2008; 102:847-853.

270. Schneider C, Malisius R, Krause K, Lampe F, Bahlmann E, Boczor S, Antz M, Ernst S, Kuck $\mathrm{KH}$ : Strain rate imaging for functional quantification of the left atrium: Atrial deformation predicts the maintenance of sinus rhythm after catheter ablation of atrial fibrillation. Eur Heart J 2008:29:1397-1409.

271. Nori D, Raff G, Gupta V, Gentry R, Boura J, Haines DE: Cardiac magnetic resonance imaging assessment of regional and global left atrial function before and after catheter ablation for atrial fibrillation. J Interv Card Electrophysiol 2009;26:109-117.

272. Rodrigues AC, Scanavacca MI, Caldas MA, Hotta VT, Pisani C, Sosa EA, Mathias W Jr: Left atrial function after ablation for paroxysmal atrial fibrillation. Am J Cardiol 2009; 103:395-398

273. Tops LF, Delgado V, Bertini M, Marsan NA, Den Uijl DW, Trines SA, Zeppenfeld K, Holman E, Schalij MJ, Bax JJ: Left atrial strain predicts reverse remodeling after catheter ablation for atrial fibrillation. J Am Coll Cardiol 2011;57:324-331

274. Jeevanantham V, Ntim W, Navaneethan SD, Shah S, Johnson AC, Hall B, Shah A, Hundley WG, Daubert JP, Fitzgerald D: Meta-analysis of the effect of radiofrequency catheter ablation on left atrial size, volumes and function in patients with atrial fibrillation. Am J Cardiol 2010;105:1317-1326.

275. Kovoor P, Ricciardello M, Collins L, Uther JB, Ross DL: Risk to patients from radiation associated with radiofrequency ablation for supraventricular tachycardia. Circulation 1998;98:15341540 .

276. Mahesh M: Fluoroscopy Patient radiation exposure issues. Radiographics 2001;21:1033-1045.

277. Perisinakis K, Damilakis J, Theocharopoulos N, Manios E, Vardas P, Gourtsoyiannis N: Accurate assessment of patient effective radiation dose and associated detriment risk from radiofrequency catheter ablation procedures. Circulation 2001;104:58-62. 
278. Efstathopoulos EP, Katritsis DG, Kottou S, Kalivas N, Tzanalaridou E, Giazitzoglou E, Korovesis S, Faulkner K: Patient and staff radiation dosimetry during cardiac electrophysiology studies and catheter ablation procedures: A comprehensive analysis. Europace 2006;8:443-448.

279. Lakkireddy D, Nadzam G, Verma A, Prasad S, Ryschon K, Di Biase L, Khan M, Burkhardt D, Schweikert R, Natale A: Impact of a comprehensive safety program on radiation exposure during catheter ablation of atrial fibrillation: A prospective study. J Interv Card Electrophysiol 2009;24:105-112.

280. Bertaglia E, Bella PD, Tondo C, Proclemer A, Bottoni N, De Ponti R, Landolina M, Bongiorni MG, Corò L, Stabile G, Dello Russo A, Verlato R, Mantica M, Zoppo F: Image integration increases efficacy of paroxysmal atrial fibrillation catheter ablation: Results from the CartoMerge Italian Registry. Europace 2009;11:1004-1010.

281. Arya A, Zaker-Shahrak R, Sommer P, Bollmann A, Wetzel U, Gaspar T, Richter S, Husser D, Piorkowski C, Hindricks G: Catheter ablation of atrial fibrillation using remote magnetic catheter navigation: A case-control study. Europace 2011;13:45-50.

282. Scaglione M, Biasco L, Caponi D, Anselmino M, Negro A, Di Donna P, Corleto A, Montefusco A, Gaita F: Visualization of multiple catheters with electroanatomical mapping reduces X-ray exposure during atrial fibrillation ablation. Europace 2011;13:955-962.

283. Dragusin O, Weerasooriya R, Jaïs P, Hocini M, Ector J, Takahashi Y, Haïssaguerre M, Bosmans $\mathrm{H}$, Heidbüchel H: Evaluation of a radiation protection cabin for invasive electrophysiological procedures. Eur Heart J 2007;28:183-189.

284. Ross AM, Segal J, Borenstein D, Jenkins E, Cho S: Prevalence of spinal disc disease among interventional cardiologists. Am J Cardiol 1997;79:68-70.

285. Goldstein JA, Balter S, Cowley M, Hodgson J, Klein LW: Occupational hazards of interventional cardiologists: Prevalence of orthopedic health problems in contemporary practice. Catheter Cardiovasc Interv 2004;63:407--411.

286. Oral H, Knight BP, Ozaydin M, Tada H, Chugh A, Hassan S, Scharf C, Lai SW, Greenstein R, Pelosi F Jr, Strickberger SA, Morady F: Clinical significance of early recurrences of atrial fibrillation after pulmonary vein isolation. J Am Coll Cardiol 2002;40:100-104.

287. Lee SH, Tai CT, Hsieh MH, Tsai CF, Lin YK, Tsao HM, Yu WC, Huang JL, Ueng KC, Cheng JJ, Ding YA, Chen SA: Predictors of early and late recurrence of atrial fibrillation after catheter ablation of paroxysmal atrial fibrillation. J Interv Card Electrophysiol 2004:10:221-226.

288. Bertaglia E, Stabile G, Senatore G, Zoppo F, Turco P, Amellone C, De Simone A, Fazzari M, Pascotto P: Predictive value of early atrial tachyarrhythmias recurrence after circumferential anatomical pulmonary vein ablation. Pacing Clin Electrophysiol 2005;28:366-371.

289. Themistoclakis S, Schweikert RA, Saliba WI, Bonso A, Rossillo A, Bader G, Wazni O, Burkhardt DJ, Raviele A, Natale A: Clinical predictors and relationship between early and late atrial tachyarrhythmias after pulmonary vein antrum isolation. Heart Rhythm 2008;5:679-685.

290. Calkins H, Reynolds MR, Spector P, Sondhi M, Xu Y, Martin A, Williams CJ, Sledge I: Treatment of atrial fibrillation with antiarrhythmic drugs or radiofrequency ablation: Two systematic literature reviews and meta-analyses. Circ Arrhythm Electrophysiol 2009;2:349361 .

291. Nair GM, Nery PB, Diwakaramenon S, Healey JS, Connolly SJ, Morillo CA: A systematic review of randomized trials comparing radiofrequency ablation with antiarrhythmic medications in patients with atrial fibrillation. J Cardiovasc Electrophysiol 2009;20:138-144.

292. Noheria A, Kumar A, Wylie JV Jr, Josephson ME: Catheter ablation vs antiarrhythmic drug therapy for atrial fibrillation: A systematic review. Arch Intern Med 2008;168:581-586.

293. Piccini JP, Lopes RD, Kong MH, Hasselblad V, Jackson K, Al-Khatib SM: Pulmonary vein isolation for the maintenance of sinus rhythm in patients with atrial fibrillation: A meta-analysis of randomized, controlled trials. Circ Arrhythm Electrophysiol 2009;2:626-633.

294. Terasawa T, Balk EM, Chung M, Garlitski AC, Alsheikh-Ali AA, Lau J, Ip S: Systematic review: Comparative effectiveness of radiofrequency catheter ablation for atrial fibrillation. Ann Intern Med 2009;151:191-202.

295. Verma A, Natale A: Should atrial fibrillation ablation be considered first-line therapy for some patients? Why atrial fibrillation ablation should be considered first-line therapy for some patients. Circulation 2005;112:1214-1222; discussion 1231

296. Wazni OM, Marrouche NF, Martin DO, Verma A, Bhargava M, Saliba W, Bash D, Schweikert R, Brachmann J, Gunther J, Gutleben K, Pisano E, Potenza D, Fanelli R, Raviele A, Themistoclakis S, Rossillo A, Bonso A, Natale A: Radiofrequency ablation vs antiarrhythmic drugs as first-line treatment of symptomatic atrial fibrillation: A randomized trial. JAMA 2005;293:2634-2640.

297. Stabile G, Bertaglia E, Senatore G, De Simone A, Zoppo F, Donnici G, Turco P, Pascotto P, Fazzari M, Vitale DF: Catheter ablation treatment in patients with drug-refractory atrial fibrillation: A prospective, multi-centre, randomized, controlled study (Catheter Ablation For The Cure Of Atrial Fibrillation Study). Eur Heart J 2006;27:216-221.

298. Oral H, Pappone C, Chugh A, Good E, Bogun F, Pelosi F Jr, Bates ER, Lehmann MH, Vicedomini G, Augello G, Agricola E, Sala S, Santinelli V, Morady F: Circumferential pulmonary-vein ablation for chronic atrial fibrillation. N Engl J Med 2006;354:934-941.

299. Pappone C, Augello G, Sala S, Gugliotta F, Vicedomini G, Gulletta S, Paglino G, Mazzone P, Sora N, Greiss I, Santagostino A, LiVolsi L, Pappone N, Radinovic A, Manguso F, Santinelli $\mathrm{V}$ : A randomized trial of circumferential pulmonary vein ablation versus antiarrhythmic drug therapy in paroxysmal atrial fibrillation: The APAF Study. J Am Coll Cardiol 2006;48:23402347.

300. Jais P, Cauchemez B, Macle L, Daoud E, Khairy P, Subbiah R, Hocini M, Extramiana F, Sacher F, Bordachar P, Klein G, Weerasooriya R, Clementy J, Haissaguerre M: Catheter ablation versus antiarrhythmic drugs for atrial fibrillation: The A4 study. Circulation 2008;118:2498-2505.

301. Wilber DJ, Pappone C, Neuzil P, De Paola A, Marchlinski F, Natale A, Macle L, Daoud EG, Calkins H, Hall B, Reddy V, Augello G, Reynolds MR, Vinekar C, Liu CY, Berry SM, Berry DA: Comparison of antiarrhythmic drug therapy and radiofrequency catheter ablation in patients with paroxysmal atrial fibrillation: A randomized controlled trial. JAMA 2010;303:333-340.

302. Packer DL, Kowal RC, Wheelan KR, Irwin JM, Champagne J, Guerra PG, Dubuc M, Reddy V, Holcomb RG, Lehmann JW, Ruskin JN: Cryo-balloon ablation of pulmonary veins for paroxysmal atrial fibrillation: First results of the North American Arctic Front STOP AF pivotal trial. J Am Coll Cardiol 2012 (submitted for publication).

303. Brooks AG, Stiles MK, Laborderie J, Lau DH, Kuklik P, Shipp NJ, Hsu LF, Sanders P: Outcomes of long-standing persistent atrial fibrillation ablation: A systematic review. Heart Rhythm 2010;7:835-846.
304. Elayi CS, Verma A, Di Biase L, Ching CK, Patel D, Barrett C, Martin D, Rong B, Fahmy TS, Khaykin Y, Hongo R, Hao S, Pelargonio G, Dello Russo A, Casella M, Santarelli P, Potenza D, Fanelli R, Massaro R, Arruda M, Schweikert RA, Natale A: Ablation for longstanding permanent atrial fibrillation: Results from a randomized study comparing three different strategies. Heart Rhythm 2008;5:1658-1664.

305. Verma A, Kilicaslan F, Pisano E, Marrouche NF, Fanelli R, Brachmann J, Geunther J, Potenza D, Martin DO, Cummings J, Burkhardt JD, Saliba W, Schweikert RA, Natale A: Response of atrial fibrillation to pulmonary vein antrum isolation is directly related to resumption and delay of pulmonary vein conduction. Circulation 2005;112:627-635.

306. Verma A: The techniques for catheter ablation of paroxysmal and persistent atrial fibrillation: A systematic review. Curr Opin Cardiol 2011;26:17-24.

307. Hsieh MH, Tai CT, Lee SH, Lin YK, Tsao HM, Chang SL, Lin YJ, Wongchaoen W, Lee KT, Chen SA: The different mechanisms between late and very late recurrences of atrial fibrillation in patients undergoing a repeated catheter ablation. J Cardiovasc Electrophysio 2006;17:231-235.

308. Verma A, Wazni OM, Marrouche NF, Martin DO, Kilicaslan F, Minor S, Schweikert RA, Saliba W, Cummings J, Burkhardt JD, Bhargava M, Belden WA, Abdul-Karim A, Natale A: Pre-existent left atrial scarring in patients undergoing pulmonary vein antrum isolation: An independent predictor of procedural failure. J Am Coll Cardiol 2005;45:285-292.

309. Matiello M, Nadal M, Tamborero D, Berruezo A, Montserrat J, Embid C, Rios J, Villacastin J, Brugada J, Mont L: Low efficacy of atrial fibrillation ablation in severe obstructive sleep apnoea patients. Europace 2010;12:1084-1089.

310. Reynolds MR, Walczak J, White SA, Cohen DJ, Wilber DJ: Improvements in symptoms and quality of life in patients with paroxysmal atrial fibrillation treated with radiofrequency catheter ablation versus antiarrhythmic drugs. Circ Cardiovasc Qual Outcomes 2010;3:615-623.

311. Pappone C, Radinovic A, Manguso F, Vicedomini G, Ciconte G, Sacchi S, Mazzone P, Paglino G, Gulletta S, Sala S, Santinelli V. Atrial fibrillation progression and management: A 5-year prospective follow-up study. Heart Rhythm 2008;5:1501-1507.

312. Fuster V, Rydén LE, Cannom DS, Crijns HJ, Curtis AB, Ellenbogen KA, Halperin JL, Le Heuzey JY, Kay GN, Lowe JE, Olsson SB, Prystowsky EN, Tamargo JL, Wann S, Smith SC Jr, Jacobs AK, Adams CD, Anderson JL, Antman EM, Hunt SA, Nishimura R, Ornato JP, Page RL, Riegel B, Priori SG, Blanc JJ, Budaj A, Camm AJ, Dean V, Deckers JW, Despres C, Dickstein K, Lekakis J, McGregor K, Metra M, Morais J, Osterspey A, Zamorano JL: ACC/AHA/ESC 2006 guidelines for the management of patients with atrial fibrillation: Executive summary: A report of the American College of Cardiology/American Heart Association Task Force on Practice Guidelines and the European Society of Cardiology Committee for Practice Guidelines. J Am Coll Cardiol 2006;48:854-906.

313. Wann LS, Curtis AB, January CT, Ellenbogen KA, Lowe JE, Estes NA 3rd, Page RL, Ezekowitz MD, Slotwiner DJ, Jackman WM, Stevenson WG, Tracy CM, Fuster V, Rydén LE, Cannom DS, Le Heuzey JY, Crijns HJ, Lowe JE, Curtis AB, Olsson SB, Ellenbogen KA, Prystowsky EN, Halperin JL, Tamargo JL, Kay GN, Wann LS, Jacobs AK, Anderson JL, Albert N, Hochman JS, Buller CE, Kushner FG, Creager MA, Ohman EM, Ettinger SM, Stevenson WG, Guyton RA, Tarkington LG, Halperin JL, Yancy CW: ACCF/AHA/HRS. 2011 ACCF/AHA/HRS focused update on the management of patients with atrial fibrillation (Updating the 2006 Guideline): A report of the American College of Cardiology Foundation/American Heart Association Task Force on Practice Guidelines. J Am Coll Cardiol 2011;57:223-242.

314. Weerasooriya R, Jais P, Le Heuzey JY, Scavee C, Choi KJ, Macle L, Raybaud F, Hocini M, Shah DC, Lavergne T, Clementy J, Haissaguerre M: Cost analysis of catheter ablation for paroxysmal atrial fibrillation. Pacing Clin Electrophysiol 2003;26:292-294.

315. Chan PS, Vijan S, Morady F, Oral H: Cost-effectiveness of radiofrequency catheter ablation for atrial fibrillation. J Am Coll Cardiol 2006;47:2513-2520.

316. Khaykin Y, Morillo CA, Skanes AC, McCracken A, Humphries K, Kerr CR: Cost comparison of catheter ablation and medical therapy in atrial fibrillation. J Cardiovasc Electrophysiol 2007;18:907-913.

317. Rodgers M, McKenna C, Palmer S, Chambers D, Van Hout S, Golder S, Pepper C, Todd D, Woolacott N: Curative catheter ablation in atrial fibrillation and typical atrial flutter: Systematic review and economic evaluation. Health Technol Assess 2008;12:III-IV. XI-XIII, 1-198.

318. Khaykin Y, Wang X, Natale A, Wazni OM, Skanes AC, Humphries KH, Kerr CR, Verm A, Morillo CA: Cost comparison of ablation versus antiarrhythmic drugs as first-line therapy for atrial fibrillation: An economic evaluation of the RAAFT pilot study. J Cardiovasc Electrophysiol 2009;20:7-12.

319. Reynolds MR, Zimetbaum P, Josephson ME, Ellis E, Danilov T, Cohen DJ: Cost-effectiveness of radiofrequency catheter ablation compared with antiarrhythmic drug therapy for paroxysmal atrial fibrillation. Circ Arrhythm Electrophysiol 2009;2:362-369.

320. McKenna C, Palmer S, Rodgers M, Chambers D, Hawkins N, Golder S, Van Hout S, Pepper C, Todd D, Woolacott N: Cost-effectiveness of radiofrequency catheter ablation for the treatment of atrial fibrillation in the United Kingdom. Heart 2009;95:542-549.

321. Andrikopoulos G, Tzeis S, Maniadakis N, Mavrakis HE, Vardas PE: Cost-effectiveness of atrial fibrillation catheter ablation. Europace 2009;11:147-151.

322. Kautzner J, Bulkova V, Hindricks G, Maniadakis N, Della Bella P, Jaïs P, Kuck KH: Atrial fibrillation ablation: A cost or an investment? Europace 2011;13 Suppl 2:ii39-43.

323. Santangeli P, Di Biase L, Pelargonio G, Dello Russo A, Casella M, Sanchez J, Horton R, Gallinghouse GJ, Natale A: Catheter ablation of atrial fibrillation: Randomized controlled trials and registries, a look back and the view forward. J Interv Card Electrophysiol 2011;31:69-80.

324. Van Gelder IC, Haegeli LM, Brandes A, Heidbuchel H, Aliot E, Kautzner J, Szumowski L, Mont L, Morgan J, Willems S, Themistoclakis S, Gulizia M, Elvan A, Smit MD, Kirchhof P: Rationale and current perspective for early rhythm control therapy in atrial fibrillation. Europace 2011;13:1517-25.

325. U.S. National Institutes of Health (2008): Atrial fibrillation management in congestive heart failure with ablation (AMICA). http://www.clinicaltrials.gov/

326. U.S. National Institutes of Health (2009): Catheter Ablation versus medical rate control for atrial fibrillation in patients with heart failure. http://www.clinicaltrials.gov/

327. Cox JL, Schuessler RB, D'Agostino HJ Jr, Stone CM, Chang BC, Cain ME, Corr PB, Boineau JP: The surgical treatment of atrial fibrillation. III. Development of a definitive surgical procedure. J Thorac Cardiovasc Surg 1991;101:569-583.

328. Prasad SM, Maniar HS, Camillo CJ, Schuessler RB, Boineau JP, Sundt TM III, Cox JL, Damiano RJ Jr: The Cox maze III procedure for atrial fibrillation: Long-term efficacy in patients 
undergoing lone versus concomitant procedures. J Thorac Cardiovasc Surg 2003;126:18221828

329. Melby SJ, Lee AM, Damiano RJ: Advances in surgical ablation devices for atrial fibrillation. In: Wang PJ, ed. New Arrhythmia Technologies. Malden, MA: Blackwell Futura; 2005, pp. 233-241.

330. Gaynor SL, Diodato MD, Prasad SM, Ishii Y, Schuessler RB, Bailey MS, Damiano NR, Bloch JB, Moon MR, Damiano RJ Jr: A prospective, single-center clinical trial of a modified Cox maze procedure with bipolar radiofrequency ablation. J Thorac Cardiovasc Surg 2004;128:535-542.

331. Lee AM, Clark K, Bailey MS, Aziz A, Schuessler RB, Damiano RJ Jr: A minimally invasive Cox-Maze procedure. Operative technique and results. Innovations 2010;5:281-286.

332. Damiano RJ Jr, Schwartz FH, Bailey MS, Maniar HS, Munfakh NA, Moon MR, Schuessler RB: The Cox maze IV procedure: Predictors of late recurrence. J Thorac Cardiovasc Surg 2011;141:113-121

333. Weimar T, Bailey MS, Watanabe Y, Marin D, Maniar HS, Schuessler RB, Damiano RJ Jr: The Cox-maze IV procedure for lone atrial fibrillation: A single center experience in 100 consecutive patients. J Interv Card Electrophyiol 2011;31:47-54

334. Wolf RK, Schneeberger EW, Osterday R, Miller D, Merrill W, Flege JB Jr, Gillinov AM: Video-assisted bilateral pulmonary vein isolation and left atrial appendage exclusion for atrial fibrillation. J Thorac Cardiovasc Surg 2005;130:797-802.

335. Han FT, Kasirajan V, Kowalski M, Kiser R, Wolfe L, Kalahasty G, Shepard RK, Wood MA, Ellenbogen KA: Results of a minimally invasive surgical pulmonary vein isolation and ganglionic plexi ablation for atrial fibrillation: Single-center experience with 12-month followup. Circ Arrhythm Electrophysiol 2009;2:370-377.

336. Edgerton JR, Edgerton ZJ, Weaver T, Reed K, Prince S, Herbert MA, Mack MJ: Minimally invasive pulmonary vein isolation and partial autonomic denervation for surgical treatment of atrial fibrillation. Ann Thorac Surg 2008;86:35-38; discussion 39.

337. Jeanmart H, Casselman F, Beelen R, Wellens F, Bakir I, Van Praet F, Cammu G, Degriek Y, Vermeulen Y, Vanermen H: Modified maze during endoscopic mitral valve surgery. The OLV clinic experience. Ann Thorac Surg 2006;82:1765-1769.

338. Edgerton JR: Total thorascopic ablation of atrial fibrillation using the Dallas Lesion Set, partial autonomic denervation, and left atrial appendectomy. Oper Tech Thorac Cardiovasc Surg 2009;14:224-242

339. Edgerton JR, Jackman WM, Mack MJ: A new epicardial lesion set for minimal access left atrial maze: The Dallas lesion set. Ann Thorac Surg 2009;88:1655-1657.

340. Lockwood D, Nakagawa H, Peyton MD, Edgerton JR, Scherlag BJ, Sivaram CA, Po SS, Beckman KJ, Abedin M, Jackman WM: Linear left atrial lesions in minimally invasive surgical ablation of persistent atrial fibrillation: Techniques for assessing conduction block across surgical lesions. Heart Rhythm 2009;6:S50-S63.

341. Krul SPJ, Driessen AHG, van Boven WJ, Linnenbank AC, Geuzebroek GSC, Jackman WM, Wilde AAM, de Bakker JM, de Groot JR: Thoracoscopic video-assisted pulmonary vein antrum isolation, ganglionated plexus ablation and periprocedural confirmation of ablation lesions. First results of a hybrid surgical-electrophysiological approach for atrial fibrillation. Circ Arrhythm Electrophysiol 2011;4:262-270.

342. Pet MA, Damiano RJ Jr, Bailey MS, Moon MR, Lawton JS, Rinne AW: Late stroke following the Cox-Maze procedure for atrial fibrillation: The impact of CHADS2 score on long-term outcomes. Heart Rhythm 2009;6(Suppl 1):S14.

343. Cox JL, Ad N, Palazzo T: Impact of the maze procedure on the stroke rate in patients with atrial fibrillation. J Thorac Cardiovasc Surg 1999;118:833-840.

344. Weimar T, Schena S, Bailey MS, Maniar HS, Schuessler RB, Cox JL, Damiano RJ Jr: The Cox-maze procedure for lone atrial fibrillation: A single center experience over two decades. Circ Arrhythm Electrophysiol 2012;5:8-14.

345. Merino JL, Arribas F, Botto GL, Huikuri H, Kraemer LI, Linde C, Morgan JM, Schalij M, Simantirakis E, Wolpert C, Villard MC, Poirey J, Karaim-Fanchon S, Deront K: 20052007 Accreditation Committee; European Heart Rhythm Association; European Society of Cardiology. Core curriculum for the heart rhythm specialist: Executive summary. Europace 2009; 11:1381-1386.

346. Tracy CM, Akhtar M, DiMarco JP, Packer DL, Weitz HH, Creager MA, Holmes DR Jr, Merl G, Rodgers GP, Tracy CM, Weitz HH; American College of Cardiology; American Heart Association; American College of Physicians Task Force on Clinical Competence and Training; Heart Rhythm Society: American College of Cardiology/American Heart Association 2006 update of the clinical competence statement on invasive electrophysiology studies, catheter ablation, and cardioversion: A report of the American College of Cardiology/American Heart Association/American College of Physicians Task Force on Clinical Competence and Training developed in collaboration with the Heart Rhythm Society. J Am Coll Cardiol 2006;48:15031517

347. Naccarelli GV, Conti JB, DiMarco JP, Tracy CM; Heart Rhythm Society: Task force 6: Training in specialized electrophysiology, cardiac pacing, and arrhythmia management endorsed by the Heart Rhythm Society. J Am Coll Cardiol 2008;51:374-380.

348. Kirchhof P, Auricchio A, Bax J, Crijns H, Camm J, Diener HC, Goette A, Hindricks G, Hohnloser S, Kappenberger L, Kuck KH, Lip GY, Olsson B, Meinertz T, Priori S, Ravens U, Steinbeck G, Svernhage E, Tijssen J, Vincent A, Breithardt G: Outcome parameters for trials in atrial fibrillation: Recommendations from a consensus conference organized by the German Atrial Fibrillation Competence NETwork and the European Heart Rhythm Association. Europace 2007;9:1006-1023.

\section{Appendix}

\section{Venice Chart Co-Chairmen}

Andrea Natale, M.D., Texas Cardiac Arrhythmia Institute, St. Davids Medical Center, Austin, TX, USA; Antonio Raviele, M.D., Department of Cardiology, Cardiovascular
Department, Arrhythmia Center \& Center for Atrial Fibrillation, Dell'Angelo Hospital, Venice-Mestre, Italy

\section{Anatomy of structures relevant to atrial fibrillation ablation}

Siew Y. Ho, M.D., Working Group Chairman, Cardiac Morphology Department, Royal Brompton Hospital, Imperial College, London, UK; Roberto De Ponti, M.D., Working Group Liaison Member, Cardiology Department, Circolo Hospital and Macchi Foundation, Varese, Italy; Cristina Basso, M.D., Cardiovascular Pathology Department, University of Padua Medical School, Padua, Italy; José A. Cabrera, M.D., Arrhythmia Unit, Cardiology Department, Quirón Hospital, Universidad Europea de Madrid. Madrid, Spain; Andrea Corrado, M.D., Cardiology Department, Dell'Angelo Hospital, Venice-Mestre, Italy; Jeronimo Farré, M.D., Cardiology Department, Jiménez Díaz-Capio Foundation, Madrid, Spain; Josef Kautzner, M.D., Cardiology Department, Institute for Clinical and Experimental Medicine, Prague, Czech Republic;

\section{Pathophysiology of atrial fibrillation}

José Jalife, M.D., Working Group Chairman, University of Michigan, Ann Arbor, MI, USA; Shih-Ann Chen, M.D., Working Group Liaison Member, Cardiology Department, Veterans General Hospital, Taipei, Taiwan; Maurits Allessie, M.D.; Cardiovascular Research Institute Maastricht, Maastricht, The Netherlands; Charles Antzelevitch, M.D., Masonic Medical Research Laboratory, Utica, NY, USA; Yoshito Iesaka, M.D., Tsuchiura Kyodo Hospital, Tsuchiura City, Japan; Warren M. Jackman, M.D., Heart Rhythm Institute, Oklahoma City, OK, USA; Melvin M. Scheinman, M.D., Cardiac Electrophysiology Department, University of California, San Francisco, CA, USA;

\section{Techniques and technologies for atrial fibrillation catheter ablation}

Karl H. Kuck, M.D., Working Group Chairman, Cardiology Department, Asklepios Klinik St. Georg, Hamburg, Germany; Vivek Y. Reddy, M.D., Working Group Liaison Member, Cardiac Arrhythmia Department, The Zena and Michael A. Wiener Cardiovascular Institute, New York, NY, USA; Pedro Adragao, M.D., Cardiology Department, Hospital Santa Cruz, Carnaxide, Portugal; David J. Burkhardt, M.D., Texas Cardiac Arrhythmia Institute, St. David's Medical Center, Austin, TX, USA; Pierre Jaïs, M.D., Cardiology Department, Hôpital Haut-Lévêque, CHU de Bordeaux, Bordeaux, France; David Keane, M.D., Cardiology Department, St. Vincent's University Hospital, Dublin, Ireland; Horoshi Nakagawa, M.D., Heart Rhythm Institute, University of Oklahoma Health Sciences Center, Oklahoma City, OK, USA; Robert A. Schweikert, M.D., Cardiology Department, Akron General Medical Center, Akron, OH, USA; Jasbir Sra, M.D., Aurora Cardiovascular Services, Aurora Sinai Medical Center, Milwaukee, WI, USA;

\section{Endpoints of catheter ablation for atrial fibrillation}

Michel Haïssaguerre, M.D., Working Group Chairman, Cardiology Department, Hôpital Haut-Lévêque, CHU de 
Bordeaux, Bordeaux, France; Stephan Willems, M.D., Working Group Liaison Member, Cardiology and Electrophysiology Department, Herzzentrum Hamburg GmbH University, Hamburg, Germany; Conor Barrett, M.D., Cardiac Arrhythmia Service, Massachusetts General Hospital, Boston, MA, USA; Luigi Di Biase, M.D., Texas Cardiac Arrhythmia Institute, St. David's Medical Center, Austin, TX, USA; Sabine Ernst, M.D., National Heart and Lung Institute, Royal Brompton and Harefield Hospital, Imperial College, London, UK; Fiorenzo Gaita, M.D., Internal Medicine Department, University of Turin, Turin, Italy; Javier E. Sanchez, M.D., Texas Cardiac Arrhythmia Institute, St. David's Medical Center, Austin, TX, USA; Prashanthan Sanders, M.D., Centre for Heart Rhythm Disorders, Royal Adelaide Hospital, North Terrace, Adelaide, Australia; Richard J. Schilling, M.D., Cardiology Department, St Bartholomew's Hospital, London, UK;

\section{Patient management pre-, during-, and postablation}

David J. Wilber, M.D., Working Group Chairman, Director of the Cardiology Department, Loyola University Medical Center, Chicago, IL, USA; Hans Kottkamp, M.D., Working Group Liaison Member, Herz-Zentrum, Hirslanden Clinic, Zürich, Switzerland; Etienne Aliot, M.D., Cardio-vascular Diseases Department, CHU de Brabois, Vandoeuvre-lèsNancy, France; Edward B. Gerstenfeld, M.D., Cardiac Electrophysiology Department, University of California, San Francisco, CA, USA; Chu-Pak Lau, M.D., Cardiology Department, University of Hong Kong-Queen Mary Hospital, Hong Kong; Martin J, Schalij, M.D., Cardiology Department, Leiden Hospital, Leiden, The Netherlands; Dipen Shah, M.D., Cardiology Cantonal Hospital of Geneva, Geneva, Switzerland;

\section{Periprocedural and long-term anticoagulation}

Stuart J. Connolly, M.D., Working Group Chairman, Cardiology Department, McMaster University, Hamilton, ON, Canada; Sakis Themistoclakis, M.D., Working Group Liaison Member, Cardiovascular Department, Dell'Angelo Hospital, Venice-Mestre, Italy; David Callans, M.D., Cardiovascular Disease Department, Hospital of the University of Pennsylvania, Philadelphia, PA, USA; Mélèze Hocini, M.D., Cardiology Department, Hôpital Haut-Lévêque, CHU de Bordeaux, Bordeaux, France; Gregory Y.H. Lip, M.D., University Department of Medicine, City Hospital, Birmingham, UK; Gregory F. Michaud, M.D., Center for Advanced Management of Atrial Fibrillation, Brigham and Women's Hospital, Boston, MA, USA; Albert L. Waldo, M.D., HarringtonMcLaughlin Heart \& Vascular Institute, Division of Cardiovascular Medicine, University Hospitals Case Medical Center, Cleveland, OH, USA;

\section{Periprocedural and late complications}

Francis E. Marchlinski, M.D., Working Group Chairman, Cardiovascular Division, Hospital of the University of Pennsylvania, Philadelphia, PA, USA; Riccardo Cappato, M.D., Working Group Liaison Member, Electrophysiology Department, Policlinico S. Donato, San Donato Milanese, Italy; Thomas Arentz, M.D., Rhythmology Department, Herz-Zentrum, Bad Krozingen, Germany; Rodney P. Horton, M.D., Texas Cardiac Arrhythmia Institute, St. David's Medical Center, Austin, TX, USA; Hakan Oral,
M.D., Cardiovascular Medicine Department, University of Michigan, Ann Arbor, MI, USA; Antonio Rossillo, M.D., Cardiovascular Department, Dell'Angelo Hospital, VeniceMestre, Italy; Eduardo Saad, M.D., Center for Atrial Fibrillation, Pro-Cardiaco Hospital, Rio de Janeiro, Brazil; Mauricio Scanavacca, M.D., Heart Institute, University of Sao Paulo Medical School, Sao Paulo, Brazil;

\section{Short- and long-term efficacy of catheter ablation procedures for atrial fibrillation}

Hugh Calkins, M.D., Working Group Chairman, Cardiology and Electrophysiology Department, The Johns Hopkins Hospital, Baltimore, MD, USA; Atul Verma, M.D., Working Group Liaison Member, Cardiology Department, Southlake Regional Health Center, Toronto, ON, Canada; Emanuele Bertaglia, M.D., Cardiology Department, ULSS 13 Mirano, Mirano, Italy; Antonio Berruezo, M.D., Cardiology Department, Clinic Hospital, Barcelona, Spain; Aldo Bonso, M.D., Cardiovascular Department, Dell'Angelo Hospital, VeniceMestre, Italy; Jonathan M. Kalman, M.D., Cardiology Department, Royal Melbourne and Western Hospitals, Melbourne, Australia; Moussa Mansour, M.D., Cardiac Arrhythmia Department, Massachusetts General Hospital, Boston, MA, USA;

\section{Indications to atrial fibrillation ablation and cost-effectiveness}

Eric N. Prystowsky, M.D., Working Group Chairman, Clinical Electrophysiology Laboratory, St. Vincent Indianapolis Hospital, Indianapolis, IN, USA; Carlo Pappone, M.D., Working Group Liaison Member, Arrhythmology Department, Villa Maria Cecilia Hospital, Cotignola, Italy; Josep Brugada, M.D., Cardiology Department, Thorax Institute, Clinic of Barcelona, Barcelona, Spain; Samuel Lévy, M.D., Cardiology Department, CHU Hôpital Nord, Marseille, France; Matthew Reynolds, M.D., Beth Israel Deaconess Medical Center, Harvard Clinical Research Institute, Boston, MA, USA; Vincenzo Santinelli, M.D., Arrhythmology Department, Villa Maria Cecilia Hospital, Cotignola, Italy; Panos E. Vardas, M.D., Cardiology Department, Heraklion University Hospital, Heraklion, Greece; Francesca Zuffada, M.D., Arrhythmology Department, Villa Maria Cecilia Hospital, Cotignola, Italy;

\section{Clinical trials on atrial fibrillation/future perspectives}

John A. Camm, M.D., Working Group Chairman, Cardiac and Vascular Sciences, St. George's Hospital Medical School, London, UK; Paulus Kirchhof, M.D., Working Group Liaison Member, Chair in Cardiovascular Medicine, School of Clinical \& Experimental Medicine, University of Birmingham, Birmingham, UK; Carina Blomström-Lundqvist, M.D., Cardiology Department, University Hospital in Uppsala, Uppsala, Sweden; Paul Dorian, M.D., Cardiology Department, St. Michael's Hospital, Toronto, ON, Canada; Stefan H. Hohnloser, M.D., Electrophysiology Department, J.W. Goethe University, Frankfurt, Germany; Carlos A. Morillo, M.D., Arrhythmia \& Pacing Department, Hamilton General Hospital, Hamilton, ON, Canada; Pasquale Santangeli, M.D., Texas Cardiac Arrhythmia Institute, St. David's Medical Center, Austin, TX, USA; Isabelle C. van Gelder, M.D., Cardiology Department, University Medical Center Groningen, Groningen, The Netherlands; Erik Wissner, M.D., 
Cardiology Department, Asklepios Klinik St. Georg, Hamburg, Germany;

\section{Surgical approach/ablation}

Ralph Damiano Jr., M.D., Working Group Chairman, Cardiothoracic Surgery Department, Washington University in St. Louis-School of Medicine, St. Louis, MO, USA; James R. Edgerton, M.D., Working Group Liaison Member, Cardiothoracic Surgery Department, The Heart Hospital, Dallas, TX, USA; Stefano Benussi, M.D., Cardiac Surgery Department, San Raffaele Hospital, Milan, Italy; Young-Hoon, Kim, M.D., Cardiology and Electrophysiology Department, Korea University Medical Center, Seoul, South Korea; Jos G. Maessen, M.D., Cardiothoracic Surgery Department, University of Maastricht, Maastricht, The Netherlands; Helmut Mair, M.D., Cardiac Surgery Department, University of Munich, Munich, Germany; Domenico Mangino, M.D., Cardiovascular Department, Dell'Angelo Hospital, Venice-Mestre, Italy; Kalyanam Shivkumar, M.D., UCLA Cardiac Arrhyth- mia Center, David Geffen School of Medicine at UCLA, Los Angeles, CA, USA;

\section{Hospital equipment and facilities, personnel, training requirements, and competences}

Douglas L. Packer, M.D., Working Group Chairman, Heart Rhythm Services, Mayo Clinic Health Systems/St. Mary's Hospital, Rochester, NY, USA; Gerhard Hindricks, M.D., Working Group Liaison Member, Herzzentrum, Leitender Arzt Universität Leipzig, Leipzig, Germany; Johannes Brachmann, M.D., Cardiology Department, II Med Klinik Klinikum Coburg, Coburg, Germany; Paolo Della Bella, M.D., Cardiology Department, San Raffaele Hospital, Milan, Italy; Luc J. Jordaens, M.D., Thoraxcenter, Clinical Electrophysiology Department, Erasmus MC, Rotterdam, The Netherlands; José L. Merino, M.D., Cardiology Department, La Paz University Hospital, Madrid, Spain; Claudio Tondo, M.D., Arrhythmology Department, Centro Cardiologico Monzino, Milan, Italy. 